\title{
Nanostructured Ternary Metal Tungstate-Based Photocatalysts for Environmental Purification and Solar Water Splitting: A Review
}

\author{
Jun $\mathrm{Ke}^{2} \cdot$ M. Adnan Younis ${ }^{1} \cdot$ Yan Kong $^{1} \cdot$ Hongru Zhou $^{2} \cdot$ Jie Liu $^{3} \cdot$ Lecheng Lei $^{1} \cdot$ Yang Hou $^{1}$
}

Received: 28 July 2018/ Accepted: 2 September 2018/Published online: 1 October 2018

(C) The Author(s) 2018

\section{Highlights}

- A series of ternary tungstate-based photocatalysts and their applications in solar energy conversion and environmental purification are systematically introduced.

- The relationship between intrinsic structures and unique properties of ternary tungstate-based photocatalysts is discussed and summarized in detail.

- Various new concepts and innovative strategies are employed to enhance the photocatalytic performance of ternary tungstate-based photocatalysts

\begin{abstract}
Visible-light-responsive ternary metal tungstate $\left(\mathrm{MWO}_{4}\right)$ photocatalysts are being increasingly investigated for energy conversion and environmental purification applications owing to their striking features, including low cost, eco-friendliness, and high stability under acidic and oxidative conditions. However, rapid recombination of photoinduced electron-hole pairs and a narrow light response range to the solar spectrum lead to low photocatalytic activity of $\mathrm{MWO}_{4^{-}}$
\end{abstract}

Jie Liu

liujiedut@hotmail.com

$\bowtie$ Yang Hou

yhou@zju.edu.cn

1 Key Laboratory of Biomass Chemical Engineering of Ministry of Education, College of Chemical and Biological Engineering, Zhejiang University, 38 Zheda Road, Hangzhou, Zhejiang, People's Republic of China

2 School of Chemistry and Environmental Engineering, Wuhan Institute of Technology, 693 Xiongchu Ave, Hongshan District, Wuhan, Hubei, People's Republic of China

3 Department of Environmental Science and Engineering, North China Electric Power University, 619 Yonghua N St, Baoding, Hebei, People's Republic of China

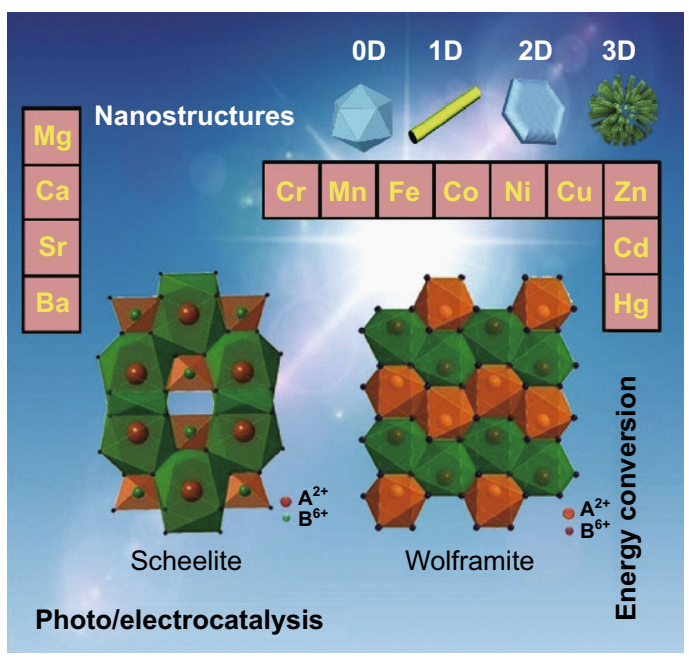

based materials, thus significantly hampering their wide usage in practice. To enable their widespread practical usage, significant efforts have been devoted, by developing new concepts and innovative strategies. In this review, we aim to provide an integrated overview of the fundamentals and recent progress of $\mathrm{MWO}_{4}$-based photocatalysts. Furthermore, different strategies, including morphological control, surface modification, heteroatom doping, and heterojunction fabrication, which are employed to promote the photocatalytic 
activities of $\mathrm{MWO}_{4}$-based materials, are systematically summarized and discussed. Finally, existing challenges and a future perspective are also provided to shed light on the development of highly efficient $\mathrm{MWO}_{4}$-based photocatalysts.

Keywords Ternary metal tungstates · Micro- and nanostructures · Photocatalysis · Environmental purification $\cdot$ Water splitting

\section{Introduction}

Since Fujishima and Honda in 1972 demonstrated that titanium dioxide $\left(\mathrm{TiO}_{2}\right)$ can be used as photoanode to split water excited by ultraviolet light, photocatalysis technology has been viewed as among the most promising approaches to solve the global energy crisis and environmental problems [1-3]. In general, a complete semiconductor photocatalytic cycle involves light-harvesting, photogenerated charge carrier excitation, charge separation and transfer, and surface redox reactions [4-6] that allow for the formation of reactive oxygen species (ROSs), such as free electrons $\left(\mathrm{e}^{-}\right)$, hydrogen peroxide $\left(\mathrm{H}_{2} \mathrm{O}_{2}\right)$, hydroxyl $(\cdot \mathrm{OH})$, and superoxide radicals $\left(\cdot \mathrm{O}_{2}^{-}\right)[7,8]$. The aforementioned ROSs play crucial roles in various important applications, including photocatalysis [9-12], photoelectrocatalysis [13-17], plasma photocatalysis [18, 19], and photothermocatalysis [20-22]. Until now, $\mathrm{TiO}_{2}$ has been among the most extensively studied semiconductor photocatalysts because of its strong oxidative ability, chemical stability, long durability, and nontoxicity [23-25]. However, the $\mathrm{TiO}_{2}$ photocatalyst possesses a wide band gap of $\sim 3.2 \mathrm{eV}$ that can only absorb ultraviolet (UV) light, which is a small fraction $(\sim 5 \%)$ of solar light, thereby hardly harvesting the remaining solar energy [26, 27]. To efficiently utilize the majority of the solar spectrum, $\mathrm{Fe}_{2} \mathrm{O}_{3}$ [28], $\mathrm{WO}_{3^{-}}[29,30], \mathrm{Bi}_{2} \mathrm{WO}_{6^{-}}$[31], $\mathrm{ZnO}-$ [32], $\mathrm{Bi}_{2} \mathrm{O}_{3^{-}}$ [33], and NiO-based semiconductors [34] have been widely developed as photocatalysts for environmental treatment and solar water splitting (Fig. 1). Nevertheless, low sunlight utilization efficiency and quantum yield, rapid reverse reactions, and poor stability still hinder practical applications of these photocatalytic materials [35-39].

Desired photocatalysts should have a suitable band gap to achieve a high harvesting efficiency of sunlight, sufficient quantum yield, and an appropriate position of the band edge to trigger redox reactions [40-42]. For an ideal photocatalyst, the conduction band (CB) edge should be sufficiently negative to drive the photo-reduction reaction. In contrast, the valence band (VB) edge should be sufficiently positive to trigger the photo-oxidation reaction [43]. For example, in photocatalytic water splitting, when the VB edge position of the semiconductor photocatalyst is more positive than the potential of $\mathrm{H}_{2} \mathrm{O} / \mathrm{O}_{2}(1.23 \mathrm{~V}$ vs. $\mathrm{NHE}$ ) and the $\mathrm{CB}$ position is more negative than the potential of $\mathrm{H}_{2} / \mathrm{H}_{2} \mathrm{O}(0 \mathrm{~V}$ vs. NHE), the water splitting reaction can occur [44-47].

Recently, ternary tungstate-based complex oxides have been developed as potential candidates for efficient photocatalytic applications [48-50]. Tungstates are described by the general formula $\mathrm{MWO}_{4}(\mathrm{M}$ denotes a bivalent cation) [51] and are widely used in the luminescence, microwave ceramics, and catalytic fields, given their selfactivating fluorescence effect, microwave, and optical properties [52-55]. Owing to the variety of bivalent cations, the crystal structure of $\mathrm{MWO}_{4}$ is dependent on the size of cationic radii. According to the literature [56], $\mathrm{MWO}_{4}$ typically has a monoclinic wolframite structure for small $\mathrm{M}^{2+}$ cations $(\mathrm{M}=\mathrm{Fe}, \mathrm{Co}, \mathrm{Sn}$, and $\mathrm{Ni})$ and a tetragonal scheelite structure for large $\mathrm{M}^{2+}$ cations $(\mathrm{M}=\mathrm{Ca}, \mathrm{Ba}, \mathrm{Pb}$, and $\mathrm{Sr})$, as shown in Fig. 2 [57]. During the past few decades, $\mathrm{MWO}_{4}$ with large radii cations, including $\mathrm{CaWO}_{4}[58,59], \mathrm{BaWO}_{4}[60,61], \mathrm{PbWO}_{4}[62]$, and $\mathrm{SrWO}_{4}$ [63], has been prepared using different synthesis approaches. However, the band gaps of these $\mathrm{MWO}_{4}$ photocatalysts are much larger than that of $\mathrm{TiO}_{2}$ and are not suitable for practical photocatalytic applications. In contrast, the band gaps of $\mathrm{MWO}_{4}$ with small-radii cations are considerably smaller than that of $\mathrm{TiO}_{2}$ and could be a promising choice for the efficient utilization of solar energy [64-72]. The band-gap energies of representative $\mathrm{MWO}_{4}$ are summarized in Fig. 3 and Table 1. In addition, the band-gap energies of various $\mathrm{MWO}_{4}$ and the radii of the metal cations are plotted in Fig. 4. It can be seen that a flock of $\mathrm{MWO}_{4}$ is in the yellow area, in which each $\mathrm{MWO}_{4}$ has a smaller metal cation radius $(<0.73 \AA)$ and narrower band-gap energy $(<3.2 \mathrm{eV})$ than those of the others. In contrast, $\mathrm{MWO}_{4}$ with a larger cation radius have larger band-gap energy. Notably, for specific $\mathrm{MWO}_{4}$, the band gaps presented in Table 1 are not the only ones, because the absorption light range of the semiconductors can be affected and controlled by various factors, including morphology, size, doping, and defects, thus resulting in one semiconductor material possessing several band-gap energies. By comparing the requirements of novel photocatalysts, $\mathrm{MWO}_{4}$ with small-radius cations is more advantageous and can be further developed as highly efficient photocatalysts. In addition, it is clearly observed that ternary $\mathrm{MWO}_{4}$ systems with a narrow band gap have transition metals as the cation component, which is earthabundant, cost effective, and low-toxicity, benefiting wide usage in the future. However, for these visible-light-responsive pristine $\mathrm{MWO}_{4}$, photocatalytic activities remain 


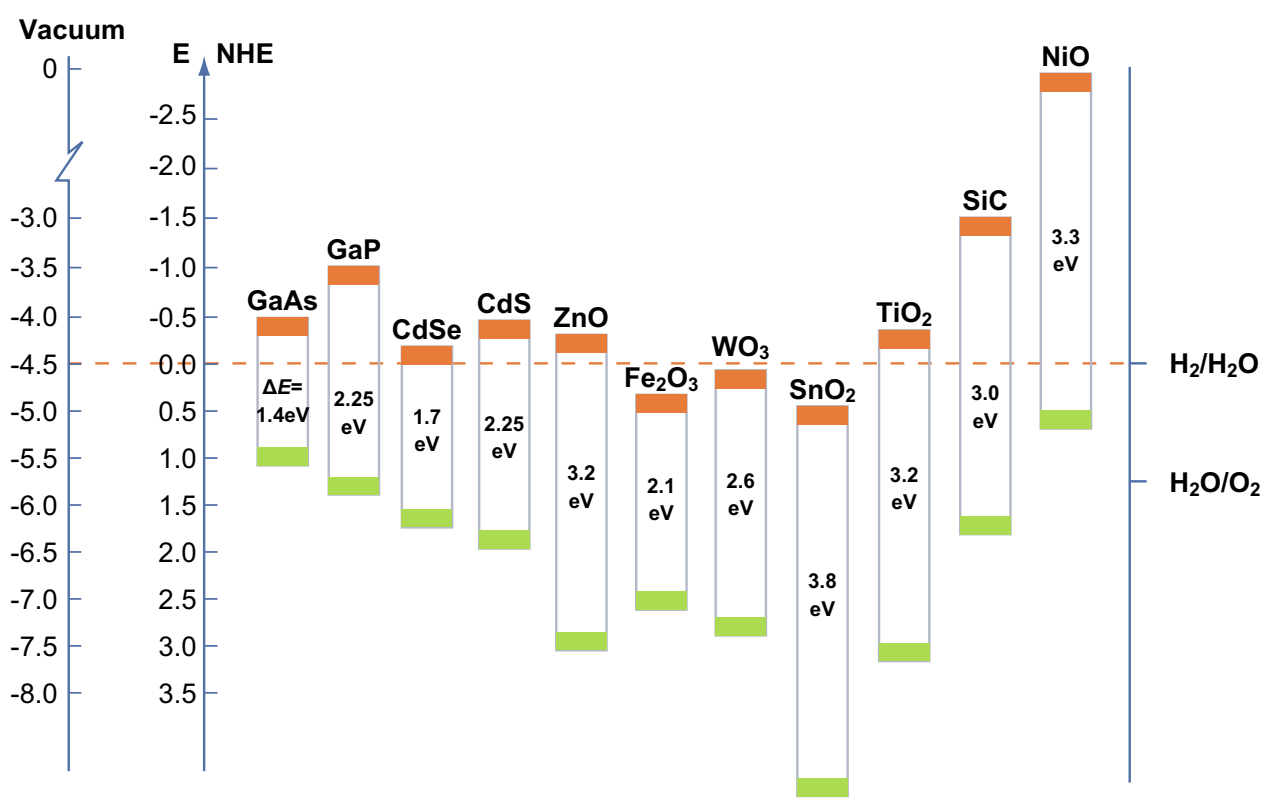

Fig. 1 Schematic overview of the band positions of representative semiconductors
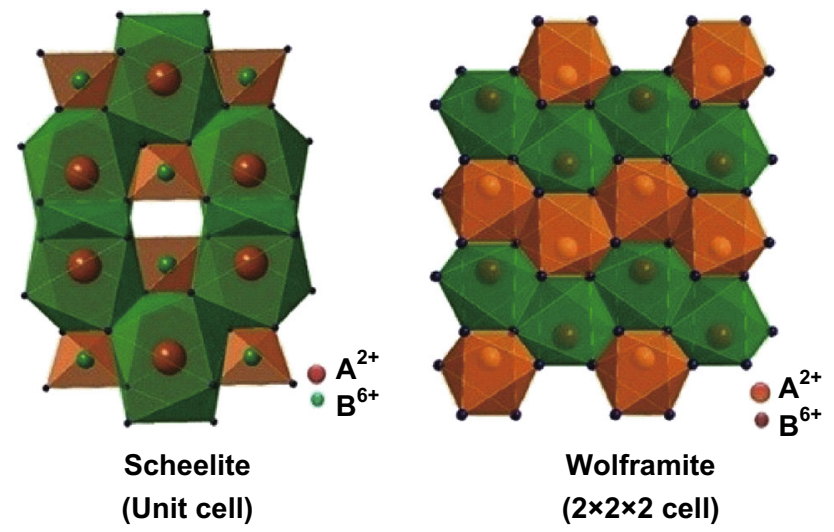

Fig. 2 Illustration of unit cells of scheelite and wolframite. Reproduced with permission from Ref. [57]. Copyright 2014 Elsevier

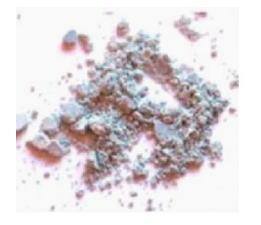

$\mathrm{MgWO}_{4}$

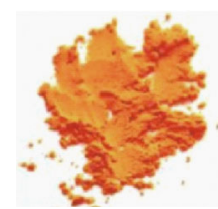

$\mathrm{NiWO}_{4}$

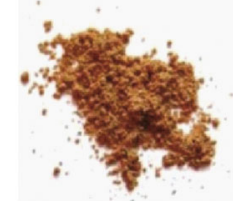

$\mathrm{MnWO}_{4}$

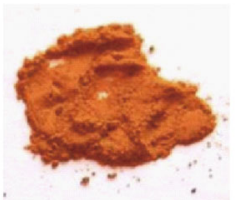

$\mathrm{CuWO}_{4}$

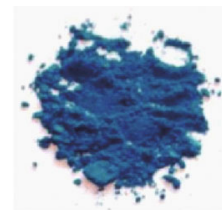

$\mathrm{CoWO}_{4}$

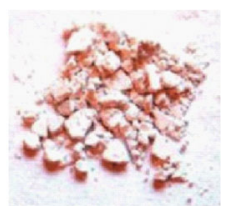

$\mathrm{ZnWO}_{4}$
Fig. 3 Colors of different $\mathrm{MWO}_{4}$ materials. Reproduced with permission from Ref. [51]. Copyright 2014 American Chemical Society inadequate for practical applications because of the rapid recombination of photogenerated holes and electrons.

Herein, we provide a comprehensive review of the evolution and current state of the development and application of ternary $\mathrm{MWO}_{4}$-based photocatalysts in environmental purification and solar water splitting. First, we discuss the fundamentals of ternary $\mathrm{MWO}_{4}$ systems, including the crystal composition, electronic structure, and relationship between the intrinsic structures and properties. Subsequently, versatile reported strategies to improve the photocatalytic activities of pristine $\mathrm{MWO}_{4}$ are systematically summarized. Finally, challenges and future developments of ternary $\mathrm{MWO}_{4}$-based photocatalysts are discussed. We believe that this review provides information on recent progress in ternary $\mathrm{MWO}_{4}$-based photocatalysts for environmental and energy applications and insight into future perspectives, which will aid the design of highly efficient semiconductor-based photocatalysts.

\section{Ternary $\mathrm{MWO}_{4}$ Photocatalysts $(\mathrm{M}=$ bivalent metal cations)}

The photocatalytic activity of semiconductor photocatalysts is known to be closely related to their crystal and electronic structures [82]. In this section, an overview of the crystal and electronic structures of ternary $\mathrm{MWO}_{4}$ is presented and the factors influencing their photocatalytic performance is explored. 
Table 1 Band gaps, crystal sizes, and effective ionic radii of different $\mathrm{MWO}_{4}$ materials

\begin{tabular}{|c|c|c|c|c|}
\hline Compounds & Ionic radius of cation $\mathrm{M}(\AA)$ & Band gap $E_{\mathrm{g}}(\mathrm{eV})$ & Crystalline sizes $(\mathrm{nm})$ via Scherrer equation & References \\
\hline $\mathrm{BaWO}_{4}$ & 1.42 & 4.79 & 55 & {$[56]$} \\
\hline $\mathrm{PbWO}_{4}$ & 1.29 & 3.2 & 11 & {$[73]$} \\
\hline $\mathrm{SrWO}_{4}$ & 1.26 & 4.66 & 33 & {$[56]$} \\
\hline $\mathrm{CaWO}_{4}$ & 1.12 & 4.27 & 32 & {$[56]$} \\
\hline $\mathrm{CdWO}_{4}$ & 0.95 & 3.77 & 21 & [74] \\
\hline $\mathrm{ZnWO}_{4}$ & 0.74 & 3.37 & 32 & {$[75]$} \\
\hline $\mathrm{CuWO}_{4}$ & 0.73 & 3.2 & 36 & {$[76]$} \\
\hline $\mathrm{MgWO}_{4}$ & 0.72 & 4.19 & 70 & [77] \\
\hline $\mathrm{SnWO}_{4}$ & 0.69 & 2.27 & 36 & [78] \\
\hline $\mathrm{NiWO}_{4}$ & 0.69 & 2.54 & 31 & [71] \\
\hline $\mathrm{MnWO}_{4}$ & 0.66 & 2.97 & 29 & [79] \\
\hline $\mathrm{CoWO}_{4}$ & 0.65 & 2.5 & 35 & [80] \\
\hline $\mathrm{FeWO}_{4}$ & 0.61 & 2.16 & 50 & [81] \\
\hline
\end{tabular}

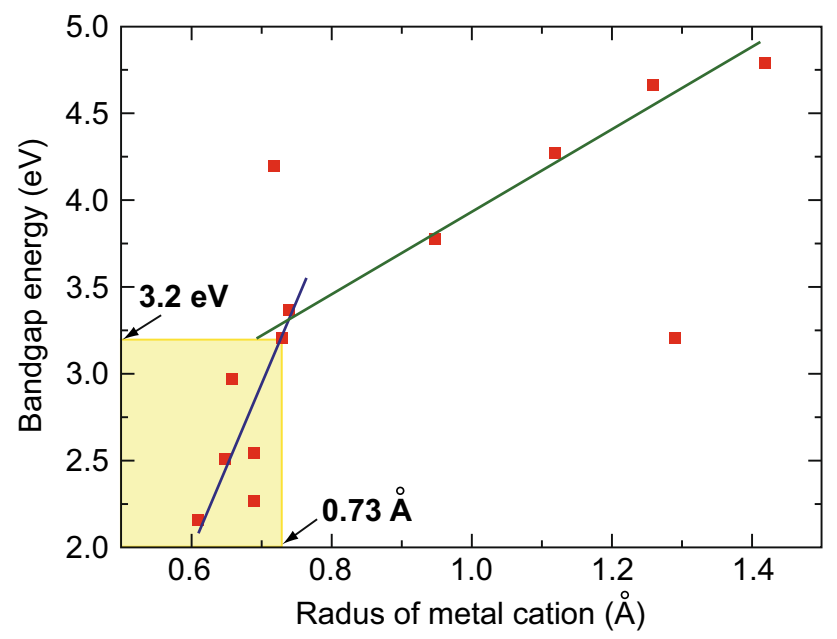

Fig. 4 Relationship between band-gap energy of $\mathrm{MWO}_{4}$ and the radii of metal cations

\subsection{Crystal Structure}

As $\mathrm{ABO}_{4}$-type compounds, ternary $\mathrm{MWO}_{4}$ complex materials possess a typical wolframite-type monoclinic crystal structure and scheelite-type tetragonal structure. In the scheelite crystal structure, one $\mathrm{W}$ atom coordinates with four $\mathrm{O}$ atoms to form the $\mathrm{WO}_{4}$ tetrahedral unit. In contrast, in the wolframite crystal structure, one $\mathrm{W}$ atom is encircled by six oxygen atoms to form the $\mathrm{WO}_{6}$ octahedral unit. For example, Yan et al. [83] reported a tetragonal structure in $\mathrm{CdWO}_{4}$ material, in which the $\mathrm{W}$ atom is situated in the center of the tetrahedra, forming four $\mathrm{W}-\mathrm{O}$ bonds of the same bond length of $1.758 \AA$, with the coordination number of the $\mathrm{Cd}$ atom being eight. However, the monoclinic structure of $\mathrm{CdWO}_{4}$ is similar to that of previously reported $\mathrm{MnWO}_{4}$ [84]. Both $\mathrm{W}(\mathrm{VI})$ and $\mathrm{Cd}(\mathrm{II})$ have octahedral $\mathrm{O}$ coordination, in which each octahedron shares two corners with its neighbors. However, the configuration of the $\mathrm{WO}_{6}$ octahedron leads to severe distortion in which two $\mathrm{W}-\mathrm{O}$ bonds are much shorter than the other four $\mathrm{W}-\mathrm{O}$ bonds. The two crystal phases of $\mathrm{CdWO}_{4}$ are shown in Fig. 5. An investigation of methyl orange (MO) degradation showed that the photocatalytic performance of monoclinic $\mathrm{CdWO}_{4}$ was much higher than that of tetragonal $\mathrm{CdWO}_{4}$ and commercial $\mathrm{TiO}_{2}$ under UV light irradiation, which can be ascribed to the lower lattice symmetry of the monoclinic $\mathrm{CdWO}_{4}$. Furthermore, the electronic structures of the wolframite- and scheelite-type $\mathrm{CdWO}_{4}$ were investigated by theoretical computations and simulations based on density functional theory (DFT). As shown in Fig. 5b-d, both monoclinic and tetragonal $\mathrm{CdWO}_{4}$ are indirect-type semiconductors because the calculated bottom of the $\mathrm{CB}$ is not situated in the same line as the top of the VB. The calculated band gap of monoclinic $\mathrm{CdWO}_{4}$ was larger than that of tetragonal $\mathrm{CdWO}_{4}$, which was not consistent with the photocatalytic results. Actually, the monoclinic $\mathrm{CdWO}_{4}$ consisted of distorted $\mathrm{WO}_{6}$ octahedra, leading to the generation of dipole moments in the $\mathrm{WO}_{6}$ octahedral units, while the tetragonal $\mathrm{CdWO}_{4}$ comprised normal $\mathrm{WO}_{4}$ tetrahedra, forming a highly symmetric lattice in the absence of dipole moments. Based on its crystal and geometric structures, the monoclinic structure of $\mathrm{CdWO}_{4}$ is considered a highly efficient photocatalyst, and its catalytic performance has been extensively explored $[74,85,86]$.

In addition, it has also been reported that $\mathrm{SnWO}_{4}$ has two crystal structures: $\alpha-\mathrm{SnWO}_{4}$ and $\beta-\mathrm{SnWO}_{4}$ [87]. The orthorhombic $\alpha-\mathrm{SnWO}_{4}$ is comparatively stable in the structure below $670{ }^{\circ} \mathrm{C}$, whereas the cubic $\beta-\mathrm{SnWO}_{4}$ is a steady structure above $670{ }^{\circ} \mathrm{C}$. In the crystal unit of 
(a)
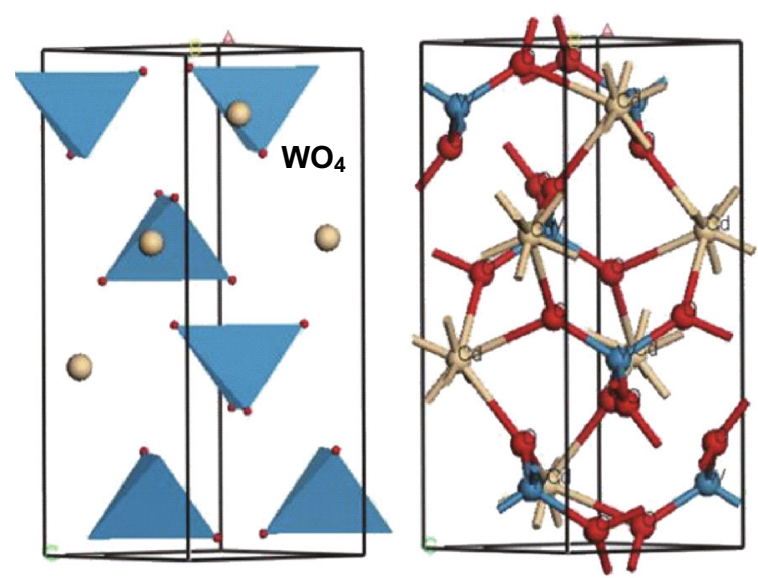

(c)

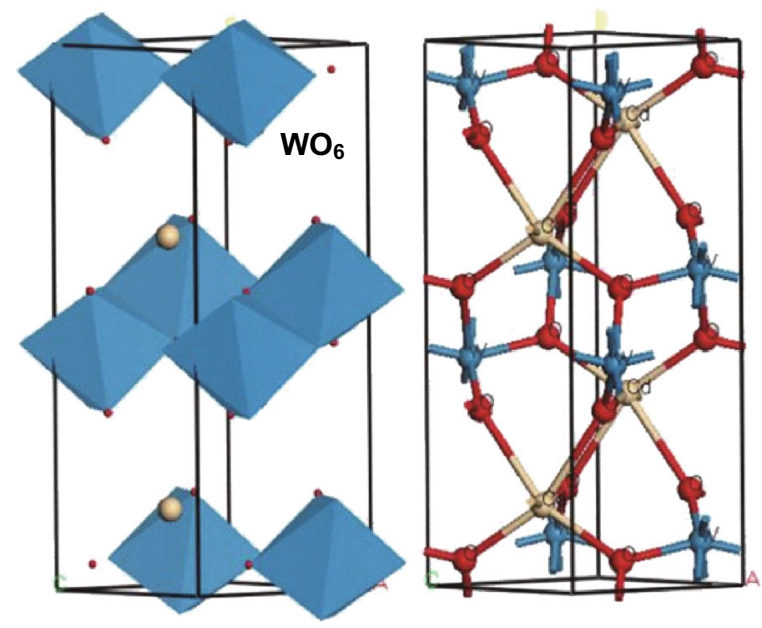

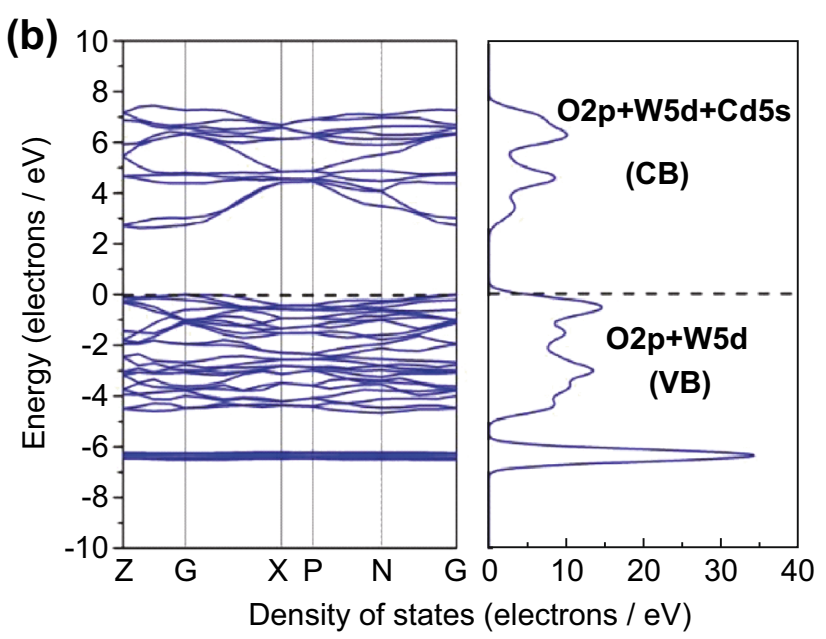

(d)

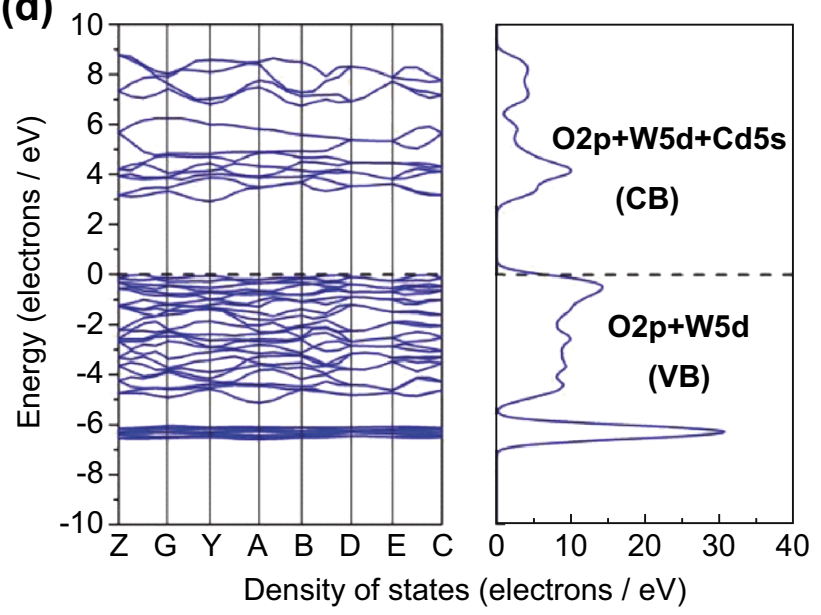

Fig. 5 Models of band structures and calculated density of states for tetragonal $(\mathbf{a}, \mathbf{b})$ and monoclinic $(\mathbf{c}, \mathbf{d}) \mathrm{CdWO}_{4}$. Reproduced with permission from Ref. [83]. Copyright 2011 Elsevier

orthorhombic $\alpha-\mathrm{SnWO}_{4}$, a single $\mathrm{W}$ atom is bonded with six $\mathrm{O}$ atoms to constitute typical corner-shared $\mathrm{WO}_{6}$ octahedra, while the unshared $\mathrm{WO}_{4}$ tetrahedra are composed of a crystal unit of $\beta-\mathrm{SnWO}_{4}$. Owing to the lone-pair effects on the $\mathrm{Sn}(\mathrm{II})$ ion, distorted $\mathrm{SnO}_{6}$ octahedra are formed in both polymorphs. Cho et al. [88] prepared the aforementioned $\mathrm{SnWO}_{4}$ materials with different types of crystal structures and investigated the relationship of the crystal structure with the optical and catalytic properties of $\mathrm{SnWO}_{4}$ (Fig. 6). It was demonstrated that a difference in atom arrangement could result in an apparent difference in electronic distribution. The VB of $\mathrm{SnWO}_{4}$ is constituted through high hybridization between the Sn 5 s orbital and O $2 p$ orbital, resulting from the strong interaction between the atomic orbitals with closer energy. Meanwhile, the Sn 5 s orbitals contribute to the lower and upper energy levels of the VB, while the $\mathrm{O} 2 \mathrm{p}$ orbitals are dedicated to the middle energy levels of the VB. Therefore, the VB and CB electronic structures of $\mathrm{SnWO}_{4}$ are totally different from those of the pristine $\mathrm{WO}_{3}$, in which the $\mathrm{VB}$ and $\mathrm{CB}$ comprise filled $\mathrm{O} 2 \mathrm{p}$ orbitals and empty W $5 \mathrm{~d}$ orbitals, respectively. The band gap of $\alpha-\mathrm{SnWO}_{4}$ was calculated to be $1.65 \mathrm{eV}$, which was lower than that of $\mathrm{WO}_{3}(1.77 \mathrm{eV})$, thereby accounting for the broadening effect of the VB, which can be attributed to the contribution of the Sn $5 \mathrm{~s}$ orbitals. In contrast, the calculated band gap of $3.45 \mathrm{eV}$ for $\beta-\mathrm{SnWO}_{4}$ was apparently much larger than that of $\alpha$ $\mathrm{SnWO}_{4}$ and $\mathrm{WO}_{3}$. Although the $\mathrm{Sn} 5$ s orbitals also contribute to the $\mathrm{VB}$ of $\beta-\mathrm{SnWO}_{4}$ (Fig. 6b), the increase in the band gap stems from the decreased length of the $\mathrm{W}-\mathrm{O}$ bonds and enhanced crystal field splits, thus resulting in the upshifting of the $\mathrm{CB}$ position. Furthermore, the experimental results showed that both $\alpha-\mathrm{SnWO}_{4}$ and $\beta-\mathrm{SnWO}_{4}$ exhibited higher photocatalytic performance for the degradation of Rhodamine B (RhB), as compared to other visible-light-response photocatalysts, such as bulk- or nanoWO 3 and nanoTiON ${ }_{x}$ (Fig. 6d). Moreover, the $\beta$ $\mathrm{SnWO}_{4}$ showed a higher photocatalytic activity for $\mathrm{H}_{2}$ evolution in the presence of methanol, accompanying Pt as a co-catalyst under visible-light irradiation (Fig. 6e), which 

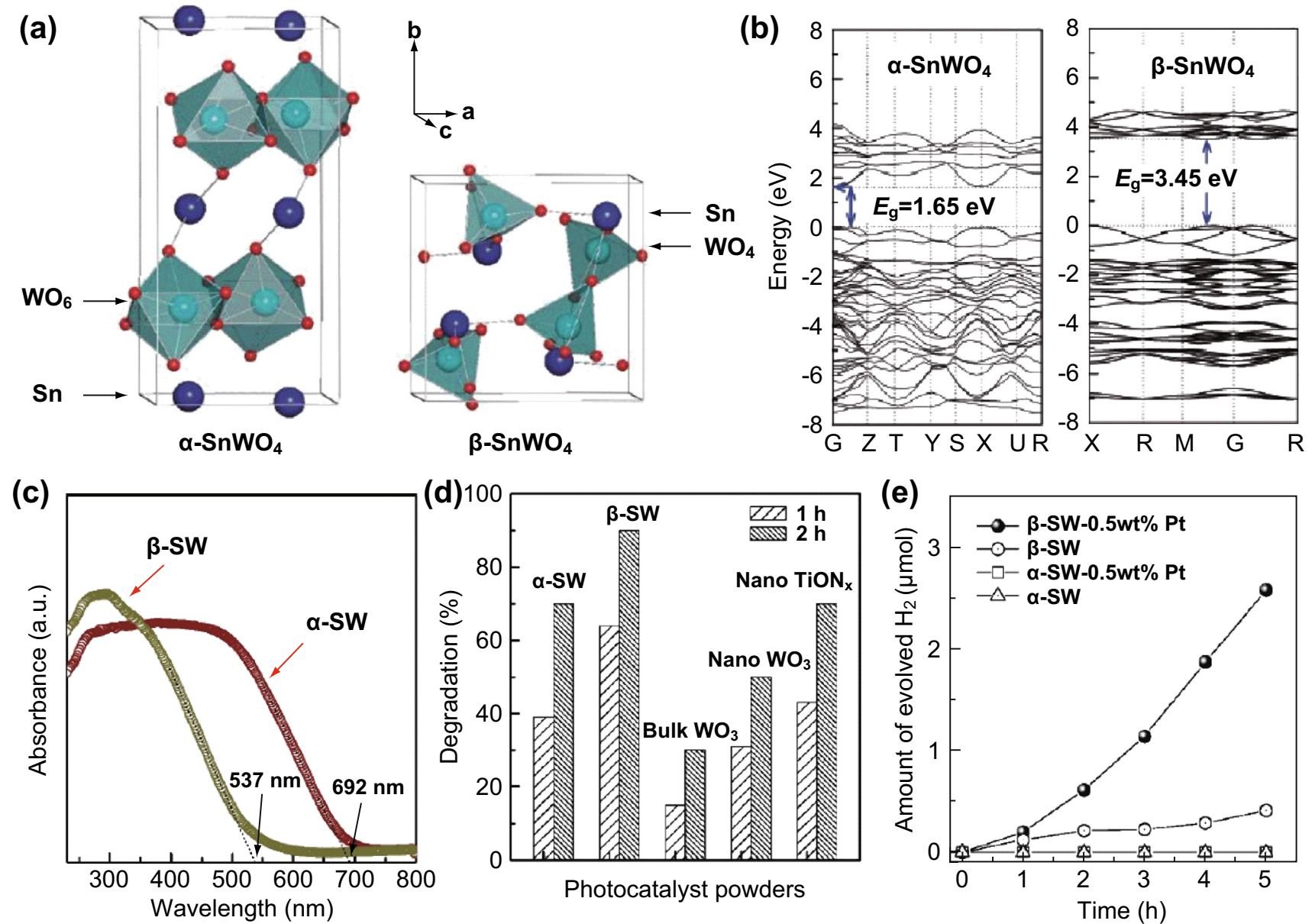

Fig. 6 a Crystal structures, $\mathbf{b}$ density of states, and $\mathbf{c}$ UV-Vis absorption spectra of $\alpha-\mathrm{SnWO}_{4}$ and $\beta$-SnWO $\mathrm{S}_{4}$. d Photocatalytic activity of $\alpha$ $\mathrm{SnWO}_{4}$ and $\beta-\mathrm{SnWO}_{4}$ in $\mathrm{RhB}$ degradation. e $\mathrm{H}_{2}$ evolution. Reproduced with permission from Ref. [88]. Copyright 2009 American Chemical Society

can be mainly ascribed to the higher $\mathrm{CB}$ edge of $\beta-\mathrm{SnWO}_{4}$ compared to that of $\alpha-\mathrm{SnWO}_{4}$. Based on the aforementioned analysis, one can conclude that the $\mathrm{MWO}_{4}$ photocatalysts usually possess more than two types of crystal structure, thus leading to a difference in geometries and local lattice distortions. The non-bonded electrons in the metal ion should be considered an important factor in analyzing the crystal field, particularly in an $\mathrm{MWO}_{4}$-based asymmetric coordination environment. The distortion of the local crystal structure influences the electronic structure and band distribution, thus affecting the catalytic performances of $\mathrm{MWO}_{4}$-based photocatalysts.

\subsection{Electronic Structure}

Generally, tungstates are considered derivatives of $\mathrm{H}_{2} \mathrm{WO}_{4}$ and $\mathrm{WO}_{3}$ because of their similar elemental constitutions and crystal structures [89-91]. The DFT [92] and ab initio [93] calculations indicate that the $\mathrm{CB}$ of $\mathrm{MWO}_{4}$ consists of $\mathrm{W} 5 \mathrm{~d}$ orbitals in tungstates, as in $\mathrm{WO}_{3}$, while the $\mathrm{O} 2 \mathrm{p}$ orbitals only comprise the upper part of the VB because the bivalent metal cation in tungstates contributes differently to the $\mathrm{VB}$ and $\mathrm{CB}$ positions given different outer electronic arrangements [55].

For instance, visible-light-driven $\mathrm{CuWO}_{4}$ is employed for photoelectrochemical (PEC) water splitting because of its suitable band gap of $2.3 \mathrm{eV}$ [94-96]. For most binary metal oxides, the VB is mainly constituted of $\mathrm{O} 2 \mathrm{p}$ orbitals; thus, the VB energy is usually in the range of $2.5-3.0 \mathrm{eV}$, indicating that the top of the VB is not significantly shifted in the metal oxides. For ternary metal oxides, however, the mixing atomic orbitals between the $\mathrm{O} 2 \mathrm{p}$ orbitals and metal orbitals could result in an apparent shift in the top position of the VB [97]. Thus, for $\mathrm{CuWO}_{4}$, the VB shifts upward, in comparison to that of $\mathrm{WO}_{3}$, accounting for the hybridization between the $\mathrm{O} 2 \mathrm{p}$ orbitals and $\mathrm{Cu} 3 \mathrm{~d}$ orbitals (Fig. 7a). The upward movement in the VB position indicates a decrease in the band gap, which results in an increased visible-light absorption range [98]. However, the composition of the $\mathrm{CB}$ is still a topic of hot debate. DFT 
calculations show that the $\mathrm{VB}$ of $\mathrm{CuWO}_{4}$ is composed of $\mathrm{O}$ 2 p orbitals with a small portion of $\mathrm{Cu} 3 \mathrm{~d}$, whereas the $\mathrm{CB}$ of $\mathrm{CuWO}_{4}$ is composed of W $5 \mathrm{~d}$ orbitals [99, 100]. Moreover, the $\mathrm{Cu} 3 \mathrm{~d}$ orbitals may contribute to the $\mathrm{CB}$ of $\mathrm{CuWO}_{4}$ except for the top of the VB [101]. Experimental results demonstrate that the $\mathrm{CB}$ shift of $\mathrm{CuWO}_{4}$ relative to that of $\mathrm{WO}_{3}$ can be ascribed to the incorporation of $\mathrm{Cu} 3 \mathrm{~d}$ orbitals into the energy level of the CB [102]. Yet, strong evidence of an accurate contribution proportion of $\mathrm{Cu} 3 \mathrm{~d}$ orbitals to the $\mathrm{CB}$ of $\mathrm{CuWO}_{4}$ has not been obtained. Although the $\mathrm{CB}$ composition of $\mathrm{CuWO}_{4}$ is unclear, the $\mathrm{CuWO}_{4}$ photoanode presented a high photocatalytic activity with a photocurrent density of up to $0.07 \mathrm{~mA} \mathrm{~cm}^{-2}$ at $1.23 \mathrm{~V}$ and a high stability under AM 1.5G illumination (Fig. 7b, c), indicating that the $\mathrm{CuWO}_{4}$ photoanode has a thermodynamic potential for water oxidation. In this system, a physical model of the photogenerated charge carrier pathways in $\mathrm{CuWO}_{4}$ is proposed as shown in Fig. 7d. It shows that when the photogenerated electrons are transferred from a solution medium to a mid-gap state, the thermodynamic potential of the mid-gap state can be utilized to determine which elementary reaction is favored to occur and which is the rate-limiting reaction.

Apart from $\mathrm{CuWO}_{4}$, the electronic structures of other $\mathrm{MWO}_{4}$ materials have also been previously studied. For example, Rajagopal and co-workers [103, 104] used X-ray emission spectroscopy and DFT computation to study the electronic structures and related properties of $\mathrm{FeWO}_{4}$ and $\mathrm{CoWO}_{4}$ photocatalysts. The theoretical calculation results demonstrated that $\mathrm{O} 2 \mathrm{p}$ orbitals mainly contributed to the
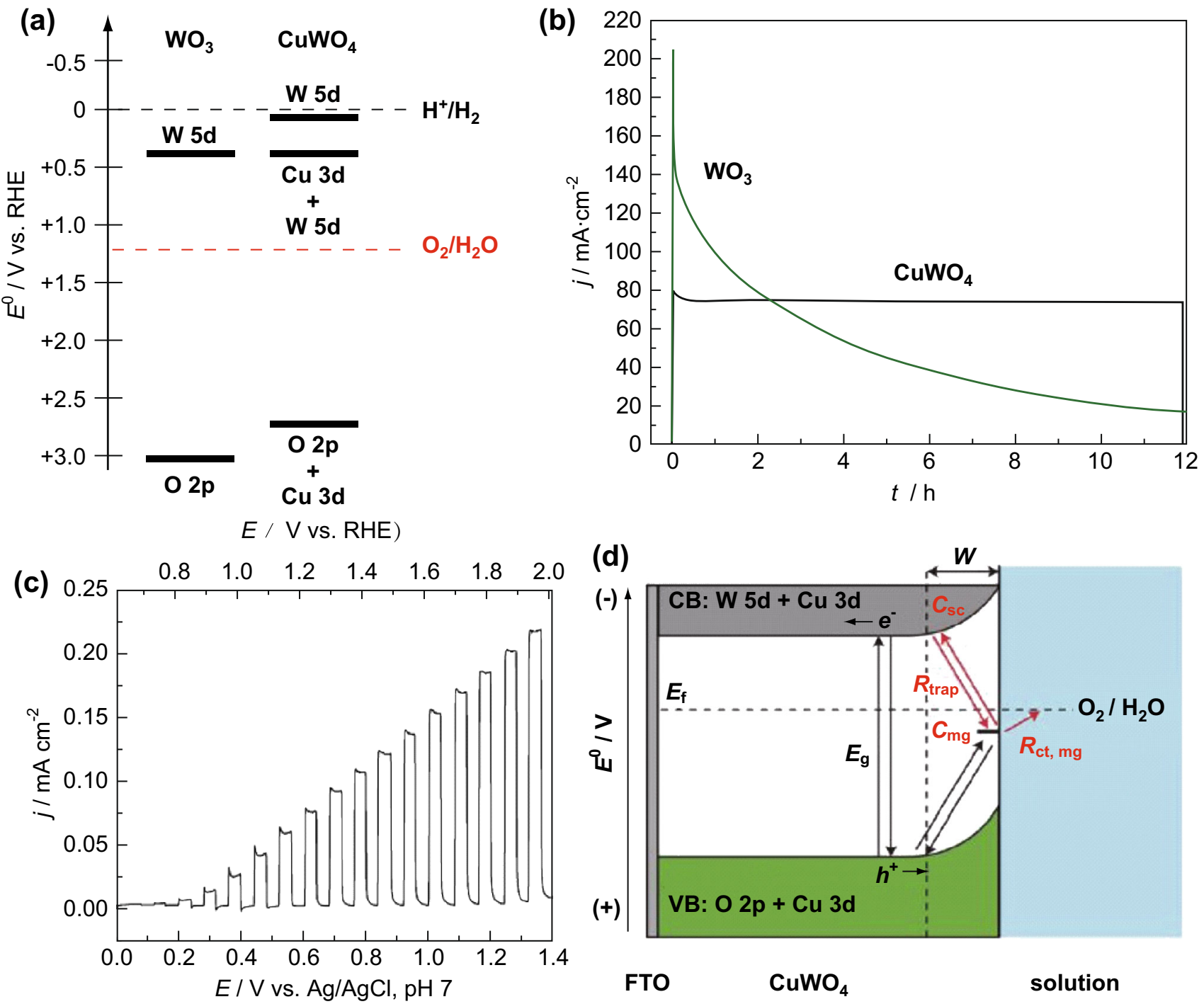

Fig. 7 a Distribution of energy level and $\mathbf{b}$ chronoamperometry curves of $\mathrm{CuWO}_{4}$ and $\mathrm{WO}_{3}$. $\mathbf{c}$ Polarization curve of CuWO 4 photoanode under AM1.5G irradiation. d Illustration of the physical model of charge carrier transfer in $\mathrm{CuWO}_{4}$. Reproduced with permission from Ref. [102]. Copyright 2016 American Chemical Society 
VB of tungstates, while the unoccupied Fe $3 d$ orbitals and Co $3 \mathrm{~d}$ orbitals were dominantly dedicated to the $\mathrm{CB}$ of $\mathrm{FeWO}_{4}$ and $\mathrm{CoWO}_{4}$, respectively. In addition, the density of states showed that $\mathrm{Co} 3 \mathrm{~d}$ and $\mathrm{W} 5 \mathrm{~d}$ orbitals also contributed to the $\mathrm{VB}$ regions of $\mathrm{CoWO}_{4}$, similar to that of $\mathrm{FeWO}_{4}$. Hence, the VBs of $\mathrm{FeWO}_{4}$ and $\mathrm{CoWO}_{4}$ are composed of O 2p, W 5d, and Fe/Co 3d orbitals. However, $\mathrm{X}$-ray emission spectroscopy results revealed that the $\mathrm{W} 5 \mathrm{~d}$ orbitals and $\mathrm{O} 2 \mathrm{p}$ orbitals are dedicated to the entire VB of the tungstates, in which the $\mathrm{O} 2 \mathrm{p}$ orbitals are dedicated to the upper region of the VB and $\mathrm{W} 5 \mathrm{~d}$ orbitals are dedicated to the lower region of the VB. The theoretical results agreed well with the experimental results for $\mathrm{FeWO}_{4}$ and $\mathrm{CoWO}_{4}$. In addition, the electronic structure of $\mathrm{NiWO}_{4}$ was obtained. For $\mathrm{NiWO}_{4}$, the $\mathrm{CB}$ predominantly consists of $\mathrm{W}$ $5 \mathrm{~d}$ orbitals and $\mathrm{Ni} 3 \mathrm{~d}$ orbitals, while the VB primarily consists of $\mathrm{Ni} 3 \mathrm{~d}$ orbitals and $\mathrm{O} 2 \mathrm{p}$ orbitals [105]. It was found that the $\mathrm{VB}$ composition of $\mathrm{NiWO}_{4}$ is different from those of $\mathrm{FeWO}_{4}$ and $\mathrm{CoWO}_{4}$, which is related to the energy level distribution of the orbital electrons around the metal ions. Therefore, based on the aforementioned results, one can conclude that the electronic structures of ternary $\mathrm{MWO}_{4}$ systems mainly depend on the position of the $\mathrm{M}^{2+}$ cation in the periodic table, which affects the outer electronic arrangements and hybridized electrons of the atomic orbital to the $\mathrm{M}^{2+}$ cation.

\section{Strategies for Enhanced Photocatalytic Activity}

As described in Sect. 1, ternary $\mathrm{MWO}_{4}$ systems can act as highly promising photocatalysts for environmental purification and solar water splitting. However, among the major limiting factors in enhancing their photocatalytic activities is the rapid recombination of photogenerated electron and hole pairs. To overcome this problem and improve the overall catalytic performance of $\mathrm{MWO}_{4}$ photocatalysts, many research groups have endeavored to develop various techniques to enhance the separation and transfer efficiency of photoexcited charge carriers inside $\mathrm{MWO}_{4}$ or at the interface between different components. In this section, an overview of the developed strategies is provided to offer insights on their effects for the separation efficiency of photogenerated charge carriers and the corresponding catalytic performance of $\mathrm{MWO}_{4}$-based photocatalysts.

\subsection{Morphological Control}

As is known, the morphology, facet exposure, and dimensions of photocatalysts have a significant influence on the photocatalytic performance. For example, nanostructured photocatalysts can exhibit excellent photocatalytic activities because the morphologies and particle sizes of the photocatalysts have a significant influence on the optical and electronic properties, which in turn affect the photocatalytic activities. For example, Yu et al. [106] prepared $\mathrm{FeWO}_{4}$ samples with different morphologies, including nanoparticles, flakes, nanorods (NRs), and a mixture of NRs with flakes and tiny granules, by varying $\mathrm{pH}$ values during the hydrothermal process, and systematically investigated their optical properties. The results indicated that the band-gap values of $\mathrm{FeWO}_{4}$ are correlated with specific morphologies. Hosseinpour-Mashkani and coworkers [75] synthesized $\mathrm{ZnWO}_{4}$ nanoparticles with different sizes through a precipitation route using different polymeric surfactants. The photocatalytic degradation experiments of $\mathrm{MO}$ demonstrated that the $\mathrm{ZnWO}_{4}$ with the smallest size of $27 \mathrm{~nm}$ exhibited the highest photoactivity, compared with other $\mathrm{ZnWO}_{4}$ samples under UV light illumination. It has been demonstrated that particle size can affect the band gap of semiconductors because of quantum size effects. The exposed surface area of nanoparticles increases with a decrease in nanoparticle size, which can provide more active sites for a surface catalytic reaction. In addition to morphologies and particle sizes, size-related crystallinity of $\mathrm{MWO}_{4}$ has an important influence on the photophysical and photocatalytic properties. For example, Tong et al. [74] reported nanostructured $\mathrm{CdWO}_{4}$ with controllable particle sizes via a hydrothermal process and studied the effects of the particle sizes on the lattice symmetry and crystallinity. It was found that the decreased size of the $\mathrm{CdWO}_{4}$ nanoparticles resulted in an expanded lattice, lowered crystallinity, and broadened band gap. Meanwhile, the decrease in particle sizes caused an apparent decrease in the photocatalytic activity of $\mathrm{CdWO}_{4}$. These results illustrate that size-related properties are closely correlated with the photocatalytic activity of $\mathrm{MWO}_{4}$. Apart from the effects of the aforementioned factors on photoactivity, the crystal phase of $\mathrm{MWO}_{4}$ is also regulated by various synthetic routes to obtain the desired physiochemical and optical properties, because different crystal phases can lead to distinct differences in the exposure of crystal facets and reactivities. For instant, different crystal phases of $\mathrm{CdWO}_{4}$ nanocrystals were prepared by adjusting the used solvents for photocatalytic $\mathrm{H}_{2}$ evolution (Fig. 8) [86]. The solvent significantly affected the chelation and growth of the $\mathrm{CdWO}_{4}$ material, thus leading to apparent differences in the crystal phase. $\mathrm{m}-\mathrm{CdWO}_{4}$ nanocrystals with particle sizes ranging from 4.4 to $31 \mathrm{~nm}$ can be prepared using short-chain solvents, while $\mathrm{t}_{-} \mathrm{CdWO}_{4}$ nanocrystals can be easily prepared utilizing long-chain solvents. The obtained $\mathrm{m}-\mathrm{CdWO}_{4}$ nanocrystals exhibited much higher $\mathrm{H}_{2}$ production than the $\mathrm{t}-\mathrm{CdWO}_{4}$ nanocrystals.

During recent years, the construction of hierarchical structures to tune the morphologies of $\mathrm{MWO}_{4}$ 

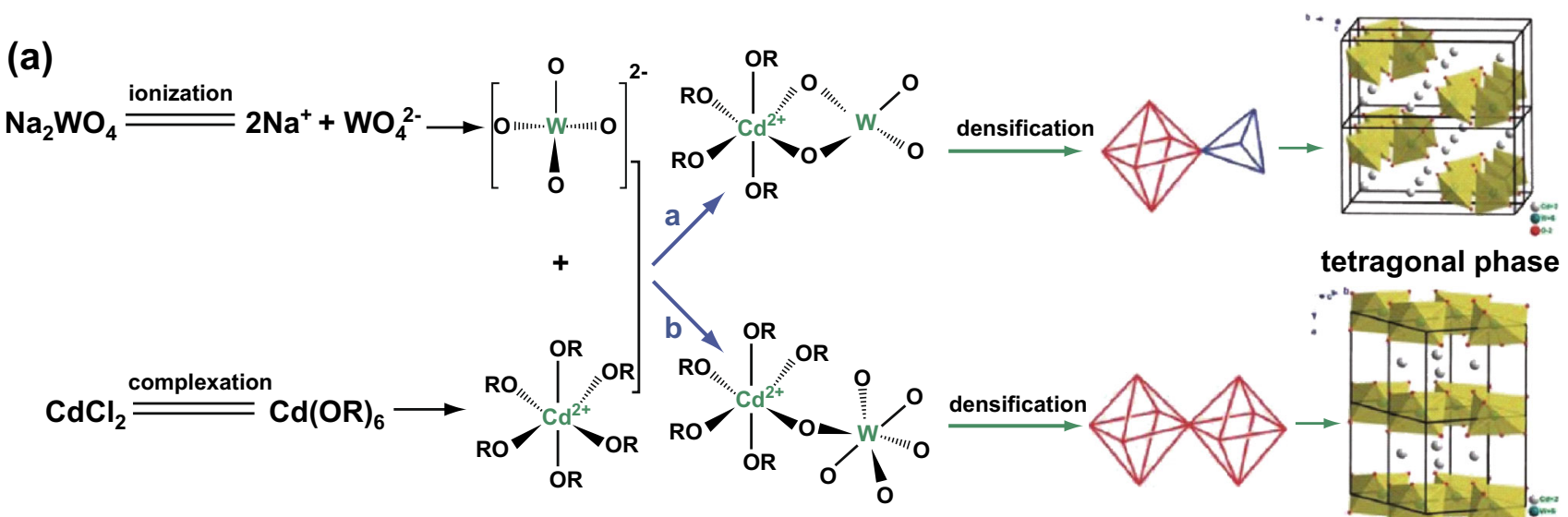

(b)

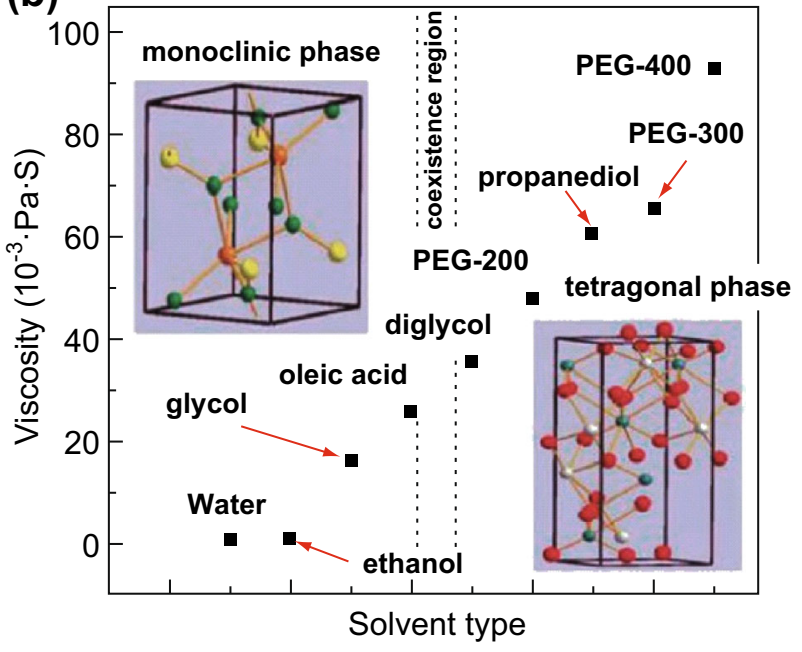

(c)

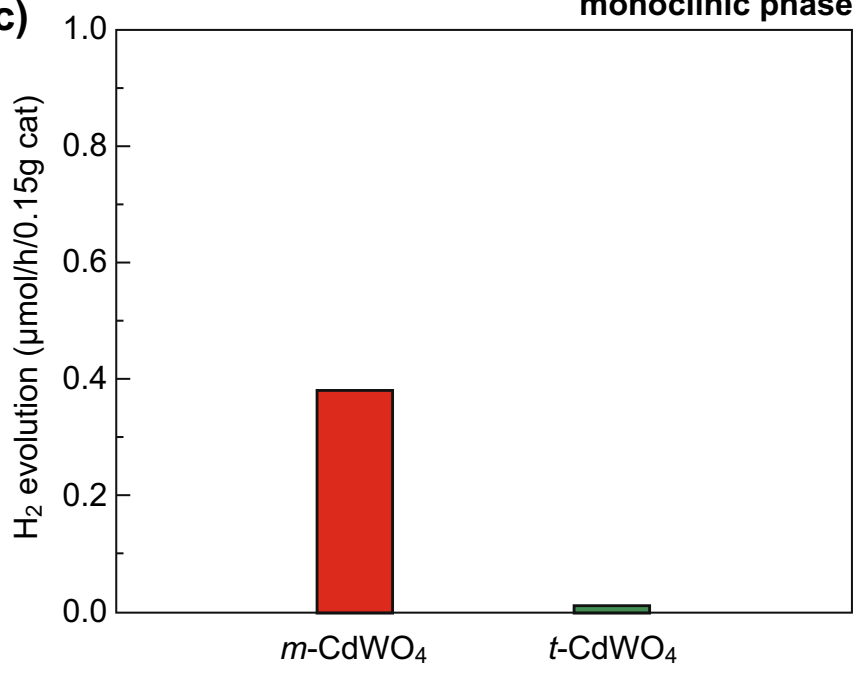

Fig. 8 a Formation mechanism of $\mathrm{m}-\mathrm{CdWO}_{4}$ and $\mathrm{t}-\mathrm{CdWO}_{4}$ and the b relationship between different crystal phases of $\mathrm{CdWO}_{4}$ and used solvents. c Photocatalytic $\mathrm{H}_{2}$ evolution of $\mathrm{m}-\mathrm{CdWO}_{4}$ and $\mathrm{t}-\mathrm{CdWO}_{4}$ under visible light irradiation. Reproduced with permission from Ref. [86]. Copyright 2012 Royal Society of Chemistry

photocatalysts has attracted more attention, because hierarchical structures can offer more exposed surfaces and/or active sites. For example, highly efficient hydrophobic $\mathrm{CdWO}_{4}$ microspheres were synthesized by Hou et al. [107] through a microwave-assisted interfacial hydrothermal strategy. The $\mathrm{CdWO}_{4}$ microspheres showed enhanced photocatalytic activity for the degradation of MO under mercury lamp irradiation (Fig. 9). The advantages of a hierarchical structure for the enhanced photocatalytic activity of $\mathrm{MWO}_{4}$ are supported by several research groups [108-111]. Chen et al. [112] prepared $\mathrm{FeWO}_{4}$ microspheres by using an ethylene glycol-assisted solvothermal approach, in which ionic1-octyl-3-methylimidazolium tetrachloroferrate was used as one of the starting materials and played an important role as both a reactant and template. The microsphere-like $\mathrm{FeWO}_{4}$ material consisted of numerous nanosheets and exhibited a much better photoFenton activity in water purification (Fig. 10) because of the generation of hydroxyl radicals, which are produced from the chemical reaction between $\mathrm{Fe}^{2+}$ on the surface of $\mathrm{FeWO}_{4}$ and $\mathrm{H}_{2} \mathrm{O}_{2}$. The formed $\mathrm{Fe}^{3+}$ was further reduced by the photoinduced electrons to generate $\mathrm{Fe}^{2+}$, which is a virtuous cycle, to maintain high photocatalytic performance. Recently, Zhou et al. [113] synthesized an urchinlike $\mathrm{MnWO}_{4}$ hierarchical structure through a facile hydrothermal process with the assistance of cetyltrimethylammonium bromide (CTAB) as surfactant. The introduction of CTAB as the surfactant had significant effects on the morphology and magnetic properties of the $\mathrm{MnWO}_{4}$ nanocrystals. Subsequently, Xing et al. [114] provided a new route for the synthesis of a complex threedimensional (3D) $\mathrm{MnWO}_{4}$ nanostructure. In this case, a 3D flower-like $\mathrm{MnWO}_{4}$ nanocomposite was synthesized using a microemulsion-based solvothermal approach. Moreover, Chen et al. [115] discussed the effect of the morphology of $\beta-\mathrm{SnWO}_{4}$ on its photocatalytic performance, in which the $\beta-\mathrm{SnWO}_{4}$ with a multi-armed architecture and hexahedral symmetry displayed much higher photocatalytic activities 

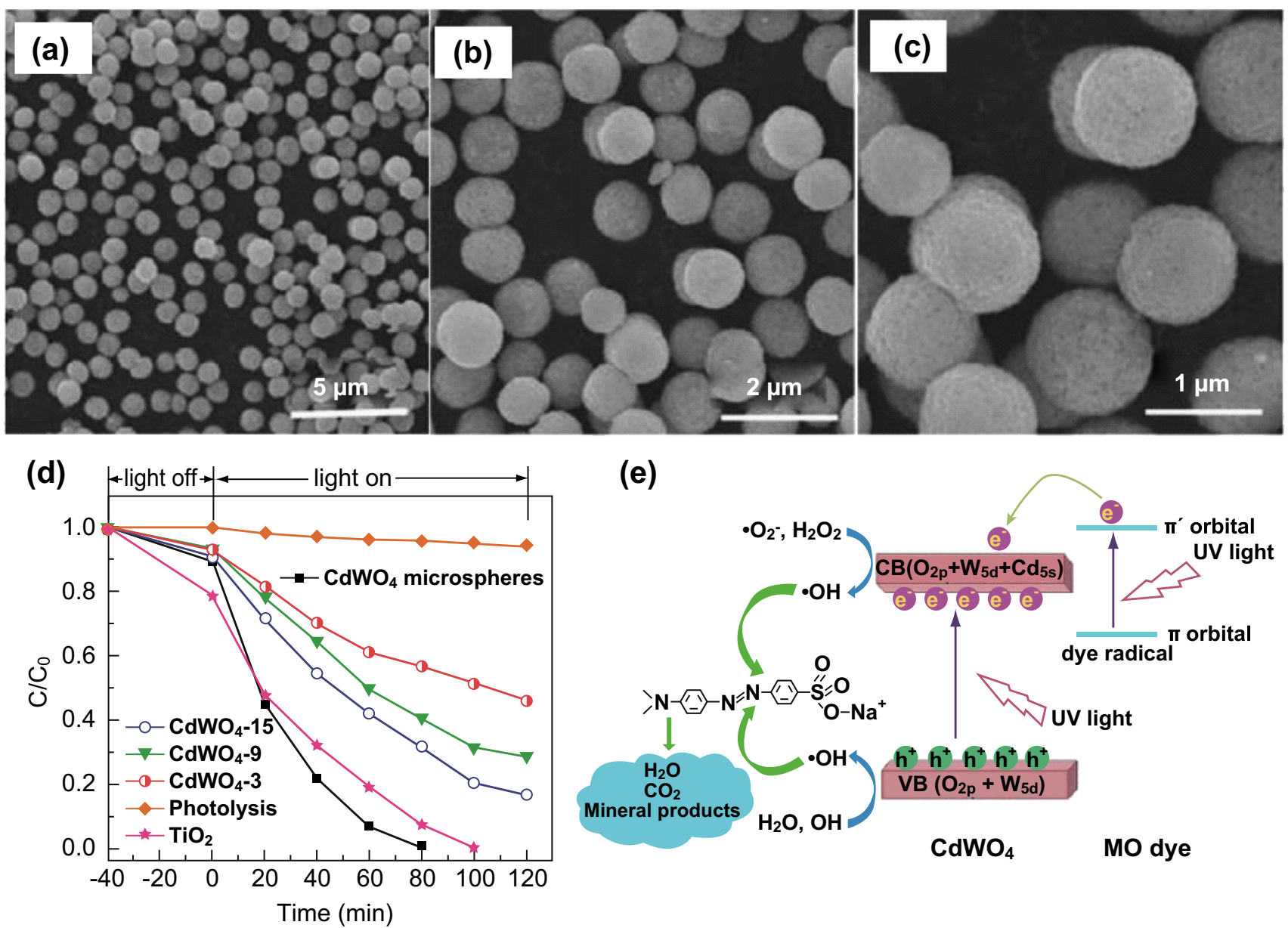

Fig. 9 a-c FESEM images of $\mathrm{CdWO}_{4}$ microspheres. d Photocatalytic degradation efficiencies of $\mathrm{MO}$ in the presence of different photocatalysts. e Photocatalytic mechanism for $\mathrm{CdWO}_{4}$ microspheres. Reproduced with permission from Ref. [107]. Copyright 2014 Royal Society of Chemistry

than those of both cubic $\beta-\mathrm{SnWO}_{4}$ and commercial $\mathrm{WO}_{3}$. Hence, more surface reaction sites induced by the hierarchically multi-armed architecture and the band structure reframing caused by incorporation of the $\mathrm{Sn}$ atom into $\mathrm{WO}_{3}$ contributed to the excellent photocatalytic activity.

Previously, crystal facet exposure was viewed as an effective strategy to regulate the surface physicochemical and photophysical properties, thus optimizing the reactivity and selectivity of photocatalysts. In general, a crystal facet with a high percentage of unbonded atoms has superior reactivity in comparison to that with a low ratio of unpaired atoms. In addition, crystal facets possessing high surface energy are usually unstable during preparation. It is desirable to synthesize photocatalysts with a high exposure of high-energy crystal facets to enhance the photocatalytic reactivity and selectivity. Using DFT calculations, Qiu and co-workers [116] reported the atom distributions and electronic properties of $\mathrm{MnWO}_{4}$ and $\mathrm{FeWO}_{4}$ with specific facets. The calculated results showed that the $\{010\}$ and $\{100\}$ facets have the lowest surface energies in wolframite-type $\mathrm{FeWO}_{4}$ and $\mathrm{MnWO}_{4}$, respectively. Meanwhile, it was observed that the $\mathrm{Fe}$ and $\mathrm{Mn}$ atoms on the $\{010\}$ and $\{001\}$ planes as absorption sites can be used to absorb anions. These results indicated that the exposed $\{100\}$ facet in $\mathrm{MnWO}_{4}$ and $\mathrm{FeWO}_{4}$ can provide a path for improving their photoactivities, while the other exposed facets can offer a certain selectivity to a specific reaction, such as a dichlorination reaction. Recently, Ungelenk et al. [117] synthesized phase-pure $\beta-\mathrm{SnWO}_{4}$ with truncated rhombic dodecahedrons using a microemulsion technique with CTAB as a co-surfactant with n-hexanol (Fig. 11). Benefitting from the rapid $\mathrm{Na}_{2} \mathrm{WO}_{4}$-induced nucleation and slow crystal growth controlled by the CTAB-mediated microemulsion reaction, the as-prepared $\beta-\mathrm{SnWO}_{4}$ with truncated rhombic dodecahedrons was encircled with highly exposed $\{100\}$ and $\{110\}$ facets. By comparing a series of $\beta-\mathrm{SnWO}_{4}$ to other photocatalysts of $\mathrm{Ag}_{3} \mathrm{PO}_{4}$ and $\mathrm{m}-\mathrm{BiVO}_{4}$, the $\beta-\mathrm{SnWO}_{4}$ microcrystals with exposed $\{100\}$ and $\{110\}$ facets showed outstanding photocatalytic activity for the degradation of organic pollutants under 

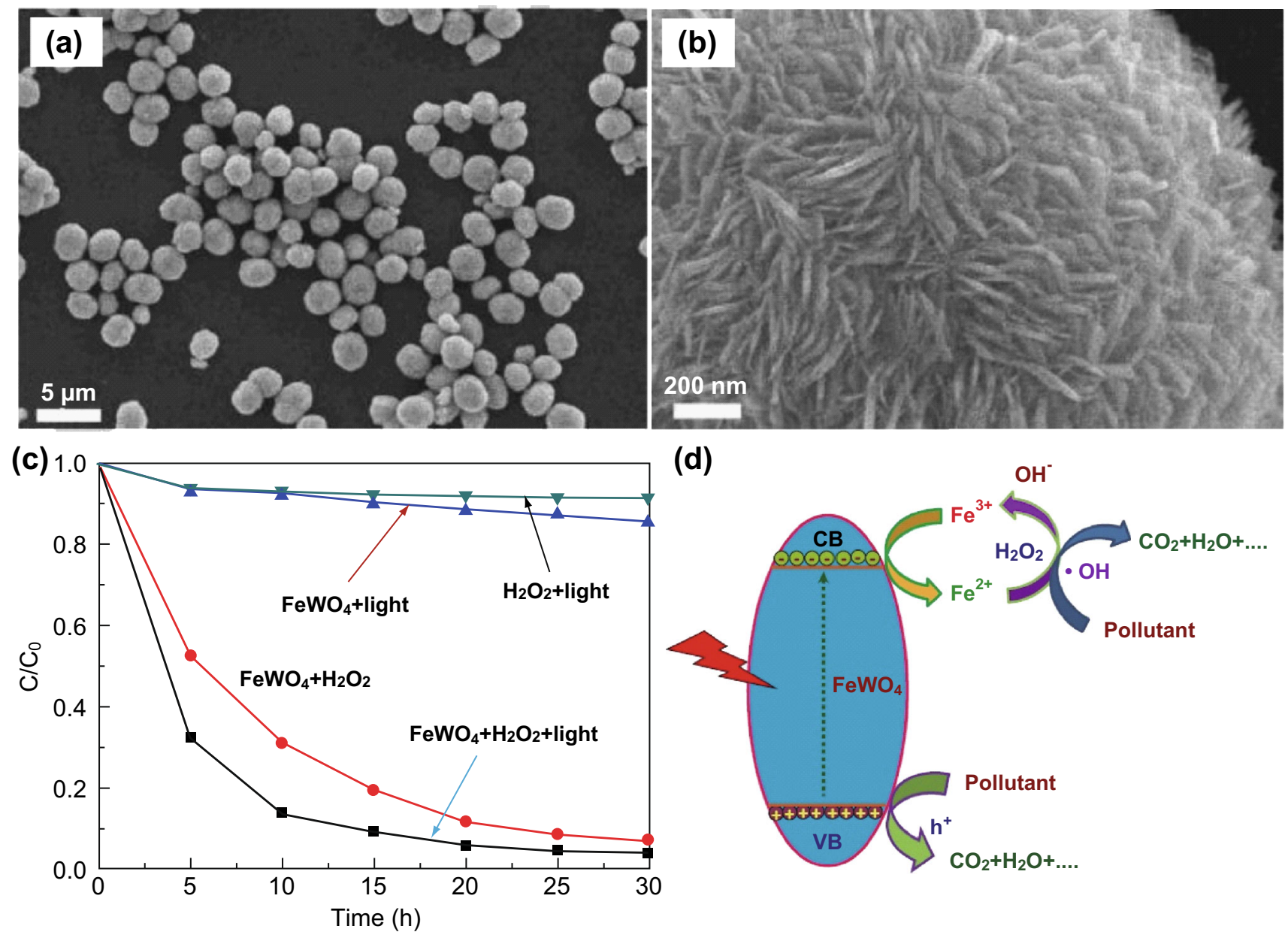

(d)

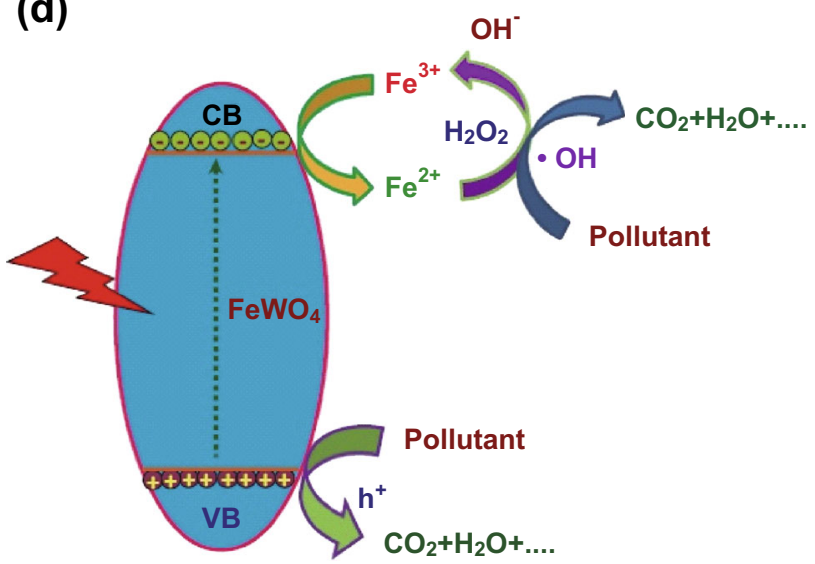

Fig. 10 a, b FESEM images of $\mathrm{FeWO}_{4}$ microspheres. c Photocatalytic performance of $\mathrm{FeWO}_{4}$ microspheres for the degradation of RhB. d Schematic illustration of photocatalysis mechanism for $\mathrm{FeWO}_{4}$ microspheres. Reproduced with permission from Ref. [112]. Copyright 2016 Elsevier

daylight irradiation, which was far better than that of other photocatalysts, including bulk non-faceted $\beta-\mathrm{SnWO}_{4}$ and spherical-like $\beta-\mathrm{SnWO}_{4}$ nanoparticles. In addition, given the slight difference in specific surface area between the faceted $\beta-\mathrm{SnWO}_{4}$ and non-faceted $\beta-\mathrm{SnWO}_{4}$, it was concluded that optimized facet exposure was the predominant reason for the distinct photocatalytic activity. In addition, Tian et al. [118] reported a facile solvothermal method for the synthesis of hierarchical $\mathrm{FeWO}_{4}$ nanosheets with an exposed $\{100\}$ facet, which exhibited excellent peroxidaselike catalytic activity for oxidizing the peroxidase substrate of $3,3^{\prime}, 5,5^{\prime}$-tetramethylbenzidine (TMB) because of the formation of hydroxyl radicals in the presence of $\mathrm{H}_{2} \mathrm{O}_{2}$. The surface $\mathrm{Fe}^{2+}$ in $\mathrm{FeWO}_{4}$ can activate the $\mathrm{H}_{2} \mathrm{O}_{2}$ molecule to produce active hydroxyl radicals for the oxidation of TMB. The results clearly indicated that the $\{100\}$ facet of $\mathrm{FeWO}_{4}$ had a much higher ratio of $\mathrm{Fe}$ atoms than that of the $\{001\}$ and $\{010\}$ facets, which explained the enhanced catalytic activity of $\mathrm{FeWO}_{4}$ with the exposed $\{100\}$ facet.
Owing to the high surface area and large absorption cross section it provides, a low-dimensional nanostructure can be constructed to manipulate and regulate optical, electrical, and magnetic properties [119, 120]. Low-dimensional nanostructures including those that are one-dimensional (1D) or two-dimensional (2D) cause the growth of a crystal along one or two directions, which can contribute to more exposure of specific surface facets. For example, $1 \mathrm{D} \mathrm{CdWO} \mathrm{CNR}_{4}$ were prepared using microwave or hydrothermal approaches and exhibited excellent photocatalytic activity for environmental treatments, as compared to nanoparticles [121-123]. Kovacs and co-workers [111] prepared a series of $\mathrm{FeWO}_{4}$ with different morphologies, including nanoparticles, NRs, and nanosheets, by varying the $\mathrm{Fe}$ precursors. The nanosheet-like $\mathrm{FeWO}_{4}$ with band-gap energy of $\sim 2.2 \mathrm{eV}$ exhibited excellent absorption ability throughout the UV and visible-light range, which was attributed to the formation of a cavity assembled by nanosheets that resulted in enhanced photon harvest. Therefore, the $\mathrm{FeWO}_{4}$ nanosheets showed higher 


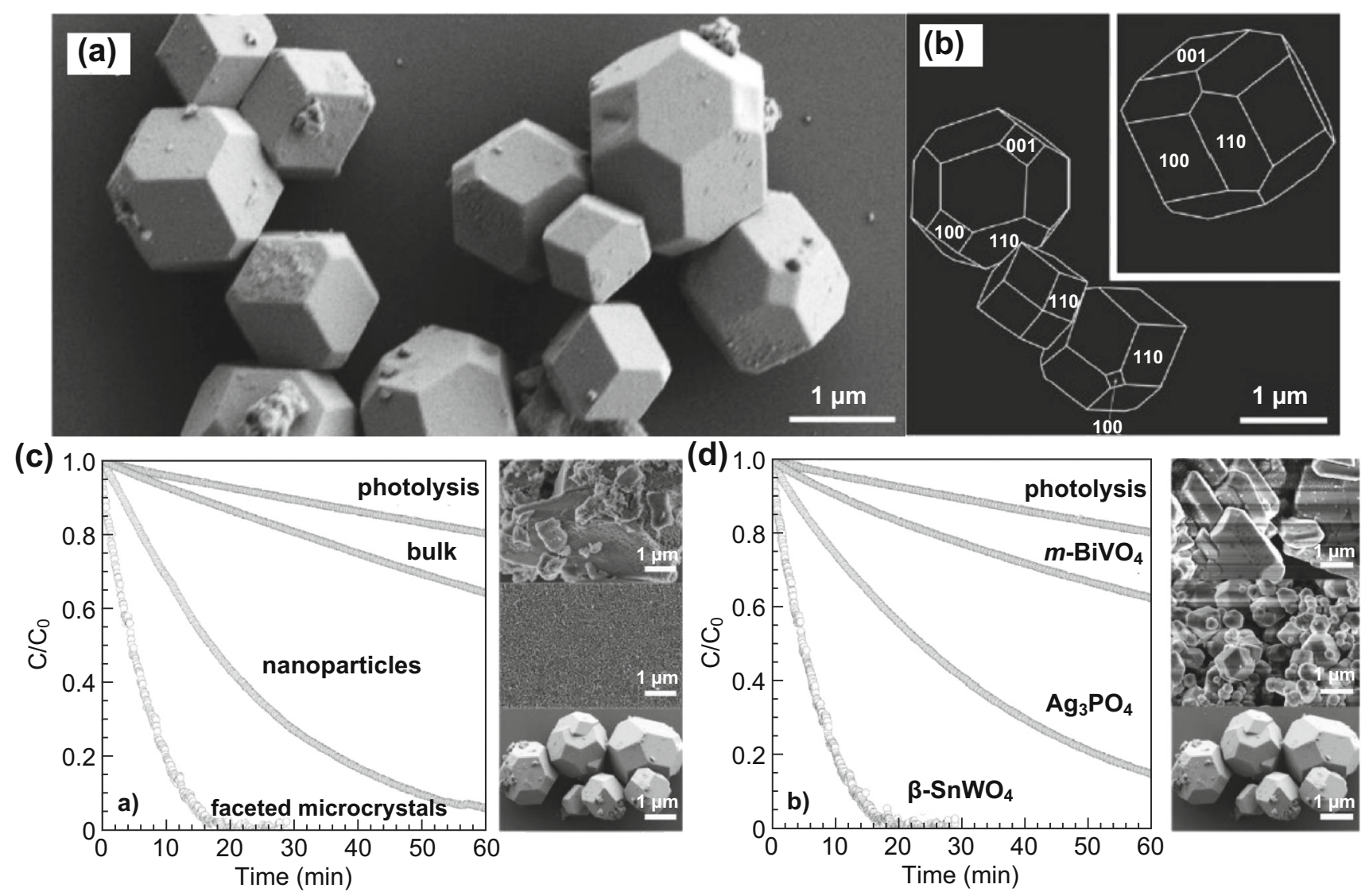

Fig. 11 a, b FESEM images of faceted $\beta$-SnWO 4 microcrystals. c, d FESEM images and photocatalytic activities for the degradation of MB over faceted $\beta-\mathrm{SnWO}_{4}$ microcrystals, bulk $\beta-\mathrm{SnWO}_{4}$, and $\beta-\mathrm{SnWO}_{4}$ nanoparticles under sunlight irradiation. Reproduced with permission from Ref. [117]. Copyright 2012 Royal Society of Chemistry

photocatalytic activity than other control samples for the degradation of organic dyes under visible-light irradiation.

\subsection{Surface Modification}

Considering that the photocatalytic reaction proceeds on the surface of semiconductors, the surface physiochemical properties of semiconductor-based photocatalysts are important for improvement of photocatalytic activity. Several strategies, including chemical etching, surface coverage, and co-catalyst attachment, have been developed to tune the surface properties of semiconductor-based photocatalysts.

The purpose of etching techniques, such as chemical etching and laser or electron-beam irradiation, is to form non-stoichiometric or metal/oxygen vacancies on the surface of an inorganic semiconductor. The formation of metal or oxygen vacancies has proven to have an apparent influence on the electronic distribution because of the introduction of a new defect energy level, thus affecting the light absorption range and photocatalytic activity. For example, Aloysius-Sabu et al. [124] investigated the effects of intentional electron-beam irradiation on the crystal phase, size, and surface properties of $\mathrm{CaWO}_{4}$ that was prepared through chemical precipitation and heat treatment. The experimental results showed that the high-energy electron beam significantly affected the crystal size and surface structure, but not the crystal phase. When the $\mathrm{CaWO}_{4}$ photocatalyst was irradiated by an electron beam, the surface atomic layers of $\mathrm{CaWO}_{4}$ underwent stretching and compressive strain, which resulted in the formation of surface defects and a new energy level in the band gap. Therefore, an apparent absorption tail and narrowed bandgap energy were observed in the irradiated $\mathrm{CaWO}_{4}$ sample. In addition, Lin et al. [125] prepared a visible-light-driven $\mathrm{Ag}_{2} \mathrm{WO}_{4}$ photocatalyst through a laser irradiation route in liquid using commercial $\mathrm{Ag}_{2} \mathrm{WO}_{4}$ as a starting material for organics degradation and $\mathrm{H}_{2}$ evolution. Because of the laser irradiation, the crystal structure was recrystallized and a lattice defect was introduced in $\mathrm{Ag}_{2} \mathrm{WO}_{4}$, leading to the formation of intermediate energy levels with a decrease of $0.44 \mathrm{eV}$ in the band gap. The synthesized $\mathrm{Ag}_{2} \mathrm{WO}_{4}$ exhibited a photocatalytic $\mathrm{H}_{2}$ evolution rate as high as $13.73 \mu \mathrm{mol}(\mathrm{hg})^{-1}$ under visible-light illumination, while no $\mathrm{H}_{2}$ evolution was observed in the unirradiated 
commercial $\mathrm{Ag}_{2} \mathrm{WO}_{4}$ sample, which was ascribed to a large band gap of $3.22 \mathrm{eV}$ for bulk $\mathrm{Ag}_{2} \mathrm{WO}_{4}$.

However, to enhance the solar conversion efficiency of tungstates, surface coverage has been adopted to increase the charge transfer efficiency by means of passivating the surface via deposition of a protective layer. For example, Karthiga and co-workers [71] reported the synthesis of $\mathrm{NiWO}_{4}$ nanoparticles modified by a plant extract, $A$. indica, as a capping agent through a precipitation route for enhanced photocatalytic activity. The introduction of $A$. indica, which possesses rich water-soluble heterocyclic groups, led to the formation of a passivation layer on the surface of the $\mathrm{NiWO}_{4}$ nanoparticles, which allowed the $\mathrm{NiWO}_{4}$ nanoparticles to separate well from each other. In comparison to the bare $\mathrm{NiWO}_{4}$ nanoparticles, the $A$. indica-coated $\mathrm{NiWO}_{4}$ exhibited a much higher photocatalytic activity for the degradation of organic contaminants under visible-light irradiation because of the formation of the passivation layer of the plant extract, which significantly suppressed the recombination of photoinduced electrons and holes. Meanwhile, modified $\mathrm{NiWO}_{4}$ presented higher antimicrobial activity as compared with pure $\mathrm{NiWO}_{4}$ nanoparticles.

Apart from chemical etching and surface coverage strategies, attachment of noble metal co-catalysts (such as, $\mathrm{Pt}, \mathrm{Au}$, and $\mathrm{Ag}$ ) is another effective means to tune the surface photophysical properties of photocatalysts because of the surface plasmon resonance (SPR) effect [126, 127]. The SPR effect not only significantly enhances visible-light absorption, but also produces a localized electromagnetic field, thus improving the separation efficiency of the photogenerated charge carriers at the interfaces between the metal and semiconductor [128, 129]. Furthermore, the metal-semiconductor heterostructure could efficiently suppress the recombination of photogenerated electrons and holes because of the formation of Schottky barriers at the contacted interface, thus enhancing photocatalytic performance [126]. Based on the aforementioned features, the introduction of a noble metal into $\mathrm{MWO}_{4}$ is a feasible approach to realize enhancement of its photocatalytic performance. Recently, Liu et al. [130] prepared Ag nanoparticles (NPs)/ $\alpha-\mathrm{SnWO}_{4}$ nanosheets through microwave-assisted anchoring of $\mathrm{Ag} \mathrm{NPs}$ on $\mathrm{SnWO}_{4}$ nanosheets. The loading amount of the deposited Ag NPs was welltuned by adjusting the initial concentration of the $\mathrm{Ag}^{+}$ precursor and CTAB surfactant (Fig. 12a). The obtained Ag NPs/ $\alpha-\mathrm{SnWO}_{4}$ hybrid showed enhanced light absorption ability and photocatalytic activity for the degradation of $\mathrm{MO}$, compared to pure $\alpha-\mathrm{SnWO}_{4}$, under visible-light irradiation. Moreover, the hybridized Ag $\mathrm{NPs} / \alpha-\mathrm{SnWO}_{4}$ system exhibited improved transient photocurrent density in comparison to that of pristine $\alpha-\mathrm{SnWO}_{4}$ (Fig. 12c), indicating that more photoinduced charge carriers could be produced and further participated in the redox reaction. In addition, Yan et al. [131] synthesized Ag-loaded $\mathrm{CdWO}_{4}$ NRs using a photo-assisted co-precipitation method with the addition of the PEG-100 surfactant, which exhibited a higher photocatalytic activity than that of pure $\mathrm{CdWO}_{4}$ NRs because of the SPR effect. In another study, Au NPs were utilized to construct Schottky barriers in an $\mathrm{MWO}_{4^{-}}$ based system. For instance, $\mathrm{Au} \mathrm{NRs} / \mathrm{MnWO}_{4}$, with a diameter of 20-40 nm, was reported by Chakraborty et al. [132] to enhance the photocatalytic decomposition of 2-propanol and phenol. The Au NPs as co-catalysts in the $\mathrm{Au} / \mathrm{MnWO}_{4}$ hybrid were beneficial to multi-electron $\mathrm{O}_{2}$ reduction and hole oxidation.

\subsection{Heteroatom Doping}

It has been demonstrated that the introduction of impurities via doping of heteroatoms into a semiconductor can influence the photocatalytic performance [133, 134]. However, heteroatom doping might either have positive or negative impacts for the photocatalytic performance of semiconductors, because there are two different doping levels - the shallow level near the surface and deep level inside the body [135]. Deep-level doping can usually provide a recombination center to intensify the meaningless dissipation of absorbed photons, thus undermining the photocatalytic activity. Therefore, appropriate heteroatom doping is vital to increasing the photocatalytic performance of heteroatom-doped photocatalysts. To overcome shortcomings, such as a narrow wavelength range and rapid recombination of photogenerated electron-hole pairs, a few recent reported types of heteroatom doping to enhance the photocatalytic performances of ternary $\mathrm{MWO}_{4}$ materials are reviewed and their roles discussed in detail.

In heteroatom doping, the dopants are mainly non-metal elements such as B [136], $\mathrm{Cl}$ [137], and various transition metals ( $\mathrm{Zn}, \mathrm{Ni}, \mathrm{Fe}, \mathrm{Co}$, etc.) [138, 139], which exhibit enhanced photocatalytic activity for mineralizing organic pollutants. For instance, Chen et al. [140] synthesized F-doped $\mathrm{ZnWO}_{4}$ nanocrystals $\left(\mathrm{F}_{\mathrm{i}}-\mathrm{ZnWO}_{4}\right.$ nanocrystals) using a two-step hydrothermal process and investigated its chemical bonds via band structure calculations (Fig. 13). In comparison to undoped $\mathrm{ZnWO}_{4}$, the $\mathrm{F}_{\mathrm{i}}-\mathrm{ZnWO}_{4}$ nanocrystals exhibited significant red shifts and improved light absorption in the range of UV-visible light, which resulted in enhancement of photocatalytic activity for the degradation of RhB under mercury lamp irradiation. Additionally, the experimental results showed that the crystallinity and morphology of the prepared $\mathrm{F}_{\mathrm{i}}-\mathrm{ZnWO}_{4}$ was strongly related to the photocatalytic activity. $\mathrm{F}_{\mathrm{i}}-\mathrm{ZnWO}_{4}$ exhibited higher photocatalytic performance for the degradation of organic dyes than $\mathrm{F}_{\mathrm{i}}-\mathrm{ZnWO}_{4}$ NPs. Based on the theoretical calculation results, the enhancement of the photocatalytic 

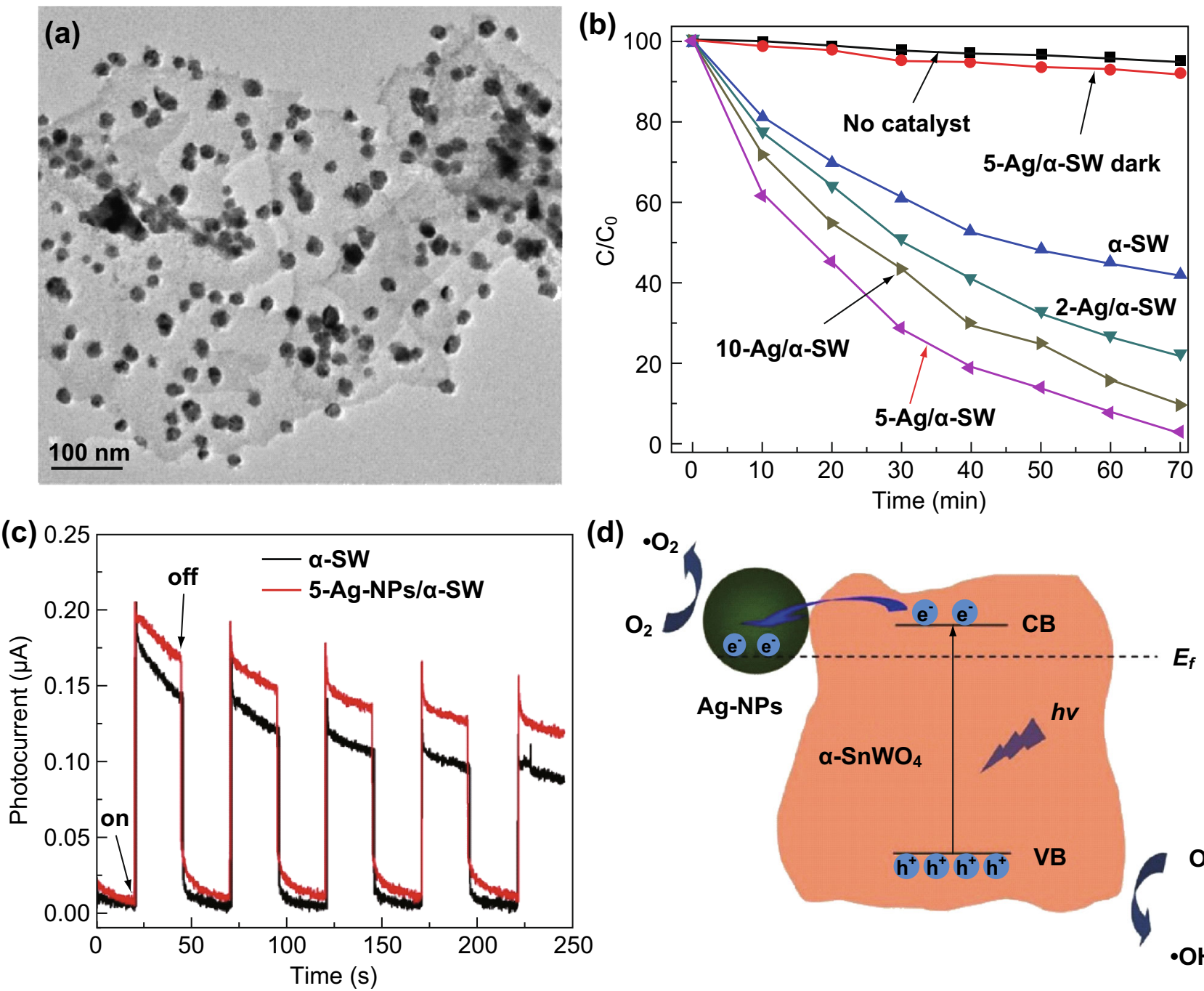

(d)

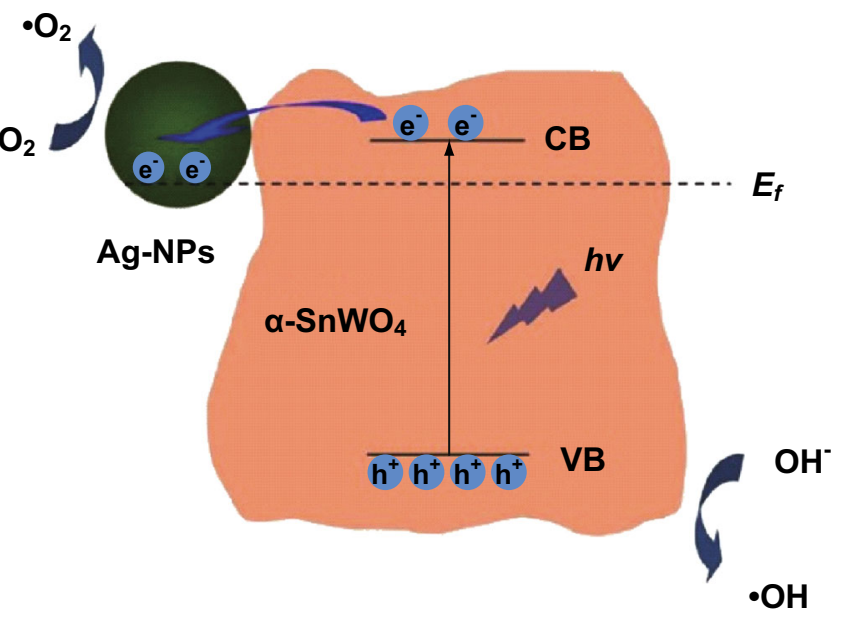

Fig. 12 a TEM image and b photodegradation efficiency of $\mathrm{Ag} \mathrm{NPs} / \alpha-\mathrm{SnWO}_{4}$ under visible-light irradiation. $\mathbf{c}$ Transient photocurrent response for different samples. d Illustration of photocatalytic mechanism of Ag NPs/ $\alpha-\mathrm{SnWO}_{4}$. Reproduced with permission from Ref. [130]. Copyright 2017 Elsevier

activity of $\mathrm{F}_{\mathrm{i}}-\mathrm{ZnWO}_{4}$ might be ascribed to the following reasons. First, F-doping increased the absorptivity of $\mathrm{F}_{\mathrm{i}^{-}}$ $\mathrm{ZnWO}_{4}$, such that it could absorb more reactants to enhance the photocatalytic activity. Second, a new halffilled state was introduced into the original band gap of $\mathrm{ZnWO}_{4}$ accompanying the F-doping, which could provide more holes to enhance the photocurrent density of $\mathrm{F}_{\mathrm{i}^{-}}$ $\mathrm{ZnWO}_{4}$. Thus, heteroatom doping could efficiently improve the photocatalytic activities of $\mathrm{MWO}_{4}$ by introducing a new energy level to regulate the original electronic structure.

Apart from the introduction of non-metal elements, transition metal elements can also be a potential dopant. For example, Su et al. [141] prepared $\mathrm{Zn}^{2+}$-doped $\mathrm{SnWO}_{4}$ nanocrystals, and reported that the morphological alteration of $\mathrm{SnWO}_{4}$ nanocrystals from nanosheets to nanowires can be controlled by $\mathrm{Zn}^{2+}$ doping. Consequently, the $\mathrm{Zn}^{2+}$ - doped $\mathrm{SnWO}_{4}$ exhibited a greater Brunauer-EmmettTeller surface area (54 and $100 \mathrm{~m}^{2} \mathrm{~g}^{-1}$ for pure $\mathrm{SnWO}_{4}$ and $\mathrm{Zn}^{2+}$-doped $\mathrm{SnWO}_{4}$, respectively), narrowed band gap (2.68 and $2.64 \mathrm{eV}$ for pure $\mathrm{SnWO}_{4}$ and $\mathrm{Zn}^{2+}$-doped $\mathrm{SnWO}_{4}$, respectively), and highly enhanced photocatalytic performance for the degradation of $\mathrm{MO}(95 \%$ and $30 \%$ for pure $\mathrm{SnWO}_{4}$ and $\mathrm{Zn}^{2+}$-doped $\mathrm{SnWO}_{4}$, respectively) compared to that of pure $\mathrm{SnWO}_{4}$. In addition, Song et al. [142] reported the synthesis of $\mathrm{Zn}$-doped $\mathrm{CdWO}_{4} \mathrm{NRs}$ using a hydrothermal process to enhance the photocatalytic conversion efficiency of organic pollutants into low-toxicity small molecules under simulated sunlight irradiation. The influence of the $\mathrm{Zn}$-doping amounts on the crystal phase, morphology, and optoelectronic properties of $\mathrm{CdWO}_{4} \mathrm{NRs}$ was also systematically investigated. Compared to the undoped sample, the Zn-doped $\mathrm{CdWO}_{4}$ NRs exhibited much higher photocatalytic activity, which was assigned to 

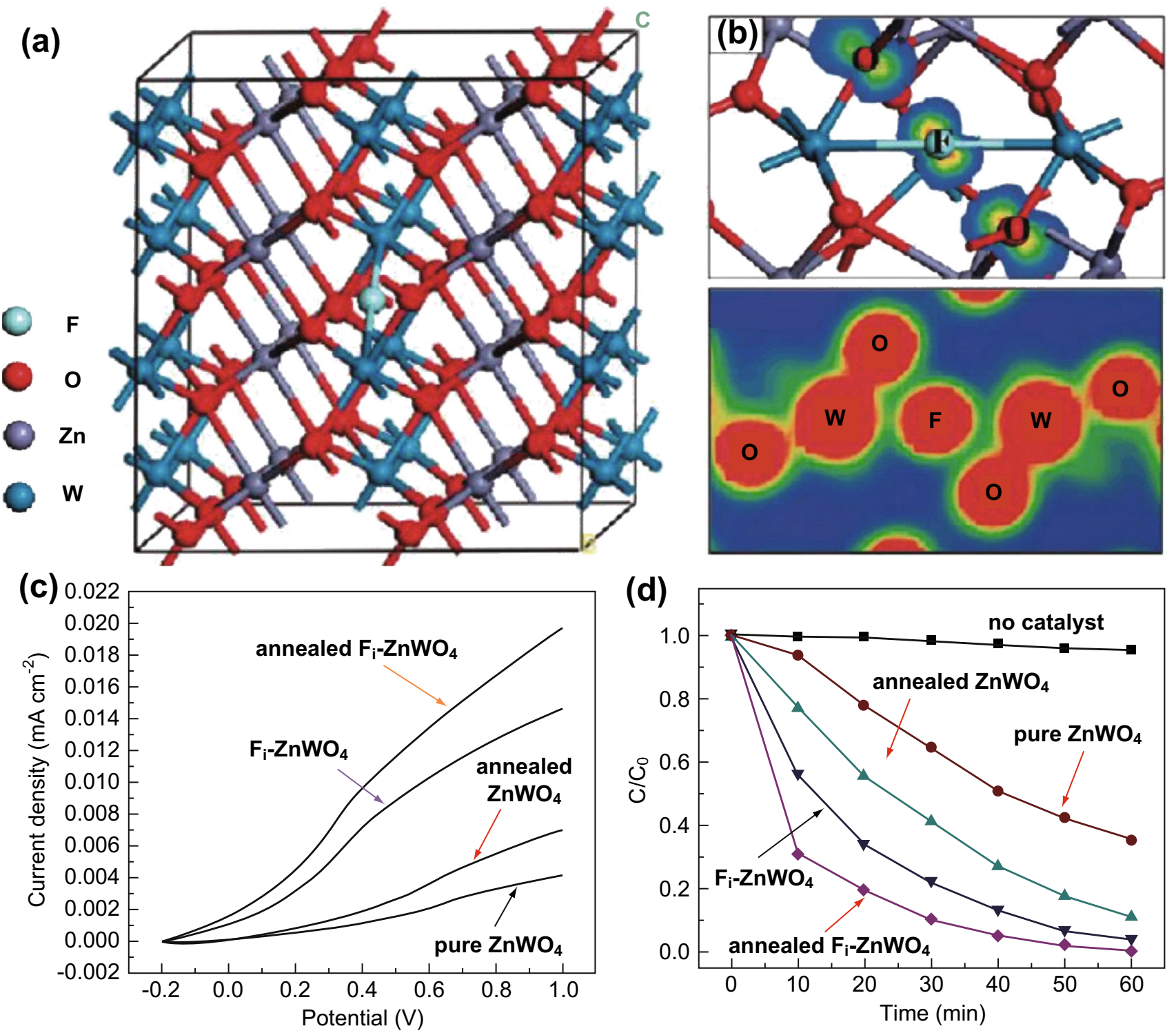

(d)

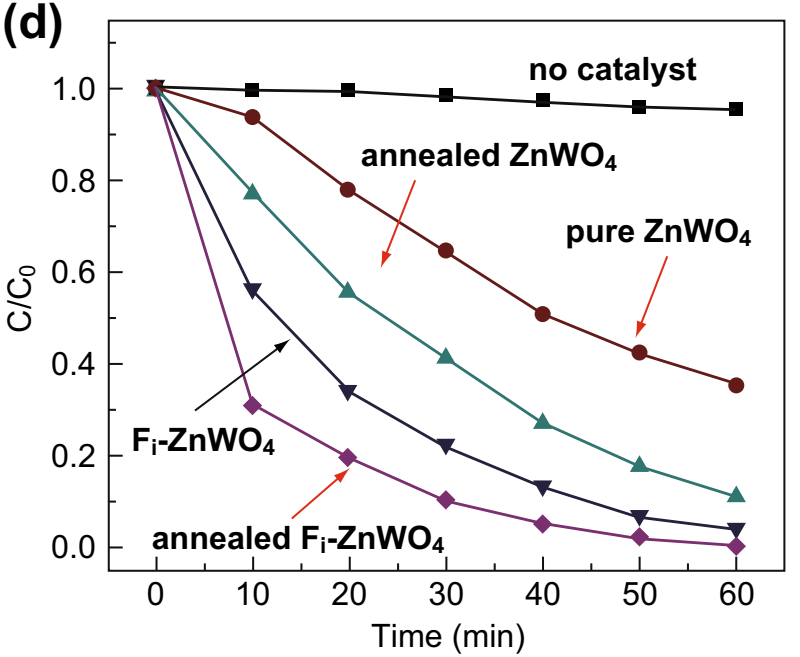

Fig. 13 a Geometric structures for the $\mathrm{F}_{\mathrm{i}}-\mathrm{ZnWO}_{4}$. Spin density (top) and total charge density (bottom) for $\mathrm{F}_{\mathrm{i}}-\mathrm{ZnWO}_{4}$. $\mathbf{c}$ Photocurrent density of the synthesized samples under UV-light irradiation. Photocatalytic degradation of RhB over different samples under UV light irradiation. Reprinted with permission from Ref. [140]. Copyright 2010 American Chemical Society

the narrowed band gap due to Zn-doping. Heteroatom doping could be an effective means to tune the distribution of the energy level and further enhance the photocatalytic performance of $\mathrm{MWO}_{4}$ without consuming excess foreign substances.

Recently, rare earth element-doped photocatalysts have attracted more attention because of their special $4 \mathrm{f}$ electron configuration, which could be beneficial for introducing a suitable energy level into the original band gap of $\mathrm{MWO}_{4}$ [143]. Phuruangrat et al. [144] synthesized Ce-doped $\mathrm{ZnWO}_{4}$ using a hydrothermal process and investigated the influence of Ce doping on the crystal phase, morphology, electronic structure, and photocatalytic activity of $\mathrm{ZnWO}_{4}$. After the introduction of $\mathrm{Ce}$ atoms, the photocatalytic activity of $\mathrm{ZnWO}_{4}$ improved with the increase in Ce content, owing to the following two reasons. First, the introduction of the $\mathrm{Ce}^{3+}$ dopant led to the generation of defects on the surface of Ce-doped $\mathrm{ZnWO}_{4}$. Second, the $\mathrm{Ce}^{4+}$ ions on the surface of $\mathrm{ZnWO}_{4}$ could efficiently trap electrons at the $\mathrm{CB}$ by the reduction of $\mathrm{Ce}^{4+}$ into $\mathrm{Ce}^{3+}$ ions, thus efficiently suppressing the recombination of photoinduced electrons and holes in the Ce-doped $\mathrm{ZnWO}_{4}$. Therefore, rare earth elements with variable valence, such as $\mathrm{Ce}, \mathrm{La}$, and $\mathrm{Eu}$, are promising dopants to improve the photocatalytic activity by trapping photogenerated electrons, consequently limiting the recombination of photogenerated charge carriers. 


\subsection{Heterojunction Fabrication}

\subsubsection{Hybridization with Semiconductors}

Among the aforementioned approaches, constructing a semiconductor heterostructure is an effective means to obtain highly efficient photocatalysts [145-148]. When heterojunctions are composed of different semiconductors that have matching band potentials to form type-I or type-II heterojunctions through realignment of the energy level, the excited photogenerated holes and electrons can be moved from one semiconductor to another in opposite directions driven by the formed built-in electric fields [149, 150], thus strengthening the separation efficiency of the photoinduced electrons and holes and further enhancing photocatalytic performance.

For constructing $\mathrm{MWO}_{4}$-based heterojunctions, semiconductors with a narrow band gap were chosen as a counterpart component to form the heterojunction system, which exhibited remarkable advantages for enhancing the photocatalytic performance. Among most semiconductors with a narrow band gap, cadmium sulfide (CdS) has attracted increasing attention for heterojunction fabrication because of its narrow band gap and high CB position, which could be beneficial for photocatalytic $\mathrm{H}_{2}$ production $[151,152]$. Therefore, various $\mathrm{CdS} / \mathrm{MWO}_{4}$ heterojunction photocatalysts have been developed, which exhibit enhanced photocatalytic activities in water purification and energy conversion [153, 154]. For instance, Yan et al. [155] prepared a CdS/MnWO${ }_{4}$ heterojunction using a facile hydrothermal method to mineralize MB and methyl violet (MV) under visible-light irradiation. Owing to the overlapping of energy bands and tightly contacted interfaces between $\mathrm{CdS}$ and $\mathrm{MnWO}_{4}$, the holes at the $\mathrm{VB}$ of $\mathrm{MnWO}_{4}$ could transfer to the $\mathrm{VB}$ of $\mathrm{CdS}$, and the excited electrons at the $\mathrm{CB}$ of $\mathrm{CdS}$ could in turn move into the $\mathrm{CB}$ of $\mathrm{MnWO}_{4}$. This model could efficiently limit the recombination rate of the photogenerated electrons and holes, thus intensifying the separation of the photogenerated charge carriers in the hybrid system (Fig. 14). Nevertheless, it is apparent that the introduced $\mathrm{CdS}$ amount was not synchronous with the photocatalytic activities of the heterojunction, while there was an optimal amount of $\mathrm{CdS}$ in the hybrid. Excessive CdS amounts caused severe agglomeration of $\mathrm{MnWO}_{4}$, damaging the heterojunction and worsening the separation efficiency of the photogenerated electrons and holes. This phenomenon was nearly discovered in the heterojunctions by combining two or more components into one system. In addition, $\mathrm{Xu}$ et al. [156] prepared a $\mathrm{CdS} / \mathrm{ZnWO}_{4}$ heterojunction consisting of $\mathrm{ZnWO}_{4} \mathrm{NRs}$ and CdS NPs using a hydrothermal method for the photodegradation of ciprofloxacin antibiotics. Compared to the $\mathrm{ZnWO}_{4} \mathrm{NRs}$ and CdS NPs, the CdS/
$\mathrm{ZnWO}_{4}$ hybrids showed higher photocatalytic activity than bare $\mathrm{ZnWO}_{4}$ NRs and CdS NPs, which was ascribed to the highly efficient separation of the photogenerated electrons and holes in the hybrid structure.

The $\mathrm{CdS} / \mathrm{CdWO}_{4}$ heterojunction also exhibited enhanced efficiency in the photocatalytic $\mathrm{H}_{2}$ production. For instance, Jia [157] and Wang et al. [158] deposited CdS on the surface of $\mathrm{CdWO}_{4}$ via an ion-exchange and in situ growth route, and the fabricated $\mathrm{Z}$-scheme $\mathrm{CdS} / \mathrm{CdWO}_{4}$ hybrid exhibited significantly enhanced photocatalytic performance for $\mathrm{H}_{2}$ evolution compared to that of the pure $\mathrm{CdWO}_{4}$ and $\mathrm{CdS}$. As discusses in the previous section, the $\mathrm{MWO}_{4}$ with a small $\mathrm{M}^{2+}$ cation has a narrow band-gap energy, which can be considered an efficient solar energy harvester to connect with wide band-gap semiconductors for constructing $\mathrm{MWO}_{4}$-based heterojunctions [159-161]. Thus, Jiang et al. [162] fabricated an $\mathrm{MnWO}_{4} / \mathrm{TiO}_{2}$ heterojunction with excellent mechanical adhesion by the in situ growth of $\mathrm{MnWO}_{4}$ on a porous $\mathrm{TiO}_{2}$ film; it presented extremely high photocatalytic performance for degrading MB because of its high crystallinity, large surface area, and strong mechanical properties (Fig. 15). Similarly, Buvaneswari et al. [163] prepared an $\mathrm{FeWO}_{4} /$ $\mathrm{ZnO}$ heterojunction via a simple co-precipitation route; the band gap of the prepared $\mathrm{FeWO}_{4} / \mathrm{ZnO}$ heterojunction was estimated to be $2.12 \mathrm{eV}$, which was apparently smaller than that of $\mathrm{ZnO}$ (3.01 eV). In comparison to pristine $\mathrm{ZnO}$, the photocatalytic activity of the $\mathrm{FeWO}_{4} / \mathrm{ZnO}$ hybrid was substantially enhanced because of the formation of a $\mathrm{FeWO}_{4} / \mathrm{ZnO}$ heterojunction structure. Additionally, the $\mathrm{CuWO}_{4} / \mathrm{ZnO}$ hybrid consisting of $\mathrm{ZnO}$ NRs and $\mathrm{CuWO}_{4}$ NPs fabricated by Mavric et al. [164] showed enhanced photocatalytic activity compared to that of pure $\mathrm{CuWO}_{4}$ NPs and ZnO NRs.

Furthermore, a $\mathrm{MO}_{\mathrm{x}} / \mathrm{MWO}_{4}$ hybrid as a smart-built heterojunction was fabricated using a facile one-pot synthetic strategy to enhance the interaction between $\mathrm{MO}_{\mathrm{x}}$ and $\mathrm{MWO}_{4}$, in which $\mathrm{M}$ is generally reported to be $\mathrm{Fe}, \mathrm{Ni}, \mathrm{Co}$, or $\mathrm{Cu}$ [165-168]. Cao et al. [169] fabricated a novel p-n heterojunction consisting of $\mathrm{Fe}_{3} \mathrm{O}_{4}$ NPs and $\mathrm{FeWO}_{4}$ nanowires. The calculated band gap of the $\mathrm{FeWO}_{4} / \mathrm{Fe}_{3} \mathrm{O}_{4}$ heterojunction was $2.50 \mathrm{eV}$, lower than that of pristine $\mathrm{FeWO}_{4}$ nanowires. The $\mathrm{FeWO}_{4} / \mathrm{Fe}_{3} \mathrm{O}_{4}$ heterojunction exhibited enhanced photo-Fenton activity compared to that of the bare $\mathrm{FeWO}_{4}$ nanowires under UV-visible-light irradiation with the addition of $\mathrm{H}_{2} \mathrm{O}_{2}$. In addition, a $\alpha$ $\mathrm{SnWO}_{4} / \mathrm{SnO}_{2}$ heterostructure was synthesized with CTAB as the surfactant [170] and displayed enhanced photocatalytic performance compared to that of pure $\alpha-\mathrm{SnWO}_{4}$. Considering that $\mathrm{WO}_{3}$ can be obtained by dehydration from tungstate acid, $\mathrm{WO}_{3}$ is considered to be simultaneously produced during the synthesis of $\mathrm{MWO}_{4}$ and is likely to form a $\mathrm{MWO}_{4} / \mathrm{WO}_{3}$ heterojunction, such as $\mathrm{CoWO} / \mathrm{WO}_{3}$ 

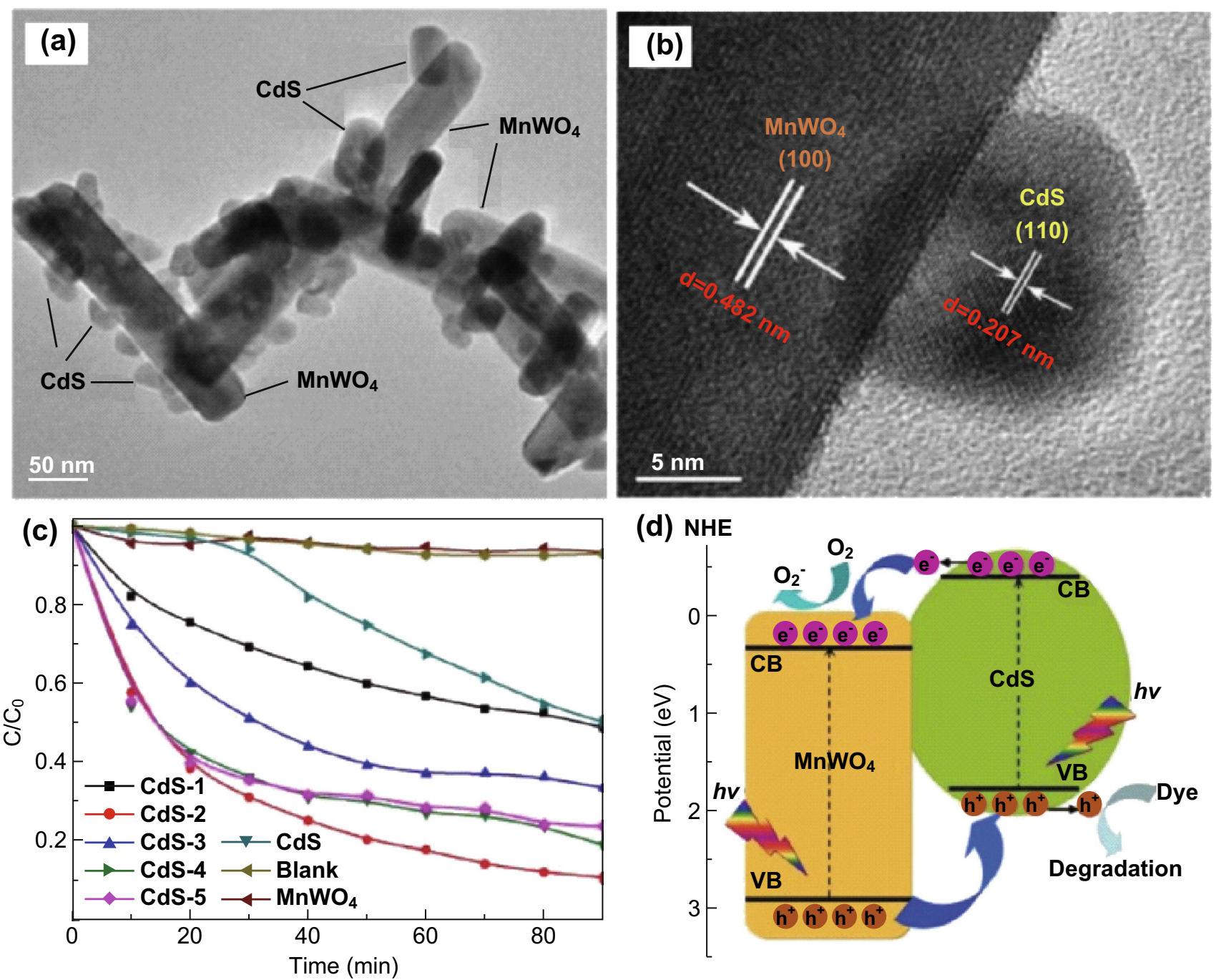

Fig. 14 a, b TEM and HRTEM images of a CdS/MnWO ${ }_{4}$ heterojunction. $\mathbf{c}$ Photocatalytic degradation of MB over CdS/MnWO $\mathrm{M}_{4}$ with different CdS contents. d Schematic photocatalytic mechanism of $\mathrm{CdS} / \mathrm{MnWO}_{4}$ heterojunction. Reproduced with permission from Ref. [155]. Copyright 2017 Elsevier

$[171,172], \mathrm{NiWO}_{4} / \mathrm{WO}_{3}[173,174]$, or $\mathrm{CuWO} / \mathrm{WO}_{3}$ $[175,176]$. Aslam et al. [177] prepared a $\mathrm{CdWO}_{4} / \mathrm{WO}_{3}$ heterojunction using a hydrothermal and chemisorption method, and reported enhanced photocatalytic activities toward the degradation of organic pollutants, compared with pure $\mathrm{CdWO}_{4}$ and $\mathrm{WO}_{3}$. This section clearly demonstrates in detail that the construction of $\mathrm{MWO}_{4}$-based heterojunction systems is an effective and controllable method for enhancing the photocatalytic activities of $\mathrm{MWO}_{4}$-based semiconductors.

\subsubsection{Hybridization with Carbon-Rich Materials}

Carbon-rich materials, including carbon nanotubes (CNTs), graphene, and graphitic carbon nitride $\left(\mathrm{g}-\mathrm{C}_{3} \mathrm{~N}_{4}\right)$, possess unique physical and chemical properties such as a large surface area, high absorption co-efficiency, and chemical stability, ensuring excellent and long-lasting applications in the fields of photochemical and PEC water treatment, photovoltaic devices, and water splitting [178-183]. Carbon-rich materials have a conjugative $\pi$ structure and unique $s p^{2} / s p^{3}$ hybrid carbon network, which are suitable substrates for constructing hybrid photocatalysts to intensify the separation and transportation of photoinduced charge carriers inside carbon-rich networks, thus improving the photocatalytic performance [184-187]. Based on this strategy, Gaillard et al. [188] synthesized a novel photoelectrode consisting of $\mathrm{CuWO}_{4}$ and a multi-wall CNT (MWCNT) to tune the photogenerated charge transfer in the nanocomposite film for enhancing the performance of solar-driven PEC water splitting. Compared to the bare $\mathrm{CuWO}_{4}$ photoelectrode, the resistance and photocurrent density of the $\mathrm{CuWO}_{4} / \mathrm{MWCNT}$ composite photoelectrode decreased and increased by $30 \%$ and $26 \%$, respectively. 
(a)
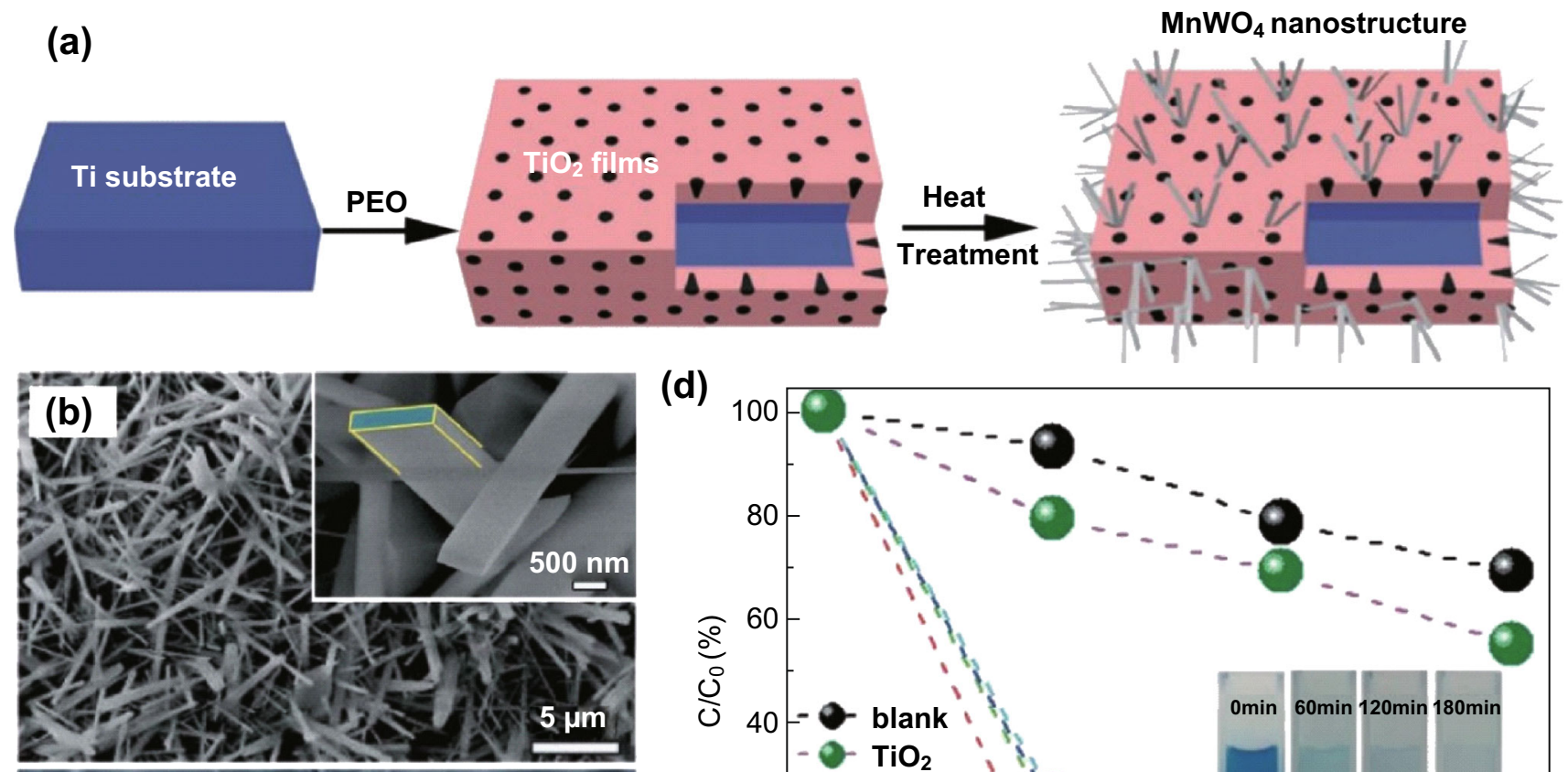

(d)
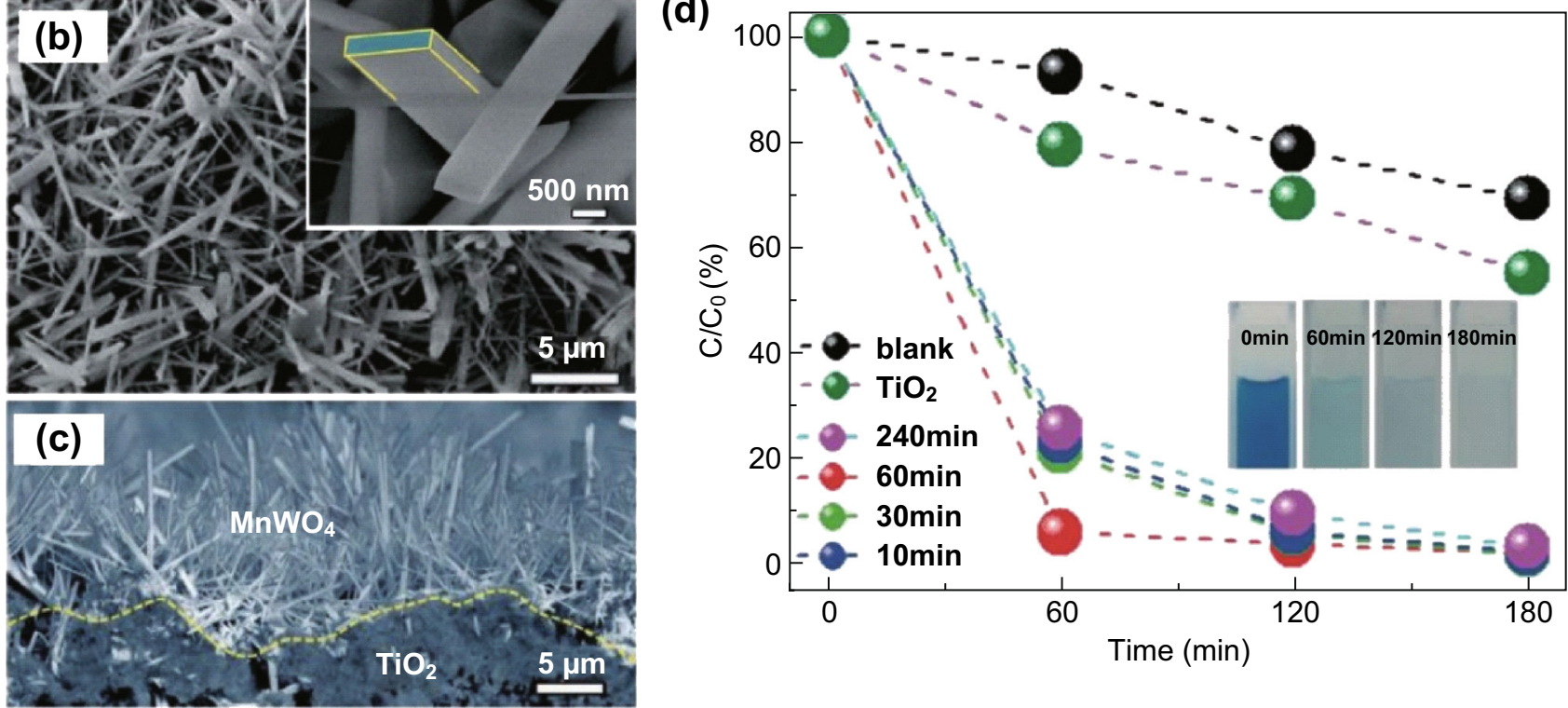

Fig. 15 a Schematic diagram describing the formation of $\mathrm{MnWO}_{4}$ nanoplates. b-c FESEM images of the $\mathrm{MnWO}_{4}$ nanoplates and $\mathrm{MnWO}_{4}$ nanoplates on $\mathrm{TiO}_{2}$ film. d Photodegradation efficiency of different samples heated at $850{ }^{\circ} \mathrm{C}$ for different times. Reproduced with permission from Ref. [162]. Copyright 2016 Royal Society of Chemistry

This was mainly attributed to the complete dispersion of the MWCNT as an electron collector in the entire $\mathrm{CuWO}_{4}$ layer. Compared to CNTs, graphene nanosheets produced via the chemical oxidation treatment of graphite have more $s p^{3}$ hybridized edge structure because of the destroyed perfect $s p^{2}$ structure. It is well-known that a perfect $s p^{2}$ carbon structure (CNT) is beneficial for rapid charge mobility, and that an $s p^{3}$-hybridized carbon structure (graphene) can lead to a small band gap in the semiconductor [189, 190]. Meanwhile, layer-structure carbon materials have a richer porosity substructure assembly from graphene stacking and surface defects, which could provide more reactive sites, in comparison to tube-like carbon materials. Recently, Bai et al. [191] designed a $\mathrm{ZnWO}_{4}$ /graphene hybrid, demonstrating that graphene could act as a photo-sensitizer in the hybrid and improve the production of $\mathrm{OH}$ and $\mathrm{O}_{2}{ }^{-}$radicals. The excited photogenerated electrons at the $\mathrm{CB}$ of $\mathrm{ZnWO}_{4}$ could be easily injected into the lowest unoccupied molecular orbital (LUMO) of graphene, resulting in a beneficial spatial separation between the holes and electrons inside the
$\mathrm{ZnWO}_{4} /$ graphene hybrid, in which more holes and electrons can participate in the production of active species, in comparison to bare $\mathrm{ZnWO}_{4}$. Xu et al. [192] reported a $\mathrm{CdWO}_{4} /$ graphene hybrid using a hydrothermal process, in which the formed heterojunction showed significantly enhanced photocatalytic activity compared to that of the bare $\mathrm{ZnWO}_{4}$. However, it was found that excessive graphene could have a negative effect on the photocatalytic performance because of the reduced light absorption efficiency of $\mathrm{CdWO}_{4}$ with the addition of the superfluous graphene.

Apart from graphene, other carbon-rich materials, such as $\mathrm{g}-\mathrm{C}_{3} \mathrm{~N}_{4}$ and mesoporous carbon materials, have been considered as promising candidates to build $\mathrm{MWO}_{4}$-based heterojunctions. $\mathrm{g}-\mathrm{C}_{3} \mathrm{~N}_{4}$, which is regarded as an allotrope of $\mathrm{C}_{3} \mathrm{~N}_{4}$, possesses excellent chemical stability, a suitable band gap of $2.7 \mathrm{eV}$, and a high specific surface area, which are beneficial for anchoring various other semiconductor materials [193-195]. For instance, Sun et al. [196] synthesized $\mathrm{g}_{-} \mathrm{C}_{3} \mathrm{~N}_{4} / \mathrm{ZnWO}_{4} \mathrm{NRs}$ via a thermal treatment route, and investigated the microcosmic mechanisms of the 

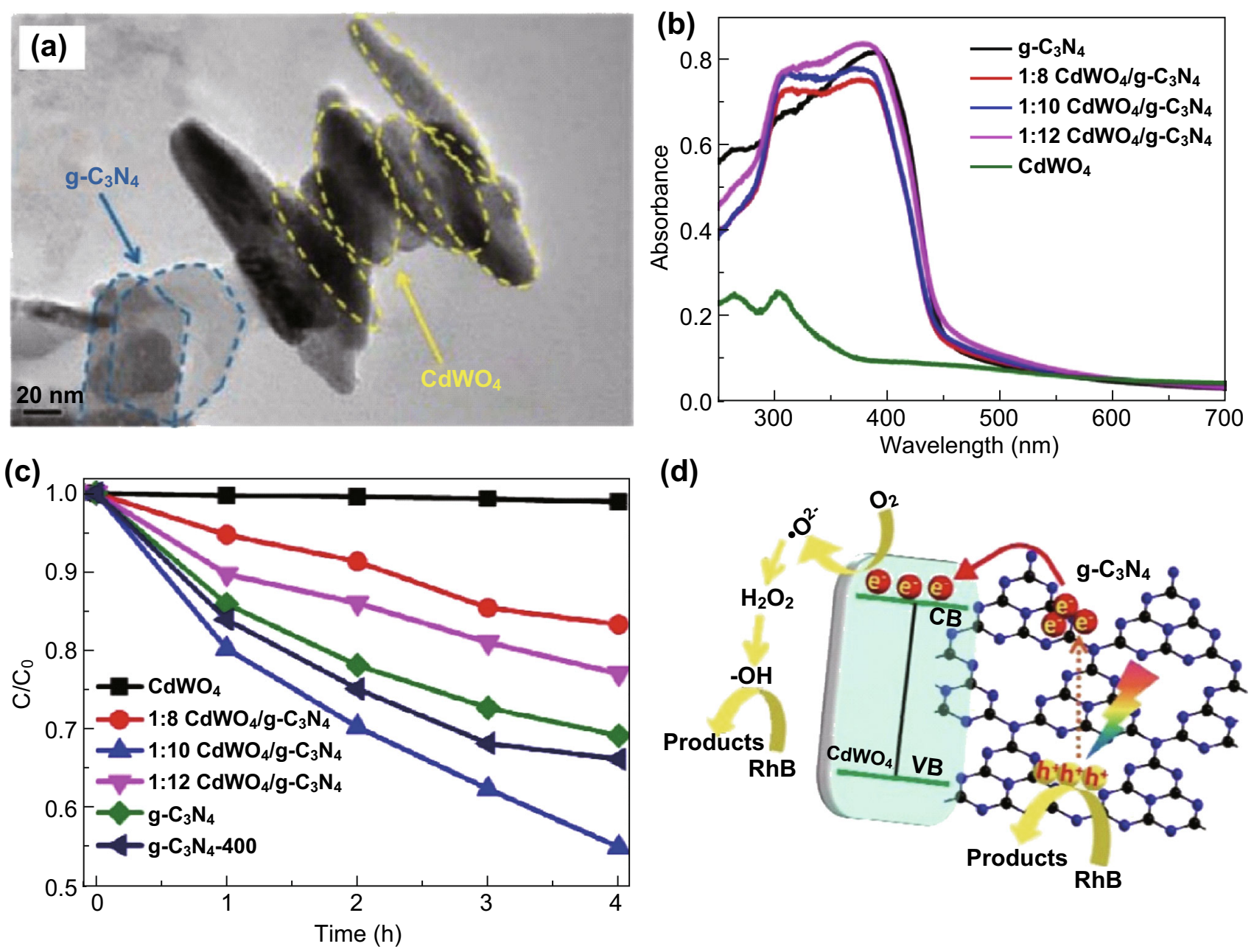

Fig. 16 a TEM image, b UV-vis diffused reflectance spectra, and c photocatalytic degradation curves of $\mathrm{CdWO}_{4} / \mathrm{C}_{3} \mathrm{~N}_{4}$. d Mechanism of photocatalytic reaction on the $\mathrm{CdWO}_{4} / \mathrm{C}_{3} \mathrm{~N}_{4}$. Reproduced with permission from Ref. [197]. Copyright 2015 Elsevier

enhanced photocatalytic activity of $\mathrm{C}_{3} \mathrm{~N}_{4} / \mathrm{ZnWO}_{4}$ in comparison to pristine $\mathrm{ZnWO}_{4} \mathrm{NRs}$ and $\mathrm{C}_{3} \mathrm{~N}_{4}$. Together with theoretical calculation results, it was found that the wellmatched energy level alignment of the $\mathrm{C}_{3} \mathrm{~N}_{4}$ and $\mathrm{ZnWO}_{4}$ NRs was the primary reason for the enhancement of the photocatalytic performance, in which the electrons at the VB top edge of the $\mathrm{C}_{3} \mathrm{~N}_{4}$, when excited by the incident light, quickly jumped to the $\mathrm{CB}$ bottom edge of $\mathrm{C}_{3} \mathrm{~N}_{4}$ and then transferred to the $\mathrm{CB}$ of $\mathrm{ZnWO}_{4}$ because of the staged alignment, thus enhancing the charge transfer and separation efficiency. In addition, Tian et al. [197] synthesized a $\mathrm{CdWO}_{4} / \mathrm{C}_{3} \mathrm{~N}_{4}$ hybrid using a hydrothermal process, followed by a mixed-calcination treatment. Compared to pure $\mathrm{CdWO}_{4}$, the $\mathrm{CdWO}_{4} / \mathrm{C}_{3} \mathrm{~N}_{4}$ heterojunction exhibited higher photocatalytic activity (Fig. 16c), the proposed mechanism for which is shown in Fig. 16d. The matched band structures between the two components contributed to the separation and transfer process, in which the excited electrons at the $\mathrm{CB}$ of $\mathrm{C}_{3} \mathrm{~N}_{4}$ moved to the $\mathrm{CB}$ of $\mathrm{CdWO}_{4}$ following a downward staged band, such that the photoinduced electrons and holes were efficiently separated, thus enhancing the overall photocatalytic activity. Considering its appropriate band energy level, g- $\mathrm{C}_{3} \mathrm{~N}_{4}$ is usually used to construct a Z-scheme hybrid system to enhance photocatalytic activities. Instead of a type-II heterojunction, the direct Z-scheme configuration not only forms a built-in electronic field to promote the separation and transfer efficiency of photogenerated electrons and holes, but it also maintains the reductive and oxidative ability of electrons and holes [198, 199]. Recently, Zhu and co-workers [200] reported a direct $\mathrm{Z}$-scheme heterojunction by combining g- $\mathrm{C}_{3} \mathrm{~N}_{4}$ with $\mathrm{Ag}_{2} \mathrm{WO}_{4}$ through a facile precipitation route. Because of the use of $\mathrm{g}_{-} \mathrm{C}_{3} \mathrm{~N}_{4}$ as a support in the precursor solution, $\mathrm{Ag}_{2} \mathrm{WO}_{4}$ was able to nucleate and grow on the surface of the layered $\mathrm{C}_{3} \mathrm{~N}_{4}$, thus resulting in the $\mathrm{Ag}_{2} \mathrm{WO}_{4}$ evenly distributing on the surface of the layered $\mathrm{g}_{-} \mathrm{C}_{3} \mathrm{~N}_{4}$-nanosheets. In comparison to the bare $\mathrm{Ag}_{2} \mathrm{WO}_{4}$ and $\mathrm{g}_{-} \mathrm{C}_{3} \mathrm{~N}_{4}$, the $\mathrm{Z}$-scheme of the $\mathrm{g}-\mathrm{C}_{3} \mathrm{~N}_{4} / \mathrm{Ag}_{2} \mathrm{WO}_{4}$ hybrid system exhibited 
a much higher photoactivity for the degradation of MO, owing to the efficient separation between the photoinduced electrons and holes in the direct Z-scheme configuration. Given the aforementioned examples and explanations, it is obvious that carbon-rich materials possess a high charge carrier mobility and large specific surface area, which could efficiently promote the separation efficiency of photoexcited electrons and holes in the $\mathrm{MWO}_{4}$, ultimately leading to improvement of the photocatalytic activity.

\section{Summary and Outlook}

This review summarized the development of novel strategies to enhance the photocatalytic performance of $\mathrm{MWO}_{4}$ based materials with a special emphasis on their applications in environmental purification and solar water splitting. Although significant improvements have been achieved in the construction of highly efficient ternary $\mathrm{MWO}_{4}$-based oxides, challenges remain that need to be addressed. First, the recombination rate of photogenerated charge carriers for $\mathrm{MWO}_{4}$-based photocatalysts is still considerably high, accounting for poor reduction ability in the photoexcited electrons at a low potential of the $\mathrm{CB}$ edge, which are easily quenched by defects and holes. Second, although morphological engineering could improve the photocatalytic activity of $\mathrm{MWO}_{4}$-based systems by regulating the crystal structure, particle size, and surface area, the current synthetic methods are inadequate for large-scale preparation, particularly for nanosized materials, which would significantly improve the separation efficiency of the photogenerated charge carriers. Third, the surface effect, particularly the crystal surface effect on the photocatalytic performance of $\mathrm{MWO}_{4}$-based systems, has not been synergistically and comprehensively investigated. It is thought that the atom configurations and surface defects should be paid more attention, to provide important information for designing highly efficient photocatalysts. Fourth, based on this review, it is clear that the $\mathrm{MWO}_{4}$ materials consisting of a single valence metal ion, such as $\mathrm{Cd}, \mathrm{Zn}$, or Sn, have been well-developed in the past, while those composed of a versatile valence metal, for instance, $\mathrm{Co}, \mathrm{Fe}$, or $\mathrm{Ni}$, have been insufficiently explored in surface engineering and theoretical computation.

To overcome these challenges, future research needs to focus on the exploration of novel photocatalytic materials. Although the sunlight-harvesting ability and separation efficiency of photogenerated charge carriers could be strengthened by heteroatom doping or heterojunction fabrication as reported by previous literature, traditional material screening, high-throughput screening, and computational materials design can guide the construction of photocatalysts with a proper band edge position and suitable band gap, thereby shortening the experimental period, reducing the workload, and saving experimental cost. In other fundamental studies, combining experiment and theory would enable understanding the photocatalytic principles and screen alternative high-performance photocatalysts. Future work also needs to focus on facile synthetic approaches for constructing stable $\mathrm{MWO}_{4}$ materials with high active crystal surface and/or quantum size, and developing advanced techniques for large-scale production. It is expected that further progress in ternary $\mathrm{MWO}_{4}$-based photocatalysts for applications in environmental purification and solar water splitting will be made in future studies.

Acknowledgements Y. Hou thanks the support of NSFC 51702284, Fundamental Research Funds for the Central Universities (112109*172210171) and the Startup Foundation for Hundred-Talent Program of Zhejiang University (112100-193820101/001/022). J. Ke thanks the support of the NSFC 21501138, the Science Research Foundation of Wuhan Institute of Technology (K201513).

Open Access This article is distributed under the terms of the Creative Commons Attribution 4.0 International License (http://crea tivecommons.org/licenses/by/4.0/), which permits unrestricted use, distribution, and reproduction in any medium, provided you give appropriate credit to the original author(s) and the source, provide a link to the Creative Commons license, and indicate if changes were made.

\section{References}

1. A. Fujishima, K. Honda, Electrochemical photolysis of water at a semiconductor electrode. Nature 238, 37-38 (1972). https:// doi.org/10.1038/238037a0

2. X.P. Chen, Z.X. Zhang, L. Chi, A.K. Nair, W.F. Shangguan, Z. Jiang, Recent advances in visible-light-driven photoelectrochemical water splitting: catalyst nanostructures and reaction systems. Nano-Micro Lett. 8(1), 1-12 (2016). https://doi.org/10. 1007/s40820-015-0063-3

3. Y. Hou, X. Li, Q. Zhao, G. Chen, C.L. Raston, Role of hydroxyl radicals and mechanism of Escherichia coli inactivation on $\mathrm{Ag} /$ $\mathrm{AgBr} / \mathrm{TiO}_{2}$ nanotube array electrode under visible light irradiation. Environ. Sci. Technol. 46(7), 4042-4050 (2012). https:// doi.org/10.1021/es204079d

4. L. Cheng, Q.J. Xiang, Y.L. Liao, H.W. Zhang, CdS-Based photocatalysts. Energ. Environ. Sci. 11(6), 1362-1391 (2018). https://doi.org/10.1039/c7ee03640j

5. F. Wang, Q. Li, D. Xu, Recent progress in semiconductor-based nanocomposite photocatalysts for solar to chemical energy conversion. Adv. Energy Mater. 7(23), 1700529 (2017). https:// doi.org/10.1002/aenm.201700529

6. Y. Hou, X. Zhuang, X. Feng, Recent advances in earth-abundant heterogeneous electrocatalysts for photoelectrochemical water splitting. Small Methods 1(6), 1700090 (2017). https://doi.org/ $10.1002 /$ smtd.201700090

7. Y. Hou, X. Li, Q. Zhao, G. Chen, $\mathrm{ZnFe}_{2} \mathrm{O}_{4}$ multi-porous microbricks/graphene hybrid photocatalyst: facile synthesis, improved activity and photocatalytic mechanism. Appl. Catal. B Environ. 142-143, 80-88 (2013). https://doi.org/10.1016/j. apcatb.2013.04.062

8. Y. Hou, X. Li, Q. Zhao, X. Quan, G. Chen, Electrochemically assisted photocatalytic degradation of 4-chlorophenol by 
$\mathrm{ZnFe}_{2} \mathrm{O}_{4}$-modified $\mathrm{TiO}_{2}$ nanotube array electrode under visible light irradiation. Environ. Sci. Technol. 44(13), 5098-5103 (2010). https://doi.org/10.1021/es100004u

9. W.Y. Teoh, J.A. Scott, R. Amal, Progress in heterogeneous photocatalysis: from classical radical chemistry to engineering nanomaterials and solar reactors. J. Phys. Chem. Lett. 3(5), 629-639 (2012). https://doi.org/10.1021/jz3000646

10. S. Banerjee, S.C. Pillai, P. Falaras, K.E. O'Shea, J.A. Byrne, D.D. Dionysiou, New insights into the mechanism of visible light photocatalysis. J. Phys. Chem. Lett. 5(15), 2543-2554 (2014). https://doi.org/10.1021/jz501030x

11. J. Schneider, M. Matsuoka, M. Takeuchi, J. Zhang, Y. Horiuchi, M. Anpo, D.W. Bahnemann, Understanding $\mathrm{TiO}_{2}$ photocatalysis: mechanisms and materials. Chem. Rev. 114(19), 9919-9986 (2014). https://doi.org/10.1021/cr5001892

12. M.J. Kale, T. Avanesian, P. Christopher, Direct photocatalysis by plasmonic nanostructures. ACS Catal. 4(1), 116-128 (2013). https://doi.org/10.1021/cs400993w

13. V. Augugliaro, G. Camera-Roda, V. Loddo, G. Palmisano, L. Palmisano, J. Soria, S. Yurdakal, Heterogeneous photocatalysis and photoelectrocatalysis: from unselective abatement of noxious species to selective production of high-value chemicals. J. Phys. Chem. Lett. 6(10), 1968-1981 (2015). https://doi.org/ 10.1021/acs.jpclett.5b00294

14. S. Xie, Q. Zhang, G. Liu, Y. Wang, Photocatalytic and photoelectrocatalytic reduction of $\mathrm{CO}_{2}$ using heterogeneous catalysts with controlled nanostructures. Chem. Commun. 52(1), 35-59 (2016). https://doi.org/10.1039/c5cc07613g

15. A. García, C. Fernandez-Blanco, J.R. Herance, J. Albero, H. García, Graphenes as additives in photoelectrocatalysis. J. Mater. Chem. A 5(32), 16522-16536 (2017). https://doi.org/ $10.1039 / \mathrm{c} 7 \mathrm{ta} 04045 \mathrm{~h}$

16. A.B. Laursen, S. Kegnæs, S. Dahl, I. Chorkendorff, Molybdenum sulfides-efficient and viable materials for electro- and photoelectrocatalytic hydrogen evolution. Energy Environ. Sci. 5(2), 5577-5591 (2012). https://doi.org/10.1039/c2ee02618j

17. Y. Yang, S. Ajmal, X. Zheng, L. Zhang, Efficient nanomaterials for harvesting clean fuels from electrochemical and photoelectrochemical $\mathrm{CO}_{2}$ reduction. Sustain. Energ. Fuels 2(3), 510-537 (2018). https://doi.org/10.1039/c7se00371d

18. R. Zhou, R. Zhou, X. Zhang, J. Li, X. Wang et al., Synergistic effect of atmospheric-pressure plasma and $\mathrm{TiO}_{2}$ photocatalysis on inactivation of Escherichia coli cells in aqueous media. Sci. Rep. 6, 39552 (2016). https://doi.org/10.1038/srep39552

19. J.J. Zou, C.J. Liu, Y.P. Zhang, Control of the metal-support interface of NiO-loaded photocatalysts via cold plasma treatment. Langmuir 22(5), 2334-2339 (2006). https://doi.org/10. 1021/la052135u

20. L. Zhang, G. Kong, Y. Meng, J. Tian, L. Zhang, S. Wan, J. Lin, Y. Wang, Direct coupling of thermo- and photocatalysis for conversion of $\mathrm{CO}_{2}-\mathrm{H}_{2} \mathrm{O}$ into fuels. Chemsuschem 10(23), 4709-4714 (2017). https://doi.org/10.1002/cssc.201701472

21. E.T. Kho, T.H. Tan, E. Lovell, R.J. Wong, J. Scott, R. Amal, A review on photo-thermal catalytic conversion of carbon dioxide. Green Energy Environ. 2(3), 204-217 (2017). https://doi.org/10. 1016/j.gee.2017.06.003

22. J. Jia, H. Wang, Z. Lu, P.G. O'Brien, M. Ghoussoub et al., Photothermal catalyst engineering: hydrogenation of gaseous $\mathrm{CO}_{2}$ with high activity and tailored selectivity. Adv. Sci. 4(10), 1700252 (2017). https://doi.org/10.1002/advs.201700252

23. H. Chen, C.E. Nanayakkara, V.H. Grassian, Titanium dioxide photocatalysis in atmospheric chemistry. Chem. Rev. 112(11), 5919-5948 (2012). https://doi.org/10.1021/cr3002092

24. L. Wan, M. Long, D. Zhou, L. Zhang, W. Cai, Preparation and characterization of freestanding hierarchical porous $\mathrm{TiO}_{2}$ monolith modified with graphene oxide. Nano-Micro Lett. 4(2), 90-97 (2012). https://doi.org/10.1007/bf03353698

25. M. Boehme, W. Ensinger, Mixed phase anatase/rutile titanium dioxide nanotubes for enhanced photocatalytic degradation of methylene blue. Nano-Micro Lett. 3(4), 236-241 (2011). https:// doi.org/10.1007/bf03353678

26. X. Li, J. Li, J. Bai, Y. Dong, L. Li, B. Zhou, The inhibition effect of tert-butyl alcohol on the $\mathrm{TiO}_{2}$ nano assays photoelectrocatalytic degradation of different organics and its mechanism. Nano-Micro Lett. 8(3), 221-231 (2016). https://doi.org/10.1007/ s40820-015-0080-2

27. X. Li, Y. Jiang, W. Cheng, Y. Li, X. Xu, K. Lin, Mesoporous $\mathrm{TiO}_{2}$ /carbon beads: one-pot preparation and their application in visible-light-induced photodegradation. Nano-Micro Lett. 7(3), 243-254 (2015). https://doi.org/10.1007/s40820-015-0029-5

28. Y. Hou, F. Zuo, A. Dagg, P. Feng, Visible light-driven $\alpha-\mathrm{Fe}_{2} \mathrm{O}_{3}$ nanorod/graphene/ $\mathrm{BiV}_{1-\mathrm{x}} \mathrm{Mo}_{\mathrm{x}} \mathrm{O}_{4}$ core/shell heterojunction array for efficient photoelectrochemical water splitting. Nano Lett. 12(12), 6464-6473 (2012). https://doi.org/10.1021/nl303961c

29. J. Ke, H. Zhou, J. Liu, X. Duan, H. Zhang, S. Liu, S. Wang, Crystal transformation of $2 \mathrm{D}$ tungstic acid $\mathrm{H}_{2} \mathrm{WO}_{4}$ to $\mathrm{WO}_{3}$ for enhanced photocatalytic water oxidation. J. Colloid Interface Sci. 514, 576-583 (2018). https://doi.org/10.1016/j.jcis.2017.12. 066

30. Y. Hou, F. Zuo, A.P. Dagg, J. Liu, P. Feng, Branched $\mathrm{WO}_{3}$ nanosheet array with layered $\mathrm{C}_{3} \mathrm{~N}_{4}$ heterojunctions and $\mathrm{CoO}_{x}$ nanoparticles as a flexible photoanode for efficient photoelectrochemical water oxidation. Adv. Mater. 26(29), 5043-5049 (2014). https://doi.org/10.1002/adma.201401032

31. S. Luo, J. Ke, M. Yuan, Q. Zhang, P. Xie, L. Deng, S. Wang, CuInS 2 quantum dots embedded in $\mathrm{Bi}_{2} \mathrm{WO}_{6}$ nanoflowers for enhanced visible light photocatalytic removal of contaminants. Appl. Catal. B: Environ. 221, 215-222 (2018). https://doi.org/ 10.1016/j.apcatb.2017.09.028

32. S.G. Kumar, K.S.R.K. Rao, Zinc oxide based photocatalysis: tailoring surface-bulk structure and related interfacial charge carrier dynamics for better environmental applications. RSC Adv. 5(5), 3306-3351 (2015). https://doi.org/10.1039/ c4ra13299h

33. J. Ke, J. Liu, H. Sun, H. Zhang, X. Duan et al., Facile assembly of $\mathrm{Bi}_{2} \mathrm{O}_{3} / \mathrm{Bi}_{2} \mathrm{~S}_{3} / \mathrm{MoS}_{2}$ n-p heterojunction with layered $n-\mathrm{Bi}_{2} \mathrm{O}_{3}$ and $\mathrm{p}-\mathrm{MoS}_{2}$ for enhanced photocatalytic water oxidation and pollutant degradation. Appl. Catal. B: Environ. 200, 47-55 (2017). https://doi.org/10.1016/j.apcatb.2016.06.071

34. J. Liu, Y. Li, J. Ke, S. Wang, L. Wang, H. Xiao, Black NiO$\mathrm{TiO}_{2}$ nanorods for solar photocatalysis: recognition of electronic structure and reaction mechanism. Appl. Catal. B: Environ. 224, 705-714 (2018). https://doi.org/10.1016/j.apcatb.2017.11.028

35. S.G. Kumar, L.G. Devi, Review on modified $\mathrm{TiO}_{2}$ photocatalysis under UV/visible light: selected results and related mechanisms on interfacial charge carrier transfer dynamics. J. Phys. Chem. A 115(46), 13211-13241 (2011). https://doi.org/10.1021/ jp204364a

36. M. Ni, M.K.H. Leung, D.Y.C. Leung, K. Sumathy, A review and recent developments in photocatalytic water-splitting using $\mathrm{TiO}_{2}$ for hydrogen production. Renew. Sustain. Energ. Rev. 11(3), 401-425 (2007). https://doi.org/10.1016/j.rser.2005.01. 009

37. J. Ke, X. Li, Q. Zhao, B. Liu, S. Liu, S. Wang, Upconversion carbon quantum dots as visible light responsive component for efficient enhancement of photocatalytic performance. J. Colloid Interface Sci. 496, 425-433 (2017). https://doi.org/10.1016/j. jcis.2017.01.121

38. A. Fujishima, X. Zhang, D. Tryk, Heterogeneous photocatalysis: from water photolysis to applications in environmental cleanup. 
Int. J. Hydrog. Energy 32(14), 2664-2672 (2007). https://doi. org/10.1016/j.ijhydene.2006.09.009

39. X. Zou, Y. Dong, S. Li, J. Ke, Y. Cui, Facile anion exchange to construct uniform $\mathrm{AgX}(\mathrm{X}=\mathrm{Cl}, \mathrm{Br}, \mathrm{I}) / \mathrm{Ag} 2 \mathrm{CrO} 4 \mathrm{NR}$ hybrids for efficient visible light driven photocatalytic activity. Sol. Energy 169, 392-400 (2018). https://doi.org/10.1016/j.solener.2018.05. 017

40. M.R. Hoffmann, S.T. Martin, W.Y. Choi, D.W. Bahnemann, Environmental applications of semiconductor photocatalysis. Chem. Rev. 95(28), 69-96 (1995). https://doi.org/10.1021/ cr00033a004

41. D. Chen, X.G. Zhang, A.F. Lee, Synthetic strategies to nanostructured photocatalysts for $\mathrm{CO}_{2}$ reduction to solar fuels and chemicals. J. Mater. Chem. A 3(28), 14487-14516 (2015). https://doi.org/10.1039/c5ta01592h

42. H.F. Cheng, K. Fuku, Y. Kuwahara, K. Mori, H. Yamashita, Harnessing single-active plasmonic nanostructures for enhanced photocatalysis under visible light. J. Mater. Chem. A 3(10), 5244-5258 (2015). https://doi.org/10.1039/c4ta06484d

43. K. Wenderich, G. Mul, Methods, mechanism, and applications of photodeposition in photocatalysis: a review. Chem. Rev. 116(23), 14587-14619 (2016). https://doi.org/10.1021/acs. chemrev.6b00327

44. T. Hisatomi, J. Kubota, K. Domen, Recent advances in semiconductors for photocatalytic and photoelectrochemical water splitting. Chem. Soc. Rev. 43(22), 7520-7535 (2014). https:// doi.org/10.1039/c3es60378d

45. G. Zhang, G. Liu, L. Wang, J.T.S. Irvine, Inorganic perovskite photocatalysts for solar energy utilization. Chem. Soc. Rev. 45(21), 5951-5984 (2016). https://doi.org/10.1039/c5cs00769k

46. D.M. Fabian, S. Hu, N. Singh, F.A. Houle, T. Hisatomi, K. Domen, F.E. Osterloh, S. Ardo, Particle suspension reactors and materials for solar-driven water splitting. Energy Environ. Sci. 8(10), 2825-2850 (2015). https://doi.org/10.1039/c5ee01434d

47. T. Takata, K. Domen, Development of non-oxide semiconductors as light harvesting materials in photocatalytic and photoelectrochemical water splitting. Dalton Trans. 46(32), 10529-10544 (2017). https://doi.org/10.1039/c7dt00867h

48. P. Mal, G. Bera, P. Rambabu, G.R. Turpu, B. Chakraborty et al., Electronic, magnetic and spectroscopic properties of doped $\mathrm{Mn}_{(1-\mathrm{x})} \mathrm{A}_{\mathrm{x}} \mathrm{WO}_{4}(\mathrm{~A}=\mathrm{Co}, \mathrm{Cu}, \mathrm{Ni}$ and $\mathrm{Fe})$ multiferroic: an experimental and DFT study. J. Phys. Condens. Matter 29(7), 075901 (2017). https://doi.org/10.1088/1361-648X/aa4e64

49. S.M.M. Zawawi, R. Yahya, Z. Hassan, E.H.N.M. Ekramul Mahmud, N.M. Daud, Structural and optical characterization of metal tungstates $\left(\mathrm{MWO}_{4} ; \mathrm{M}=\mathrm{Ni}, \mathrm{Ba}, \mathrm{Bi}\right)$ synthesized by a sucrose-templated method. Chem. Cent. J. 7, 80 (2013). https:// doi.org/10.1186/1752-153X-7-80

50. X.A. López, A.F. Fuentes, M.M. Zaragoza, J.A. Díaz Guillén, J.S. Gutiérrez, A.L. Ortiz, V. Collins-Martínez, Synthesis, characterization and photocatalytic evaluation of MWO4 $(\mathrm{M}=\mathrm{Ni} \mathrm{Co}, \mathrm{Cu}$ and $\mathrm{Mn}$ ) tungstates. Int. J. Hydrog. Energy 41(48), 23312-23317 (2016). https://doi.org/10.1016/j.ijhydene. 2016.10.117

51. S. Dey, R.A. Ricciardo, H.L. Cuthbert, P.M. Woodward, Metalto-metal charge transfer in AWO4 $(\mathrm{A}=\mathrm{Mg}, \mathrm{Mn} \mathrm{Co}, \mathrm{Ni}, \mathrm{Cu}$, or $\mathrm{Zn})$ compounds with the wolframite structure. Inorg. Chem. 53(9), 4299-4394 (2014). https://doi.org/10.1021/ic4031798

52. M. Nikl, P. Bohacek, E. Mihokova, M. Kobayashi, M. Ishii et al., Excitonic emission of scheelite tungstates $\mathrm{AWO}_{4}$ $(\mathrm{A}=\mathrm{Pb}, \mathrm{Ca}, \mathrm{Ba}, \mathrm{Sr})$. J. Lumin. 87-89, 1136-1139 (2000). https://doi.org/10.1016/S0022-2313(99)00569-4

53. R.C. Pullar, S. Farrah, N.M. Alford, $\mathrm{MgWO}_{4}, \mathrm{ZnWO}_{4}, \mathrm{NiWO}_{4}$ and $\mathrm{CoWO}_{4}$ microwave dielectric ceramics. J. Eur. Ceram. Soc. 27(2-3), 1059-1063 (2007). https://doi.org/10.1016/j.jeurcer amsoc.2006.05.085
54. G. Zhang, R. Jia, Q. Wu, Preparation, structural and optical properties of $\mathrm{AWO}_{4}(\mathrm{~A}=\mathrm{Ca}, \mathrm{Ba}, \mathrm{Sr})$ nanofilms. Mater. Sci. Eng. B 128(1-3), 254-259 (2006). https://doi.org/10.1016/j. mseb.2005.11.040

55. R. Lacomba-Perales, J. Ruiz-Fuertes, D. Errandonea, D. Martínez-García, A. Segura, Optical absorption of divalent metal tungstates: correlation between the band-gap energy and the cation ionic radius. EPL 83(3), 37002 (2008). https://doi.org/10. 1209/0295-5075/83/37002

56. C. Shivakumara, R. Saraf, S. Behera, N. Dhananjaya, H. Nagabhushana, Scheelite-type $\mathrm{MWO}_{4}(\mathrm{M}=\mathrm{Ca}, \mathrm{Sr}$, and $\mathrm{Ba})$ nanophosphors: facile synthesis, structural characterization, photoluminescence, and photocatalytic properties. Mater. Res. Bull. 61, 422-432 (2015). https://doi.org/10.1016/j.materresbull. 2014.09.096

57. S.D. Ramarao, S. Roopas Kiran, V.R.K. Murthy, Structural, lattice vibrational, optical and microwave dielectric studies on $\mathrm{Ca}_{1-\mathrm{x}} \mathrm{Sr}_{\mathrm{x}} \mathrm{MoO}_{4}$ ceramics with scheelite structure. Mater. Res. Bull. 56, 71-79 (2014). https://doi.org/10.1016/j.materresbull. 2014.04.064

58. Y.G. Su, G.S. Li, Y.F. Xue, L.P. Li, Tunable physical properties of $\mathrm{CaWO}_{4}$ nanocrystals via particle size control. J. Phys. Chem. C 111(18), 6684-6689 (2007). https://doi.org/10.1021/ jp068480p

59. S.M. Ghoreishi, Facile synthesis and characterization of $\mathrm{CaWO}_{4}$ nanoparticles using a new Schiff base as capping agent: enhanced photocatalytic degradation of methyl orange. J. Mater. Sci. Mater. Electron. 28(19), 14833-14838 (2017). https://doi. org/10.1007/s10854-017-7354-z

60. M. Mohamed Jaffer Sadiq, A. Samson Nesaraj, Soft chemical synthesis and characterization of $\mathrm{BaWO}_{4}$ nanoparticles for photocatalytic removal of Rhodamine $\mathrm{B}$ present in water sample. J. Nanostruct. Chem. 5(1), 45-54 (2014). https://doi.org/10. 1007/s40097-014-0133-y

61. M.C. Oliveira, L. Gracia, I.C. Nogueira, M.F.D. Carmo Gurgel, J.M.R. Mercury, E. Longo, J. Andrés, Synthesis and morphological transformation of $\mathrm{BaWO}_{4}$ crystals: experimental and theoretical insights. Ceram. Int. 42(9), 10913-10921 (2016). https://doi.org/10.1016/j.ceramint.2016.03.225

62. C. Yu, F. Cao, X. Li, G. Li, Y. Xie, J.C. Yu, Q. Shu, Q. Fan, J. Chen, Hydrothermal synthesis and characterization of novel $\mathrm{PbWO}_{4}$ microspheres with hierarchical nanostructures and enhanced photocatalytic performance in dye degradation. Chem. Eng. J. 219, 86-95 (2013). https://doi.org/10.1016/j.cej.2012.12. 064

63. D. Chen, Z. Liu, S.X. Ouyang, J.H. Ye, Simple room-temperature mineralization method to $\mathrm{SrWO}_{4}$ micro/nanostructures and their photocatalytic properties. J. Phys. Chem. C 115(32), 15778-15784 (2011). https://doi.org/10.1021/jp202406n

64. D. Ye, D.Z. Li, W.J. Zhang, M. Sun, Y. Hu, Y.F. Zhang, X.Z. $\mathrm{Fu}, \mathrm{A}$ new photocatalyst $\mathrm{CdWO}_{4}$ prepared with a hydrothermal method. J. Phys. Chem. C 112(44), 17351-17356 (2008). https:// doi.org/10.1021/jp8059213

65. A.M. Priya, R.K. Selvan, B. Senthilkumar, M.K. Satheeshkumar, C. Sanjeeviraja, Synthesis and characterization of $\mathrm{CdWO}_{4}$ nanocrystals. Ceram. Int. 37(7), 2485-2488 (2011). https://doi. org/10.1016/j.ceramint.2011.03.040

66. C. Zhang, H. Zhang, K. Zhang, X. Li, Q. Leng, C. Hu, Photocatalytic activity of $\mathrm{ZnWO}_{4}$ : band structure, morphology and surface modification. ACS Appl. Mater. Interfaces 6(16), 14423-14432 (2014). https://doi.org/10.1021/am503696b

67. J. Guo, X. Zhou, Y. Lu, X. Zhang, S. Kuang, W. Hou, Monodisperse spindle-like $\mathrm{FeWO}_{4}$ nanoparticles: controlled hydrothermal synthesis and enhanced optical properties. J. Solid State Chem. 196, 550-556 (2012). https://doi.org/10.1016/j.jssc. 2012.07.026 
68. M. Sivakumar, R. Madhu, S.M. Chen, V. Veeramani, A. Manikandan, W.H. Hung, N. Miyamoto, Y.L. Chueh, Lowtemperature chemical synthesis of $\mathrm{CoWO}_{4}$ nanospheres for sensitive nonenzymatic glucose sensor. J. Phys. Chem. C 120(30), 17024-17028 (2016). https://doi.org/10.1021/acs.jpcc. $6 \mathrm{~b} 04116$

69. F. Ahmadi, M. Rahimi-Nasrabadi, M. Eghbali-Arani, The synthesize of $\mathrm{CuWO}_{4}$ nanoparticles by a new morphological control method, characterization of its photocatalytic activity. J. Mater. Sci. Mater. Electron. 28(7), 5244-5249 (2016). https://doi.org/ 10.1007/s10854-016-6181-y

70. M. Vosoughifar, Preparation, characterization, and morphological control of $\mathrm{MnWO}_{4}$ nanoparticles through novel method and its photocatalyst application. J. Mater. Sci. Mater. Electron. 28(2), 2135-2140 (2016). https://doi.org/10.1007/s10854-016$5777-6$

71. R. Karthiga, B. Kavitha, M. Rajarajan, A. Suganthi, Photocatalytic and antimicrobial activity of $\mathrm{NiWO}_{4}$ nanoparticles stabilized by the plant extract. Mater. Sci. Semicond. Process. 40, 123-129 (2015). https://doi.org/10.1016/j.mssp.2015.05.037

72. G. Zhu, W. Que, J. Zhang, P. Zhong, Photocatalytic activity of $\mathrm{SnWO}_{4}$ and $\mathrm{SnW}_{3} \mathrm{O}_{9}$ nanostructures prepared by a surfactantassisted hydrothermal process. Mater. Sci. Eng. B 176(18), 1448-1455 (2011). https://doi.org/10.1016/j.mseb.2011.08.003

73. S. Pourmasoud, M. Eghbali-Arani, F. Ahmadi, M. RahimiNasrabadi, Synthesis, characterization, and morphological control of $\mathrm{PbWO}_{4}$ nanostructures through precipitation method and its photocatalyst application. J. Mater. Sci. Mater. Electron. 28(22), 17089-17097 (2017). https://doi.org/10.1007/s10854017-7635-6

74. W.M. Tong, L.P. Li, W.B. Hu, T.J. Yan, G.S. Li, Systematic control of monoclinic $\mathrm{CdWO}_{4}$ nanophase for optimum photocatalytic activity. J. Phys. Chem. C 114(3), 1512-1519 (2010). https://doi.org/10.1021/jp910284u

75. S.M. Hosseinpour-Mashkani, M. Maddahfar, A. Sobhani-Nasab, Precipitation synthesis, characterization, morphological control, and photocatalyst application of $\mathrm{ZnWO}_{4}$ nanoparticles. J. Electron. Mater. 45(7), 3612-3620 (2016). https://doi.org/10.1007/ s11664-016-4532-3

76. S.M. Hosseinpour-mashkani, A. Sobhani-Nasab, Simple synthesis and characterization of copper tungstate nanoparticles: investigation of surfactant effect and its photocatalyst application. J. Mater. Sci. Mater. Electron. 27(7), 7548-7553 (2016). https://doi.org/10.1007/s10854-016-4735-7

77. S. Wannapop, T. Thongtem, S. Thongtem, Photoemission and energy gap of $\mathrm{MgWO}_{4}$ particles connecting as nanofibers synthesized by electrospinning-calcination combinations. Appl. Surf. Sci. 258(11), 4971-4976 (2012). https://doi.org/10.1016/j. apsusc. 2012.01.133

78. A.T. Raj, S. Thangavel, A. Rose, C.V. Jipsa, M. Jose, G. Nallamuthu, S.J. Kim, G. Venugopal, Influence of morphology and common oxidants on the photocatalytic property of $\beta-\mathrm{SnWO}_{4}$ nanoparticles. J. Nanosci. Nanotechnol. 16(3), 2541-2547 (2016). https://doi.org/10.1166/jnn.2016.10961

79. W.M. Tong, L.P. Li, W.B. Hu, T.J. Yan, X.F. Guan, G.S. Li, Kinetic control of $\mathrm{MnWO}_{4}$ nanoparticles for tailored structural properties. J. Phys. Chem. C 114(36), 15298-15305 (2010). https://doi.org/10.1021/jp103879c

80. M.I. Ahmed, A. Adam, A. Khan, A.U. Rehman, M. Qamaruddin, M.N. Siddiqui, M. Qamar, Improved photoelectrochemical water oxidation under visible light with mesoporous $\mathrm{CoWO}_{4}$. Mater. Lett. 183, 281-284 (2016). https://doi.org/10.1016/j.mat let.2016.07.137

81. Q. Gao, Z. Liu, $\mathrm{FeWO}_{4}$ nanorods with excellent UV-Visible light photocatalysis. Prog. Nat. Sci. Mater. 27(5), 556-560 (2017). https://doi.org/10.1016/j.pnsc.2017.08.016
82. J. Di, J. Xiong, H. Li, Z. Liu, Ultrathin 2D photocatalysts: electronic-structure tailoring, hybridization, and applications. Adv. Mater. 30(1), 1704548 (2018). https://doi.org/10.1002/ adma.201704548

83. T. Yan, L. Li, W. Tong, J. Zheng, Y. Wang, G. Li, CdWO polymorphs: selective preparation, electronic structures, and photocatalytic activities. J. Solid State Chem. 184(2), 357-364 (2011). https://doi.org/10.1016/j.jssc.2010.12.013

84. L.G. Cai, F.M. Liu, D. Zhang, W.W. Zhong, Dependence of optical properties of monoclinic $\mathrm{MnWO}_{4}$ on the electric field of incident light. Phys. B 407(17), 3654-3659 (2012). https://doi. org/10.1016/j.physb.2012.05.044

85. S.M. Hosseinpour-Mashkani, A. Sobhani-Nasab, A simple sonochemical synthesis and characterization of $\mathrm{CdWO}_{4}$ nanoparticles and its photocatalytic application. J. Mater. Sci. Mater. Electron. 27(4), 3240-3244 (2015). https://doi.org/10. 1007/s10854-015-4150-5

86. Y. Wang, X. Guan, L. Li, H. Lin, X. Wang, G. Li, Solventdriven polymorphic control of $\mathrm{CdWO}_{4}$ nanocrystals for photocatalytic performances. New J. Chem. 36(9), 1852-1858 (2012). https://doi.org/10.1039/c2nj40504k

87. M. Dan, M. Cheng, H. Gao, H. Zheng, C. Feng, Synthesis and electrochemical properties of $\mathrm{SnWO}_{4}$. J. Nanosci. Nanotechnol. 14(3), 2395-2399 (2014). https://doi.org/10.1166/jnn.2014.8497

88. I.S. Cho, C.H. Kwak, D.W. Kim, S.W. Lee, K.S. Hong, Photophysical, photoelectrochemical, and photocatalytic properties of novel $\mathrm{SnWO}_{4}$ oxide semiconductors with narrow band gaps. J. Phys. Chem. C 113(24), 10647-10653 (2009). https://doi.org/ $10.1021 / \mathrm{jp} 901557 \mathrm{z}$

89. D. Chen, L. Gao, A. Yasumori, K. Kuroda, Y. Sugahara, Sizeand shape-controlled conversion of tungstate-based inorganicorganic hybrid belts to $\mathrm{WO}_{3}$ nanoplates with high specific surface areas. Small 4(10), 1813-1822 (2008). https://doi.org/10. 1002/smll.200800205

90. L. Liang, J. Zhang, Y. Zhou, J. Xie, X. Zhang, M. Guan, B. Pan, Y. Xie, High-performance flexible electrochromic device based on facile semiconductor-to-metal transition realized by $\mathrm{WO}_{3}$ $2 \mathrm{H}_{2} \mathrm{O}$ ultrathin nanosheets. Sci. Rep. 3, 1936 (2013). https://doi. org/10.1038/srep01936

91. Z.F. Huang, J. Song, L. Pan, X. Zhang, L. Wang, J.J. Zou, Tungsten oxides for photocatalysis, electrochemistry, and phototherapy. Adv. Mater. 27(36), 5309-5327 (2015). https://doi. org/10.1002/adma.201501217

92. Y. Abraham, N.A.W. Holzwarth, R.T. Williams, Electronic structure and optical properties of $\mathrm{CdMoO}_{4}$ and $\mathrm{CdWO}_{4}$. Phys. Rev. B 62(3), 1733-1741 (2000). https://doi.org/10.1103/Phys RevB.62.1733

93. S. Shepard, M. Smeu, Ab initio study of structural and electronic properties of copper and nickel tungstate. Comput. Mater. Sci. 143, 301-307 (2018). https://doi.org/10.1016/j.commatsci.2017. 11.021

94. A.E.B. Lima, M.J.S. Costa, R.S. Santos, N.C. Batista, L.S. Cavalcante, E. Longo, G.E. Luz, Facile preparation of $\mathrm{CuWO}_{4}$ porous films and their photoelectrochemical properties. Electrochim. Acta 256, 139-145 (2017). https://doi.org/10.1016/j. electacta.2017.10.010

95. L. Wang, F. Ke, Q. Wang, J. Yan, C. Liu et al., Effect of crystallization water on the structural and electrical properties of $\mathrm{CuWO}_{4}$ under high pressure. Appl. Phys. Lett. 107(20), 201603 (2015). https://doi.org/10.1063/1.4935978

96. D. Wang, P.S. Bassi, H. Qi, X. Zhao, Gurudayal, L.H. Wong, R. $\mathrm{Xu}, \mathrm{T}$. Sritharan, Z. Chen, Improved charge separation in $\mathrm{WO}_{3} /$ $\mathrm{CuWO}_{4}$ composite photoanodes for photoelectrochemical water oxidation. Materials 9(5), 348 (2016). https://doi.org/10.3390/ ma9050348 
97. S. Sun, W. Wang, Advanced chemical compositions and nanoarchitectures of bismuth based complex oxides for solar photocatalytic application. RSC Adv. 4(88), 47136-47152 (2014). https://doi.org/10.1039/c4ra06419d

98. V.V. Atuchin, B.I. Troitskaia, O.Y. Khyzhun, V.L. Bekenev, Y.M. Solonin, Electronic properties of $\mathrm{h}-\mathrm{WO}_{3}$ and $\mathrm{CuWO}_{4}$ nanocrystals as determined from $\mathrm{X}$-ray spectroscopy and first principles band structure calculations. Int. J. Appl. Phys. Math. 1(1), 19-23 (2011). https://doi.org/10.7763/ijapm.2011.V1.4

99. O.Y. Khyzhun, V.L. Bekenev, Y.M. Solonin, First-principles calculations and X-ray spectroscopy studies of the electronic structure of $\mathrm{CuWO}_{4}$. J. Alloy. Compd. 480(2), 184-189 (2009). https://doi.org/10.1016/j.jallcom.2009.01.119

100. O.Y. Khyzhun, T. Strunskus, S. Cramm, Y.M. Solonin, Electronic structure of $\mathrm{CuWO}_{4}$ : XPS, XES and NEXAFS studies. J. Alloy. Compd. 389(1-2), 14-20 (2005). https://doi.org/10. 1016/j.jallcom.2004.08.013

101. M.V. Lalić, Z.S. Popović, F.R. Vukajlović, Ab initio study of electronic, magnetic and optical properties of $\mathrm{CuWO}_{4}$ tungstate. Comp. Mater. Sci. 50(3), 1179-1186 (2011). https://doi.org/10. 1016/j.commatsci.2010.11.018

102. C.R. Lhermitte, B.M. Bartlett, Advancing the chemistry of $\mathrm{CuWO}_{4}$ for photoelectrochemical water oxidation. Acc. Chem. Res. 49(6), 1121-1129 (2016). https://doi.org/10.1021/acs. accounts.6b00045

103. S. Rajagopal, D. Nataraj, O.Y. Khyzhun, Y. Djaoued, J. Robichaud, D. Mangalaraj, Hydrothermal synthesis and electronic properties of $\mathrm{FeWO}_{4}$ and $\mathrm{CoWO}_{4}$ nanostructures. J. Alloy. Compd. 493(1-2), 340-345 (2010). https://doi.org/10.1016/j. jallcom.2009.12.099

104. S. Rajagopal, V.L. Bekenev, D. Nataraj, D. Mangalaraj, O.Y. Khyzhun, Electronic structure of $\mathrm{FeWO}_{4}$ and $\mathrm{CoWO}_{4}$ tungstates: first-principles FP-LAPW calculations and X-ray spectroscopy studies. J. Alloy. Compd. 496(1-2), 61-68 (2010). https://doi.org/10.1016/j.jallcom.2010.02.107

105. K. Hoang, M. Oh, Y. Choi, Electronic structure, polaron formation, and functional properties in transition-metal tungstates. RSC Adv. 8(8), 4191-4196 (2018). https://doi.org/10.1039/ c7ra13436c

106. F. Yu, L. Cao, J. Huang, J. Wu, Effects of $\mathrm{pH}$ on the microstructures and optical property of $\mathrm{FeWO}_{4}$ nanocrystallites prepared via hydrothermal method. Ceram. Int. 39(4), 4133-4138 (2013). https://doi.org/10.1016/j.ceramint.2012.10. 269

107. L. Hou, L. Lian, L. Zhang, T. Wu, C. Yuan, Microwave-assisted interfacial hydrothermal fabrication of hydrophobic $\mathrm{CdWO}_{4}$ microspheres as a high-performance photocatalyst. RSC Adv. 4(5), 2374-2381 (2014). https://doi.org/10.1039/c3ra45784b

108. Y. Ling, L. Zhou, L. Tan, Y. Wang, C. Yu, Synthesis of urchinlike $\mathrm{CdWO}_{4}$ microspheres via a facile template free hydrothermal method. CrystEngComm 12(10), 3019-3026 (2010). https:// doi.org/10.1039/b927420k

109. S. Kang, Y. Li, M. Wu, M. Cai, P.K. Shen, Synthesis of hierarchically flower-like $\mathrm{FeWO}_{4}$ as high performance anode materials for $\mathrm{Li}$-ion batteries by a simple hydrothermal process. Int. J. Hydrog. Energy 39(28), 16081-16087 (2014). https://doi. org/10.1016/j.ijhydene.2014.02.101

110. S. Liu, S. Tian, R. Xing, $\mathrm{CaWO}_{4}$ hierarchical nanostructures: hydrothermal synthesis, growth mechanism and photoluminescence properties. CrystEngComm 13(24), 7258-7261 (2011). https://doi.org/10.1039/c1ce05790a

111. T.N. Kovács, G. Pokol, F. Gáber, D. Nagy, T. Igricz, I.E. Lukács, Z. Fogarassy, K. Balázsi, I.M. Szilágyi, Preparation of iron tungstate $\left(\mathrm{FeWO}_{4}\right.$ ) nanosheets by hydrothermal method. Mater. Res. Bull. 95, 563-569 (2017). https://doi.org/10.1016/j. materresbull.2017.08.031
112. Z.G. Chen, H.J. Ma, J.X. Xia, J. Zeng, J. Di, S. Yin, L. Xu, H.M. $\mathrm{Li}$, Ionic liquid-induced strategy for $\mathrm{FeWO}_{4}$ microspheres with advanced visible light photocatalysis. Ceram. Int. 42(7), 8997-9003 (2016). https://doi.org/10.1016/j.ceramint.2016.02. 117

113. Y.X. Zhou, Q. Zhang, J.Y. Gong, S.H. Yu, Surfactant-assisted hydrothermal synthesis and magnetic properties of urchin-like $\mathrm{MnWO}_{4}$ microspheres. J. Phys. Chem. C 112(35), 13383-13389 (2008). https://doi.org/10.1021/jp804211w

114. Y. Xing, S. Song, J. Feng, Y. Lei, M. Li, H. Zhang, Microemulsion-mediated solvothermal synthesis and photoluminescent property of 3D flowerlike $\mathrm{MnWO}_{4}$ micro/nanocomposite structure. Solid State Sci. 10(10), 1299-1304 (2008). https://doi.org/10.1016/j.solidstatesciences.2008.01.019

115. Y.C. Chen, Y.G. Lin, L.C. Hsu, A. Tarasov, P.T. Chen, M. Hayashi, J. Ungelenk, Y.K. Hsu, C. Feldmann, $\beta-\mathrm{SnWO}_{4}$ photocatalyst with controlled morphological transition of cubes to spikecubes. ACS Catal. 6(4), 2357-2367 (2016). https://doi.org/ 10.1021/acscatal.5b02444

116. X.Y. Qiu, H.W. Huang, Y.D. Gao, Effects of surface properties of 010$\},\{001$ and 100 of MnWO4 and FeWO4 on absorption of collector. Appl. Surf. Sci. 367, 354-361 (2016). https://doi.org/ 10.1016/j.apsusc.2016.01.190

117. J. Ungelenk, C. Feldmann, Synthesis of faceted beta-SnWO microcrystals with enhanced visible-light photocatalytic properties. Chem. Commun. 48(63), 7838-7840 (2012). https://doi. org/10.1039/c2cc33224h

118. T. Tian, L. Ai, X. Liu, L. Li, J. Li, J. Jiang, Synthesis of hierarchical $\mathrm{FeWO}_{4}$ architectures with $\{100\}$-faceted nanosheet assemblies as a robust biomimetic catalyst. Ind. Eng. Chem. Res. 54(4), 1171-1178 (2015). https://doi.org/10.1021/ ie $504114 \mathrm{v}$

119. Y. Hou, X. Li, X. Zou, X. Quan, G. Chen, Photoeletrocatalytic activity of a $\mathrm{Cu}_{2} \mathrm{O}$-loaded self-organized highly oriented $\mathrm{TiO}_{2}$ nanotube array electrode for 4-chlorophenol degradation. Environ. Sci. Technol. 43(3), 858-863 (2009). https://doi.org/10. 1021/es802420u

120. Y. Hou, X. Li, Q. Zhao, X. Quan, G. Chen, Electrochemical method for synthesis of a $\mathrm{ZnFe}_{2} \mathrm{O}_{4} / \mathrm{TiO}_{2}$ composite nanotube array modified electrode with enhanced photoelectrochemical activity. Adv. Funct. Mater. 20(13), 2165-2174 (2010). https:// doi.org/10.1002/adfm. 200902390

121. J. Yan, Y. Shen, R. Cao, T. $\mathrm{Li}, \mathrm{CdWO}_{4}$ nanorods: ultrafast synthesis via a PEG-1000 polymer-assisted enhanced microwave synthesis route and their photoluminescence property. Ceram. Int. 40(6), 8081-8085 (2014). https://doi.org/10.1016/j. ceramint.2014.01.003

122. H.W. Liao, Y.F. Wang, X.M. Liu, Y.D. Li, Y.T. Qian, Hydrothermal preparation and characterization of luminescent $\mathrm{CdWO}_{4}$ nanorods. Chem. Mater. 12(10), 2819-2821 (2000). https://doi.org/10.1021/cm000096w

123. C. Zhang, D. Guo, W. Xu, C. Hu, Y. Chen, Radiative/nonradiative recombination affected by defects and electron-phone coupling in $\mathrm{CdWO}_{4}$ nanorods. J. Phys. Chem. C 120(22), 12218-12225 (2016). https://doi.org/10.1021/acs.jpcc.6b04145

124. N. Aloysius Sabu, K.P. Priyanka, S. Ganesh, T. Varghese, Modifications in the structural and optical properties of nanocrystalline $\mathrm{CaWO}_{4}$ induced by $8 \mathrm{MeV}$ electron beam irradiation. Radiat. Phys. Chem. 123, 1-5 (2016). https://doi.org/10. 1016/j.radphyschem.2016.02.006

125. Z. Lin, J. Li, Z. Zheng, J. Yan, P. Liu, C. Wang, G. Yang, Electronic reconstruction of $\alpha-\mathrm{Ag}_{2} \mathrm{WO}_{4}$ nanorods for visiblelight photocatalysis. ACS Nano 9(7), 7256-7265 (2015). https:// doi.org/10.1021/acsnano.5b02077 
126. W. Hou, S.B. Cronin, A review of surface plasmon resonanceenhanced photocatalysis. Adv. Funct. Mater. 23(13), 1612-1619 (2013). https://doi.org/10.1002/adfm.201202148

127. Y. Hou, F. Zuo, Q. Ma, C. Wang, L. Bartels, P. Feng, $\mathrm{Ag}_{3} \mathrm{PO}_{4}$ oxygen evolution photocatalyst employing synergistic action of $\mathrm{Ag} / \mathrm{AgBr}$ nanoparticles and graphene sheets. J. Phys. Chem. C 116(38), 20132-20139 (2012). https://doi.org/10.1021/ jp303219j

128. F. Wang, R.J. Wong, J.H. Ho, Y. Jiang, R. Amal, Sensitization of $\mathrm{Pt} / \mathrm{TiO}_{2}$ using plasmonic $\mathrm{Au}$ nanoparticles for hydrogen evolution under visible-light irradiation. ACS Appl. Mater. Interfaces 9(36), 30575-30582 (2017). https://doi.org/10.1021/ acsami.7b06265

129. J. Liu, Y. Li, Z. Li, J. Ke, H. Xiao, Y. Hou, In situ growing of $\mathrm{Bi} / \mathrm{Bi}_{2} \mathrm{O}_{2} \mathrm{CO}_{3}$ on $\mathrm{Bi}_{2} \mathrm{WO}_{6}$ nanosheets for improved photocatalytic performance. Catal. Today 314, 2-9 (2018). https://doi. org/10.1016/j.cattod.2017.12.001

130. X. Liu, B. Liang, M. Zhang, Y. Long, W. Li, Enhanced photocatalytic properties of alpha-SnWO $\mathrm{W}_{4}$ nanosheets modified by Ag nanoparticles. J. Colloid Interface Sci. 490, 46-52 (2017). https://doi.org/10.1016/j.jcis.2016.11.029

131. Y. Yan, H. Xing, C. Han, A. Yang, Synthesis and photocatalytic activity of Ag-CdWO ${ }_{4}$ nanorods. Ceram. Int. 43(4), 3905-3909 (2017). https://doi.org/10.1016/j.ceramint.2016.11.186

132. A.K. Chakraborty, S. Ganguli, M.A. Kebede, Photocatalytic degradation of 2-propanol and phenol using Au loaded $\mathrm{MnWO}_{4}$ nanorod under visible light irradiation. J. Clust. Sci. 23(2), 437-448 (2012). https://doi.org/10.1007/s10876-012-0450-6

133. X. Zong, C. Sun, H. Yu, Z.G. Chen, Z. Xing, D. Ye, G.Q. Lu, X. $\mathrm{Li}$, L. Wang, Activation of photocatalytic water oxidation on $\mathrm{N}$-doped $\mathrm{ZnO}$ bundle-like nanoparticles under visible light. J. Phys. Chem. C 117(10), 4937-4942 (2013). https://doi.org/10. 1021/jp311729b

134. Z. Mei, B. Zhang, J. Zheng, S. Yuan, Z. Zhuo et al., Tuning $\mathrm{Cu}$ dopant of $\mathrm{Zn}_{0.5} \mathrm{Cd}_{0.5} \mathrm{~S}$ nanocrystals enables high-performance photocatalytic $\mathrm{H}_{2}$ evolution from water splitting under visiblelight irradiation. Nano Energy 26, 405-416 (2016). https://doi. org/10.1016/j.nanoen.2016.05.051

135. A.K. Ambast, S.K. Sharma, Variation of trap depth by dopant/codopant and heating rate in $\mathrm{CaWO}_{4}$ phosphors. Opt. Quant. Electron. 49(2), 58 (2017). https://doi.org/10.1007/ s11082-017-0889-7

136. Z. Liu, J. Tian, D. Zeng, C. Yu, L. Zhu, W. Huang, K. Yang, D. $\mathrm{Li}$, A facile microwave-hydrothermal method to fabricate B doped $\mathrm{ZnWO}_{4}$ nanorods with high crystalline and highly efficient photocatalytic activity. Mater. Res. Bull. 94, 298-306 (2017). https://doi.org/10.1016/j.materresbull.2017.06.021

137. G. Huang, Y. Zhu, Synthesis and photoactivity enhancement of $\mathrm{ZnWO}_{4}$ photocatalysts doped with chlorine. CrystEngComm 14(23), 8076-8082 (2012). https://doi.org/10.1039/c2ce26005k

138. X. Tian, G. Jiang, Y. Chen, M. Yin, $\mathrm{Eu}^{3+}, \mathrm{Li}^{+}$doped $\mathrm{CaWO}_{4}$ nanorods: synthesis, emission-decay curves and effective-refractive index. Curr. Appl. Phys. 14(12), 1612-1615 (2014). https://doi.org/10.1016/j.cap.2014.09.010

139. C.K. Choo, S. Suzuki, K. Tanaka, Photoluminescence intensity enhancement of ion-doped $\mathrm{CdWO}_{4}$ thin films prepared with pulsed laser deposition. Thin Solid Films 458(1-2), 179-185 (2004). https://doi.org/10.1016/j.tsf.2003.12.062

140. S.H. Chen, S.X. Sun, H.G. Sun, W.L. Fan, X. Zhao, X. Sun, Experimental and theoretical studies on the enhanced photocatalytic activity of $\mathrm{ZnWO}_{4}$ nanorods by fluorine doping. J. Phys. Chem. C 114(17), 7680-7699 (2010). https://doi.org/10. $1021 / j p 911952 \mathrm{v}$

141. Y. Su, L. Hou, C. Du, L. Peng, K. Guan, X. Wang, Rapid synthesis of $\mathrm{Zn}^{2+}$ doped $\mathrm{SnWO}_{4}$ nanowires with the aim of exploring doping effects on highly enhanced visible photocatalytic activities. RSC Adv. 2(15), 6266-6273 (2012). https://doi.org/10.1039/c2ra20401k

142. X.C. Song, X. Cui, W.Z. Huang, Y. Zhang, H.Y. Yin, Y.F. Zheng, Photoactivity enhancement of Zn-doped $\mathrm{CdWO}_{4}$ prepared with a hydrothermal method. Mater. Sci. Eng. B 197, 31-35 (2015). https://doi.org/10.1016/j.mseb.2015.03.007

143. D. Ye, D. Li, W. Chen, Y. Shao, G. Xiao, M. Sun, X. Fu, Characterization and properties of $\mathrm{Eu}^{3+}$-doped $\mathrm{CdWO}_{4}$ prepared by a hydrothermal method. Res. Chem. Intermed. 35(6-7), 675-683 (2009). https://doi.org/10.1007/s11164-009-0104-y

144. A. Phuruangrat, P. Dumrongrojthanath, T. Thongtem, S. Thongtem, Effect of Ce dopant on structure, morphology, photoabsorbance and photocatalysis of $\mathrm{ZnWO}_{4}$ nanostructure. J. Ceram. Soc. Jpn. 125(2), 62-64 (2017). https://doi.org/10. $2109 /$ jcersj2.16176

145. H. Wei, L. Wang, Z. Li, S. Ni, Q. Zhao, Synthesis and photocatalytic activity of one-dimensional $\mathrm{CdS} @ \mathrm{TiO}_{2}$ core-shell heterostructures. Nano-Micro Lett. 3(1), 6-11 (2011). https:// doi.org/10.1007/bf03353645

146. C. Zhang, H. Hua, J. Liu, X. Han, Q. Liu, Z. Wei, C. Shao, C. $\mathrm{Hu}$, Enhanced photocatalytic activity of nanoparticle-aggregated $\mathrm{Ag}-\mathrm{AgX}(\mathrm{X}=\mathrm{Cl}, \mathrm{Br}) @ \mathrm{TiO}_{2}$ microspheres under visible light. Nano-Micro Lett. 9(4), 49 (2017). https://doi.org/10.1007/ s40820-017-0150-8

147. C. Liu, F. Wang, J. Zhang, K. Wang, Y. Qiu, Q. Liang, Z. Chen, Efficient photoelectrochemical water splitting by $\mathrm{g}-\mathrm{C}_{3} \mathrm{~N}_{4} / \mathrm{TiO}_{2}$ nanotube array heterostructures. Nano-Micro Lett. 10(2), 37 (2018). https://doi.org/10.1007/s40820-018-0192-6

148. J. Liu, Y. Li, J. Ke, Z. Wang, H. Xiao, Synergically improving light harvesting and charge transportation of $\mathrm{TiO}_{2}$ nanobelts by deposition of $\mathrm{MoS}_{2}$ for enhanced photocatalytic removal of Cr(VI). Catalysts 7(12), 30 (2017). https://doi.org/10.3390/ catal7010030

149. J. Liu, J. Ke, Y. Li, B. Liu, L. Wang, H. Xiao, S. Wang, $\mathrm{Co}_{3} \mathrm{O}_{4}$ quantum dots $/ \mathrm{TiO}_{2}$ nanobelt hybrids for highly efficient photocatalytic overall water splitting. Appl. Catal. B Environ. 236, 396-403 (2018). https://doi.org/10.1016/j.apcatb.2018.05.042

150. L. Pan, S. Wang, J. Xie, L. Wang, X. Zhang, J.J. Zou, Constructing $\mathrm{TiO}_{2}$ p-n homojunction for photoelectrochemical and photocatalytic hydrogen generation. Nano Energy 28, 296-303 (2016). https://doi.org/10.1016/j.nanoen.2016.08.054

151. Y. Xu, Y. Huang, B. Zhang, Rational design of semiconductorbased photocatalysts for advanced photocatalytic hydrogen production: the case of cadmium chalcogenides. Inorg. Chem. Front. 3(5), 591-615 (2016). https://doi.org/10.1039/c5qi00217f

152. S. Kment, F. Riboni, S. Pausova, L. Wang, L. Wang et al., Photoanodes based on $\mathrm{TiO}_{2}$ and $\alpha-\mathrm{Fe}_{2} \mathrm{O}_{3}$ for solar water splitting-superior role of $1 \mathrm{D}$ nanoarchitectures and of combined heterostructures. Chem. Soc. Rev. 46(12), 3716-3769 (2017). https://doi.org/10.1039/c6cs00015k

153. P. Huo, Y. Tang, M. Zhou, J. Li, Z. Ye, C. Ma, L. Yu, Y. Yan, Fabrication of $\mathrm{ZnWO}_{4}$-CdS heterostructure photocatalysts for visible light induced degradation of ciprofloxacin antibiotics. J. Ind. Eng. Chem. 37, 340-346 (2016). https://doi.org/10.1016/ j.jiec.2016.03.043

154. K. Vignesh, R. Priyanka, R. Hariharan, M. Rajarajan, A. Suganthi, Fabrication of $\mathrm{CdS}$ and $\mathrm{CuWO}_{4}$ modified $\mathrm{TiO}_{2}$ nanoparticles and its photocatalytic activity under visible light irradiation. J. Ind. Eng. Chem. 20(2), 435-443 (2014). https:// doi.org/10.1016/j.jiec.2013.04.038

155. X. Yan, K. Liu, W. Shi, Facile synthesis of $\mathrm{CdS} / \mathrm{MnWO}_{4}$ heterojunction with enhanced visible-light-driven photocatalytic activity and mechanism investigation. Colloids Surf. A Physicochem. Eng. Asp. 520, 138-145 (2017). https://doi.org/10.1016/ j.colsurfa.2017.01.065 
156. M. Xu, T. Ye, F. Dai, J. Yang, J. Shen et al., Rationally designed n-n heterojunction with highly efficient solar hydrogen evolution. Chemsuschem 8(7), 1218-1225 (2015). https://doi.org/10. $1002 /$ cssc. 201403334

157. X. Jia, M. Tahir, L. Pan, Z.F. Huang, X. Zhang, L. Wang, J.J. Zou, Direct Z-scheme composite of CdS and oxygen-defected CdWO4: an efficient visible-light-driven photocatalyst for hydrogen evolution. Appl. Catal. B: Environ. 198, 154-161 (2016). https://doi.org/10.1016/j.apcatb.2016.05.046

158. L. Wang, W. Wang, In situ synthesis of CdS modified $\mathrm{CdWO}_{4}$ nanorods and their application in photocatalytic $\mathrm{H}_{2}$ evolution. CrystEngComm 14(9), 3315-3320 (2012). https://doi.org/10. 1039/c2ce06656d

159. S. Bera, S.B. Rawal, H.J. Kim, W.I. Lee, Novel coupled structures of $\mathrm{FeWO}_{4} / \mathrm{TiO}_{2}$ and $\mathrm{FeWO}_{4} / \mathrm{TiO}_{2} / \mathrm{CdS}$ designed for highly efficient visible-light photocatalysis. ACS Appl. Mater. Interfaces 6(12), 9654-9663 (2014). https://doi.org/10.1021/ am502079x

160. A. Habibi-Yangjeh, M. Shekofteh-Gohari, Novel magnetic $\mathrm{Fe}_{3} \mathrm{O}_{4} / \mathrm{ZnO} / \mathrm{NiWO}_{4}$ nanocomposites: enhanced visible-light photocatalytic performance through p-n heterojunctions. Sep. Purif. Technol. 184, 334-346 (2017). https://doi.org/10.1016/j. seppur.2017.05.007

161. M.S. Hassan, T. Amna, S.S. Al-Deyab, H.C. Kim, M.S. Khil, Monodispersed 3D $\mathrm{MnWO}_{4}-\mathrm{TiO}_{2}$ composite nanoflowers photocatalysts for environmental remediation. Curr. Appl. Phys. 15(6), 753-758 (2015). https://doi.org/10.1016/j.cap.2015.03. 022

162. Y.N. Jiang, B.D. Liu, W.J. Yang, B. Yang, X.Y. Liu, X.L. Zhang, M.A. Mohsin, X. Jiang, New strategy for the in situ synthesis of single-crystalline $\mathrm{MnWO}_{4} / \mathrm{TiO}_{2}$ photocatalysts for efficient and cyclic photodegradation of organic pollutants. CrystEngComm 18(10), 1832-1841 (2016). https://doi.org/10. $1039 / \mathrm{c} 5 \mathrm{ce} 02445 \mathrm{e}$

163. K. Buvaneswari, R. Karthiga, B. Kavitha, M. Rajarajan, A. Suganthi, Effect of $\mathrm{FeWO}_{4}$ doping on the photocatalytic activity of $\mathrm{ZnO}$ under visible light irradiation. Appl. Surf. Sci. 356, 333-340 (2015). https://doi.org/10.1016/j.apsusc.2015.08.060

164. T. Mavric, M. Valant, M. Forster, A.J. Cowan, U. Lavrencic, S. Emin, Design of a highly photocatalytically active $\mathrm{ZnO} / \mathrm{CuWO}_{4}$ nanocomposite. J. Colloid Interf. Sci. 483, 93-101 (2016). https://doi.org/10.1016/j.jcis.2016.08.019

165. H. Wang, C. Wang, X. Cui, L. Qin, R. Ding, L. Wang, Z. Liu, Z. Zheng, B. Lv, Design and facile one-step synthesis of $\mathrm{FeWO}_{4} /$ $\mathrm{Fe}_{2} \mathrm{O}_{3}$ di-modified $\mathrm{WO}_{3}$ with super high photocatalytic activity toward degradation of quasi-phenothiazine dyes. Appl. Catal. B Environ. 221, 169-178 (2018). https://doi.org/10.1016/j. apcatb.2017.09.011

166. T.H. Kim, C.H. Kwak, J.H. Lee, NiO/NiWO 4 composite yolkshell spheres with nanoscale $\mathrm{NiO}$ outer layer for ultrasensitive and selective detection of subppm-level p-xylene. ACS Appl. Mater. Interfaces 9(37), 32034-32043 (2017). https://doi.org/10. 1021/acsami.7b10294

167. K. Ding, X. Zhang, J. Li, P. Yang, X. Cheng, Formation of dandelion-like $\mathrm{Co}_{3} \mathrm{O}_{4} / \mathrm{CoWO}_{4}$ heterojunctions for enhanced supercapacitive performance. ChemElectroChem 4(11), 3011-3017 (2017). https://doi.org/10.1002/celc.201700704

168. B. Polyakov, A. Kuzmin, S. Vlassov, E. Butanovs, J. Zideluns, J. Butikova, R. Kalendarev, M. Zubkins, A comparative study of heterostructured $\mathrm{CuO} / \mathrm{CuWO}_{4}$ nanowires and thin films. J. Cryst. Growth 480, 78-84 (2017). https://doi.org/10.1016/j. jcrysgro.2017.10.011

169. X. Cao, Y. Chen, S. Jiao, Z. Fang, M. Xu, X. Liu, L. Li, G. Pang, S. Feng, Magnetic photocatalysts with a p-n junction: $\mathrm{Fe}_{3} \mathrm{O}_{4}$ nanoparticle and $\mathrm{FeWO}_{4}$ nanowire heterostructures. Nanoscale 6(21), 12366-12370 (2014). https://doi.org/10.1039/c4nr03729d
170. S. Yao, M. Zhang, J. Di, Z. Wang, Y. Long, W. Li, Preparation of $\alpha-\mathrm{SnWO}_{4} / \mathrm{SnO}_{2}$ heterostructure with enhanced visible-lightdriven photocatalytic activity. Appl. Surf. Sci. 357, 1528-1535 (2015). https://doi.org/10.1016/j.apsusc.2015.10.012

171. G.Q. Shao, J.K. Guo, J.R. Xie, X.L. Duan, B.L. Wu, R.Z. Yuan, The Preparation of $\mathrm{CoWO}_{4} / \mathrm{WO}_{3}$ nanocomposite powder. J. Wuhan Univ. Technol. 19(2), 1-3 (2004)

172. H. Zhang, W. Tian, Y. Li, H. Sun, M.O. Tadé, S. Wang, Heterostructured $\mathrm{WO}_{3} @ \mathrm{CoWO}_{4}$ bilayer nanosheets for enhanced visible-light photo, electro and photoelectro-chemical oxidation of water. J. Mater. Chem. A 6(15), 6265-6272 (2018). https://doi.org/10.1039/c8ta00555a

173. T.H. Do, C. Van Nguyen, K.A. Tsai, L.T. Quynh, J.W. Chen et al., Superior photoelectrochemical activity of self-assembled $\mathrm{NiWO}_{4}-\mathrm{WO}_{3}$ heteroepitaxy. Nano Energy 23, 153-160 (2016). https://doi.org/10.1016/j.nanoen.2016.03.021

174. S.F. Anis, B.S. Lalia, G. Palmisano, R. Hashaikeh, Photoelectrochemical activity of electrospun $\mathrm{WO}_{3} / \mathrm{NiWO}_{4}$ nanofibers under visible light irradiation. J. Mater. Sci. 53(3), 2208-2220 (2017). https://doi.org/10.1007/s10853-017-1633-1

175. J.E. Yourey, J.B. Kurtz, B.M. Bartlett, Water oxidation on a $\mathrm{CuWO}_{4}-\mathrm{WO}_{3}$ composite electrode in the presence of $\left[\mathrm{Fe}(\mathrm{CN})_{6}\right]^{3-}$ : toward solar Z-scheme water splitting at zero bias. J. Phys. Chem. C 116(4), 3200-3205 (2012). https://doi.org/10. 1021/jp211409x

176. F. Zhan, J. Li, W. Li, Y. Liu, R. Xie, Y. Yang, Y. Li, Q. Chen, In situ formation of $\mathrm{CuWO}_{4} / \mathrm{WO}_{3}$ heterojunction plates array films with enhanced photoelectrochemical properties. Int. J. Hydrog. Energy 40(20), 6512-6520 (2015). https://doi.org/10. 1016/j.ijhydene.2015.03.131

177. I. Aslam, C. Cao, M. Tanveer, M.H. Farooq, W.S. Khan, M. Tahir, F. Idrees, S. Khalid, A novel Z-scheme $\mathrm{WO}_{3} / \mathrm{CdWO}_{4}$ photocatalyst with enhanced visible-light photocatalytic activity for the degradation of organic pollutants. RSC Adv. 5(8), 6019-6026 (2015). https://doi.org/10.1039/c4ra15847d

178. Y. Hou, Z. Wen, S. Cui, S. Ci, S. Mao, J. Chen, An advanced nitrogen-doped graphene/cobalt-embedded porous carbon polyhedron hybrid for efficient catalysis of oxygen reduction and water splitting. Adv. Funct. Mater. 25(6), 872-882 (2014). https://doi.org/10.1002/adfm.201403657

179. Y. Qin, M. Long, B. Tan, B. Zhou, RhB adsorption performance of magnetic adsorbent $\mathrm{Fe}_{3} \mathrm{O}_{4} / \mathrm{rGO}$ composite and its regeneration through a Fenton-like reaction. Nano-Micro Lett. 6(2), 125-135 (2014). https://doi.org/10.1007/bf03353776

180. P. Russo, A. Hu, G. Compagnini, Synthesis, properties and potential applications of porous graphene: a review. Nano-Micro Lett. 5(4), 260-273 (2013). https://doi.org/10.1007/bf03353757

181. A. Wang, C. Wang, L. Fu, W. Wong-Ng, Y. Lan, Recent advances of graphitic carbon nitride-based structures and applications in catalyst, sensing, imaging, and LEDs. NanoMicro Lett. 9(4), 47 (2017). https://doi.org/10.1007/s40820-0170148-2

182. L. Pan, T. Muhammad, L. Ma, Z.F. Huang, S. Wang, L. Wang, J.J. Zou, X. Zhang, MOF-derived C-doped $\mathrm{ZnO}$ prepared via a two-step calcination for efficient photocatalysis. Appl. Catal. B Environ. 189, 181-191 (2016). https://doi.org/10.1016/j. apcatb.2016.02.066

183. J. Liu, J. Ke, D. Li, H. Sun, P. Liang et al., Oxygen vacancies in shape controlled $\mathrm{Cu}_{2} \mathrm{O} /$ reduced graphene oxide/ $/ \mathrm{In}_{2} \mathrm{O}_{3}$ hybrid for promoted photocatalytic water oxidation and degradation of environmental pollutants. ACS Appl. Mater. Interfaces 9(13), 11678-11688 (2017). https://doi.org/10.1021/acsami.7b01605

184. A.K. Singh, K. Mathew, H.L. Zhuang, R.G. Hennig, Computational screening of 2D materials for photocatalysis. J Phys. Chem. Lett. 6(6), 1087-1098 (2015). https://doi.org/10.1021/ jz502646d 
185. G. Zhang, Z.A. Lan, X. Wang, Surface engineering of graphitic carbon nitride polymers with cocatalysts for photocatalytic overall water splitting. Chem. Sci. 8(8), 5261-5274 (2017). https://doi.org/10.1039/c7sc01747b

186. Y. Hou, M. Qiu, T. Zhang, J. Ma, S. Liu, X. Zhuang, C. Yuan, $\mathrm{X}$. Feng, Efficient electrochemical and photoelectrochemical water splitting by a 3D nanostructured carbon supported on flexible exfoliated graphene foil. Adv. Mater. 29(3), 1604480 (2017). https://doi.org/10.1002/adma.201604480

187. J. Ke, X. Duan, S. Luo, H. Zhang, H. Sun, J. Liu, M. Tade, S. Wang, UV-assisted construction of $3 \mathrm{D}$ hierarchical $\mathrm{rGO} / \mathrm{Bi}_{2}$ $\mathrm{MoO}_{6}$ composites for enhanced photocatalytic water oxidation. Chem. Eng. J. 313, 1447-1453 (2017). https://doi.org/10.1016/j. cej.2016.11.048

188. N. Gaillard, Y. Chang, A. DeAngelis, S. Higgins, A. Braun, A nanocomposite photoelectrode made of $2.2 \mathrm{eV}$ band gap copper tungstate $\left(\mathrm{CuWO}_{4}\right)$ and multi-wall carbon nanotubes for solarassisted water splitting. Int. J. Hydrog. Energy 38(8), 3166-3176 (2013). https://doi.org/10.1016/j.ijhydene.2012.12.104

189. P. Wadhwa, S. Kumar, T.J. Dhilip Kumar, A. Shukla, R. Kumar, Effect of edge defects on band structure of zigzag graphene nanoribbons. J. Appl. Phys. 123(16), 161416 (2018). https://doi. org/10.1063/1.5011310

190. Z.B. Liu, X. Zhao, X.L. Zhang, X.Q. Yan, Y.P. Wu, Y.S. Chen, J.G. Tian, Ultrafast dynamics and nonlinear optical responses from $\mathrm{sp}^{2}$ - and $\mathrm{sp}^{3}$-hybridized domains in graphene oxide. J. Phys. Chem. Lett. 2(16), 1972-1977 (2011). https://doi.org/ 10.1021/jz2008374

191. X.J. Bai, L. Wang, Y.F. Zhu, Visible photocatalytic activity enhancement of $\mathrm{ZnWO}_{4}$ by graphene hybridization. ACS Catal. 2(12), 2769-2778 (2012). https://doi.org/10.1021/cs3005852

192. J. Xu, M. Chen, Z. Wang, Preparation of $\mathrm{CdWO}_{4}$-deposited reduced graphene oxide and its enhanced photocatalytic properties. Dalton Trans. 43(9), 3537-3544 (2014). https://doi.org/ $10.1039 / \mathrm{c} 3 \mathrm{dt} 52120 \mathrm{f}$

193. J. Hao, S. Zhang, F. Ren, Z. Wang, J. Lei, X. Wang, T. Cheng, L. Li, Synthesis of $\mathrm{TiO}_{2} @ \mathrm{~g}-\mathrm{C}_{3} \mathrm{~N}_{4}$ core-shell nanorod arrays with
Z-scheme enhanced photocatalytic activity under visible light. J. Colloid Interface Sci. 508, 419-425 (2017). https://doi.org/10. 1016/j.jcis.2017.08.065

194. Y. Hou, Z. Wen, S. Cui, X. Guo, J. Chen, Constructing 2D porous graphitic $\mathrm{C}_{3} \mathrm{~N}_{4}$ nanosheets/nitrogen-doped graphene/ layered $\mathrm{MoS}_{2}$ ternary nanojunction with enhanced photoelectrochemical activity. Adv. Mater. 25(43), 6291-6297 (2013). https://doi.org/10.1002/adma.201303116

195. Y. Liu, H. Zhang, J. Ke, J. Zhang, W. Tian et al., OD $\left(\mathrm{MoS}_{2}\right) / 2 \mathrm{D}$ $\left(\mathrm{g}-\mathrm{C}_{3} \mathrm{~N}_{4}\right)$ heterojunctions in Z-scheme for enhanced photocatalytic and electrochemical hydrogen evolution. Appl. Catal. B: Environ. 228, 64-74 (2018). https://doi.org/10.1016/j.apcatb. 2018.01.067

196. L. Sun, X. Zhao, C.-J. Jia, Y. Zhou, X. Cheng, P. Li, L. Liu, W. Fan, Enhanced visible-light photocatalytic activity of $\mathrm{g}_{-} \mathrm{C}_{3} \mathrm{~N}_{4}$ $\mathrm{ZnWO}_{4}$ by fabricating a heterojunction: investigation based on experimental and theoretical studies. J. Mater. Chem. A 22(44), 23428-23438 (2012). https://doi.org/10.1039/c2jm34965e

197. N. Tian, H. Huang, Y. Zhang, Mixed-calcination synthesis of $\mathrm{CdWO}_{4} / \mathrm{g}_{-} \mathrm{C}_{3} \mathrm{~N}_{4}$ heterojunction with enhanced visible-light-driven photocatalytic activity. Appl. Surf. Sci. 358, 343-349 (2015). https://doi.org/10.1016/j.apsusc.2015.07.154

198. Z.F. Huang, J. Song, X. Wang, L. Pan, K. Li, X. Zhang, L. Wang, J.J. Zou, Switching charge transfer of $\mathrm{C}_{3} \mathrm{~N}_{4} / \mathrm{W}_{18} \mathrm{O}_{49}$ from type-II to Z-scheme by interfacial band bending for highly efficient photocatalytic hydrogen evolution. Nano Energy 40, 308-316 (2017). https://doi.org/10.1016/j.nanoen.2017.08.032

199. L. Pan, J. Zhang, X. Jia, Y.H. Ma, X. Zhang, L. Wang, J.J. Zou, Highly efficient $\mathrm{Z}$-scheme $\mathrm{WO}_{3-\mathrm{x}}$ quantum dots/ $/ \mathrm{TiO}_{2}$ for photocatalytic hydrogen generation. Chin. J. Catal. 38(2), 253-259 (2017). https://doi.org/10.1016/s1872-2067(16)62576-7

200. B. Zhu, P. Xia, Y. Li, W. Ho, J. Yu, Fabrication and photocatalytic activity enhanced mechanism of direct Z-scheme g- $\mathrm{C}_{3} \mathrm{~N}_{4} / \mathrm{Ag}_{2} \mathrm{WO}_{4}$ photocatalyst. Appl. Surf. Sci. 391, 175-183 (2017). https://doi.org/10.1016/j.apsusc.2016.07.104 